TESIS PARA OPTAR POR EL GRADO DE Doctor en Astronomía

\title{
Evolución Dinámica Post Escape de los Asteroides Hildas
}

\author{
Romina Paula Di Sisto \\ Director: Dr. Adrián Brunini \\ Co-Directora: Dra. Rosa B. Orellana \\ Facultad de Ciencias Astronómicas \\ Y GEOFÍSICAS \\ Universidad Nacional de La Plata \\ LA Plata \\ Argentina \\ Marzo 2004
}


A Mercedes,

por su infinita ternura

por su sonrisa y por

hacer que todo lo que nos

pasa sea cada dia mejor.
A Eduardo

por su amor, su apoyo

y su generosidad

y por compartir

la vida conmigo. 


\section{Agradecimientos}

Quiero agradecer a mi Director Adrián Brunini, en primer lugar por haberme aceptado como tesista, por enseñarme, guiarme y apoyarme en este trabajo. Pero sobre todo le agradezco haberme hecho acordar porqué empecé a estudiar Astronomía, y por devolverme el entusiasmo e inquietudes que después de tanto estudiar se suelen dejar por el camino.

A mi co-directora Rosa Orellana, quien siempre me escuchó y comprendió, más allá de las idas y vueltas. Agradezco su cariño y apoyo.

A Lorena Dirani por su ayuda incondicional y su reciente amistad.

A mis compañeros, Gustavo Cionco y Gonzalo de Elía por su ayuda y apoyo.

A Federico Bareilles y Hector Viturro por soportar, atender y responder todas mis consultas.

A José y Regina por su ayuda y comprensión.

A mis hermanos Juliana y Valentín por su cariño y por estar siempre presentes.

A mi papá por su cariño y cuidado de siempre.

A mi mamá por su cariño, comprensión y ayuda y por cuidar incondicionalmente a Mercedes.

A mi papá y a mi mamá por ser un ejemplo para mi y por enseñarme que siempre hay más para aprender y seguir creciendo.

Especialmente y con todo mi amor, te agradezco Gor, por todos estos años de vivencias compartidas. Por toda tu ayuda, comprensión, apoyo y paciencia y por crecer y aprender juntos todos los días. 


\section{Resumen}

El cinturón de asteroides entre Marte y Júpiter constituye un ejemplo a menor escala del gradiente de elementos observados en los planetas del Sistema Solar. Preservan el registro de la composición y mecánica del origen del Sistema Solar. Los asteroides Hildas en resonancia 3:2 con Júpiter $(\sim 4 \mathrm{UA})$, tienen alto porcentaje de materiales volátiles, son una población dinámicamente muy estable aunque colisionalmente activa, y por tanto tienen una cierta tasa de despoblación.

En esta Tesis estudiamos la evolución dinámica de esta población mediante simulaciones numéricas con un código simpléctico híbrido realizado por el Dr. Adrián Brunini y colaboradores y realizamos una pseudo evolución colisional. El objetivo de este trabajo es estudiar las rutas que siguen los Hildas que escapan de la resonancia y su contribución a diferentes poblaciones y procesos en el Sistema Solar.

Encontramos que en su mayoría, los Hildas que escapan de la resonancia son controlados gravitatoriamente por Júpiter y por tanto, terminan colisionando con este planeta o siendo eyectados por él. En este sentido, estudiamos dos aspectos importantes de las partículas escapadas: los impactos de cráteres que producen estas partículas en los satélites de Júpiter y por otro lado su contribución a la población de Cometas de la Familia de Júpiter (JFC).

Encontramos que los Hildas son la fuente más importante de cráteres en los satélites de Júpiter.

En cuanto al segundo tema, las similitudes espectrales de los Hildas y los cometas soportan la idea de que estos asteroides sean en realidad cometas potenciales. Dado que no se ha detectado actividad en los Hildas no es posible asegurar este punto. Sin embargo desde el punto de vista dinámico, encontramos en nuestro estudio que los asteroides Hildas contribuyen principalmente a la población de los JFC con $q>2.5$ UA y la contribución a la población con $q<2.5$ UA es despreciable. En aquella región tienen una vida media de $1.33 \times 10^{6}$ años. Casi todos los Hildas escapados pasan a través de la región dinámica de los JFC, siendo la vida media en esa zona de $1.4 \times 10^{6}$ años. Si forman parte, o no de los JFC dependerá de su composición química real y del tiempo que han estado expuestos a la radiación solar (y el posible desarrollo de mantos de carbón) antes de alcanzar la región cometaria observable.

Como caso particular analizamos si el cometa Shoemaker - Levy 9 (SL9) podría haber sido un Hilda escapado. Encontramos que la zona de los elementos pre-captura del SL9 se superponen con la zona de elementos orbitales de los Hildas escapados.

En cuanto a la contribución de los Hildas a la zona interna del Sistema Solar, analizamos en particular si las colisiones de estos objetos con los planetas terrestres podrían haber contribuido al agua en estos planetas. Además analizamos la contribución a la población de NEOs. En ambos casos, concluimos que es despreciable. 


\section{Índice}

1. Introducción $\quad 1$

1.1. Asteroides . . . . . . . . . . . . . . . . . . . . 4

1.1.1. Cinturón de asteroides . . . . . . . . . . . . . . . . 4

1.1.2. Objetos cercanos a la Tierra, Centauros y Trans - Neptunianos . . . 9

1.1.3. Composición y taxonomía de asteroides . . . . . . . . . . . . . . 12

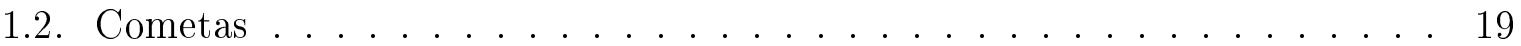

1.2.1. Clasificación de cometas . . . . . . . . . . . . . . . . 21

1.3. La Familia de los Hildas . . . . . . . . . . . . . . . . . . . . 25

1.3.1. Distribución de tamaños . . . . . . . . . . . . . . . . . . . 27

2. Simulación numérica, evolución colisional y análisis estadístico 30

2.1. Simulación numérica y Condiciones iniciales . . . . . . . . . . . . . . 30

2.2. Resultados y análisis estadístico . . . . . . . . . . . . . . . . . 32

2.3. Algunas rutas dinámicas y evoluciones típicas . . . . . . . . . . . . . 36

2.4. Evolución colisional: cálculo de la tasa de evaporación por colisiones . . . . 43

3. Contribución de los Hildas a la producción de cráteres en los satélites $\begin{array}{ll}\text { galileanos } & 48\end{array}$

3.1. Cálculo de las velocidades y tasas de impacto sobre los satélites galileanos . 51

3.2. Tasa de producción de cráteres . . . . . . . . . . . . . . . . 53

3.3. Comparación con Troyanos y Cometas de la Familia de Júpiter . . . . . . . 57

4. Contribución de los Hildas a la población de Cometas de la Familia de Júpiter $\quad 60$ 
4.1. La región de los JFC . . . . . . . . . . . . . . . . . . . . . . . 62

4.2. Método y resultados . . . . . . . . . . . . . . . . . 63

4.3. El número de JFC y la contribución de los Hildas . . . . . . . . . . . . . . 67

4.4. El caso del Shoemaker - Levy $9 \ldots \ldots 8$

4.5. Discusión ....................... . . 70

5. Conclusiones

A. Resonancias

A.0.1. Resonancias de movimientos medios . . . . . . . . . . . 76

A.0.2. Resonancias seculares . . . . . . . . . . . . . . . . 79

B. Hildas en la región de los planetas terrestres

81 


\section{Capítulo 1}

\section{Introducción}

El cinturón de asteroides entre las órbitas de Marte y Júpiter representa un amplio escenario para observar, estudiar y analizar los mecanismos físicos que han dado origen al Sistema Solar y que han operado desde ese entonces hasta configurar el estado actual. El cinturón de asteroides constituye un registro del espectro de planetesimales formados en la Nebulosa primordial, preservados en o cerca de los lugares de formación. Son un ejemplo a menor escala del gradiente de elementos observados en los planetas del Sistema Solar. La composición de los asteroides va desde elementos pesados como el hierro en el interior del cinturón hasta elementos volátiles en la zona externa.

En el cinturón de asteroides externo se encuentra en particular la familia de asteroides Hildas, en resonancia 3:2 con Júpiter, que tienen alto porcentaje de materiales volátiles. Por otro lado constituyen una población dinámicamente muy estable aunque colisionalmente activa, y por tanto tiene una cierta tasa de despoblación.

En la figura 1.1 están representados los asteroides del cinturón principal, los NEOS, los asteroides Hildas y Troyanos y los Cometas de la Familia de Júpiter. Los elementos orbitales de estos objetos fueron tomados de las bases de datos:

http://asteroid.lowell.edu, http://neo.jpl.nasa.gov, http://arnold.usno.navy.mil y http://ssd.jpl.nasa.gov. Se pueden observar los asteroides Hildas y Troyanos, dos poblaciones relativamente aisladas y concentradas en la zona externa del Cinturón de asteroides, el Cinturón principal entre $\sim 2$ y $\sim 3,5$ y los NEOs cuyos perihelios son menores que 1,3 
UA. Se grafican también las curvas que delimitan las diferentes poblaciones. Estos límites, así como también los distintos objetos se discuten en los capítulos siguientes. Sin embargo, se puede observar en principio la posición del grupo de los Hildas en relación a las demás poblaciones ya sean asteroides o cometas a fin de tener una impresión global de su posible relación con aquellas.

En esta Tesis, estudiamos la evolución dinámica de los Hildas mediante simulaciones numéricas con un código simpléctico híbrido realizado por el Dr. Adrián Brunini y colaboradores y realizamos una pseudo evolución colisional. El objetivo de este trabajo es estudiar las rutas que siguen los Hildas que escapan de la resonancia y su contribución a diferentes poblaciones y procesos en el Sistema Solar.

En el capítulo 2 describimos los métodos utilizados y presentamos algunos resultados generales de la simulación numérica. Presentamos también características generales de las evoluciones post-escape de los Hildas.

Fundamentalmente estudiamos dos aspectos importantes de las partículas escapadas. Analizamos en el capítulo 3, los cráteres de impacto que producen estas partículas en los satélites de Júpiter y en el capítulo 4 su contribución a la población de Cometas de la Familia de Júpiter (JFC). 




Figura 1.1: Semieje mayor vs excentricidad de asteroides del cinturón principal, los objetos cercanos a la Tierra (NEOS) (fuxia), los asteroides Hildas (verde), los asteroides del cinturón principal y los Troyanos en $\sim 5,2$ UA (azul) y los Cometas de la Familia de Júpiter (rojo). Las curvas delimitan las diferentes poblaciones. 


\subsection{Asteroides}

Los asteroides son cuerpos sólidos pequeños que orbitan el Sol. En general son rocosos, algunos metálicos, y los más alejados del Sol son ricos en agua, volátiles y materiales orgánicos.

La característica principal que define a un asteroide es su tamaño: menor que un planeta. El primer asteroide, fue descubierto por un astrónomo italiano en 1810, se lo llamó Ceres y se le asignó el número 1. Ceres es el mayor de todos y tiene apenas una longitud de $1000 \mathrm{~km}$. Le siguen Pallas y Vesta que miden alrededor de la mitad de Ceres. Desde entonces se han identificado más de 250000 asteroides y continúan descubriéndose nuevos. No se sabe exactamente el número total de asteroides pero se cree que puede haber más de 1 millón de ellos de más de $1 \mathrm{Km}$. de diámetro. Probablemente el cinturón principal esté observacionalmente completo hasta magnitud $H \sim 13$ (Jedicke y otros, 2002).

\subsubsection{Cinturón de asteroides}

Los asteroides se encuentran distribuidos por todo el Sistema Solar pero en su gran mayoría se concentran en un cinturón, entre las órbitas de Marte y Júpiter. Esta zona puede dividirse en el llamado Cinturón Principal de Asteroides entre 2 y $~ 3,3$ UA y el Cinturón de asteroides externo entre 3,3 y 5,2 UA. En el Cinturón externo se encuentran dos concentraciones importantes de asteroides, los asteroides Hildas en $\sim 4$ UA (descriptos en la sección 1.3) y los asteroides Troyanos (descriptos en el próximo item).

En el Cinturón principal las excentricidades e inclinaciones son, en promedio altas, mayores que los valores típicos planetarios. Los valores medios son de $<e>\sim 0,14 \mathrm{y}$ $<i>\sim 12^{\circ}$. Como consecuencia, sus órbitas se cortan y se dan frecuentes colisiones. Las velocidades relativas son altas: $v_{R} \sim 5-10 \mathrm{~km} / \mathrm{s}$, suficientes como para que la mayoría de los asteroides menores a $50 \mathrm{~km}$ de diámetro sean fragmentos. De hecho se supone que la mayoría de los asteroides pequeños actuales son fragmentos de cuerpos más grandes que colisionaron con otros asteroides de similar tamaño y se destruyeron en muchos fragmentos 
pequeños. Por lo tanto sus formas son muy irregulares. Sin embargo, está ampliamente aceptado que los asteroides grandes (mayores que $\sim 100 \mathrm{~km}$ ) serían objetos primordiales que no habrían alterado su forma por colisiones (Davis y otros, 2002).

Hasta el presente, los asteroides Gaspra $(18,2 \times 10,5 \times 8,9 \mathrm{~km})$, Ida $(29,9 \times 12,7 \times 9,3$ $\mathrm{km})$, Mathilde $(66 \times 48 \times 46 \mathrm{~km})$ y Eros (forma curva de longitud de $34 \mathrm{~km}$ ) han sido visitados por misiones espaciales. Todos ellos tienen formas y superficies determinadas por colisiones (Sullivan y otros, 2002).

Aunque los asteroides representan un remanente de los planetesimales que existieron en las primeras etapas de la formación del Sistema Solar, existen varios factores que han afectado (y continúan afectando) su composición original, su forma y distribución de tamaños y su dinámica. Estos son, procesos térmicos, dinámicos y colisionales en el cinturón en sí y mecanismos ligados a la formación de los planetas.

La composición de un asteroide depende de la composición del planetesimal madre y de procesos endogénicos como el calentamiento, fundición, etc., o exogénicos como craterización y fragmentación por colisiones, etc. (Gaffey y otros, 1989). En la sección 1.1.3 se describe detalladamente el tema de la composición y formación de los asteroides.

Las colisiones entre asteroides representan un proceso fundamental en la historia del cinturón de asteroides. Un resultado de este proceso es la distribución de tamaños observada. La función acumulativa de tamaños está dada por la relación:

$$
N(>D) \propto D^{q}
$$

donde $N(>D)$ es el número de objetos de diámetro mayor que D. Diversos estudios dan un índice q variable para objetos del cinturón principal menores que $20 \mathrm{~km}$, entre $\sim-2 \mathrm{y} \sim-4$ (Davis y otros 2002).

Una restricción para la evolución colisional es el hecho de que Vesta ha preservado su corteza basáltica intacta durante toda la edad del Sistema Solar (Davis y otros 1984). Por otro lado, las colisiones tienen que haber sido lo suficientemente fuertes como para fragmentar un asteroide, descubriendo su nucleo metálico y así dar cuenta de la amplia 
colección de meteoritos metálicos encontrados en la Tierra. Este es un problema actualmente en discusión, Davis y otros (1999), encuentran a través de una evolución colisional que es muy difícil preservar un objeto como Vesta (pero no imposible) y obtener objetos totalmente fragmentados.

Otro producto de la evolución colisional del cinturón de asteroides es la formación de Familias. En 1918 K. Hirayama sugirió la existencia de "Familias de asteroides". Estas "Familias"son seguramente el resultado de la fragmentación por un choque en el pasado de un gran asteroide "padre"en pequeños fragmentos. El tiempo y la influencia de los cuerpos del Sistema Solar han dispersado gradualmente las órbitas de estos fragmentos pero no lo suficiente como para borrar las características de la familia. Actualmente hay alrededor de 25 familias bien identificadas.

\section{Troyanos}

Los Troyanos, son objetos que libran en torno a los puntos triangulares de Lagrange $L_{4}$ y $L_{5}$ del problema restringido de los tres cuerpos Sol - Júpiter - partícula. Por tanto están en resonancia 1: 1 con Júpiter (ver figura 1.1), orbitando a $60^{\circ}$ por delante y $60^{\circ}$ por detrás del planeta. Las colisiones son el mecanismo que modela la distribución espacial y de tamaños de los Troyanos. En una colisión, cambian los elementos del movimiento de libración, y los fragmentos producidos pueden alcanzar una velocidad y parámetros orbitales de libración nuevos tales que puedan escapar del grupo. Jewitt y otros (2000), estimaron que la población de Troyanos en $L_{4}$ con radios mayores que $1 \mathrm{~km}$ es de $\sim 1,6 \times 10^{5}$. Tienen clases taxonómicas principalmente D, P y C y albedos bajos, 0.065 de promedio (Marzari y otros, 2002). Se cree que el origen de los Troyanos son los planetesimales orbitando en la zona de Júpiter que fueron capturados en las últimas etapas de la formación planetaria. Las amplitudes de libración entorno a $L_{4}$ van de $0,6^{\circ}$ a $88,7^{\circ}$ con un valor medio de $32,7^{\circ}$ y no hay diferencias significativas de su distribución entre $L_{4}$ y $L_{5}$ (Marzari y otros, 2002). 


\section{Resonancias en el Cinturón de asteroides}

El cinturón de asteroides muestra un claro patrón asociado con resonancias de movimientos medios con Júpiter, en las cuales el período de revolución de los asteroides alrededor del Sol es conmensurable con el período de Júpiter. En la figura 1.2 se muestra esta característica donde se señalan las principales resonancias con Júpiter. Los asteroides Troyanos en resonancia 1:1 con Júpiter ejecutan libraciones alrededor de los puntos de Lagrange $L 4$ y $L 5$ posicionados $60^{\circ}$ por delante y $60^{\circ}$ por detrás de Júpiter y por tanto nunca sufren un encuentro cercano con este planeta. Este es un ejemplo de mecanismo de protección provocado por la resonancia. Otro ejemplo de este mecanismo son los asteroides Hildas en resonancia $3: 2$ con Júpiter y el asteroide 279 Thule en la resonancia 4:3. El ángulo crítico, $\varphi=3 \lambda_{J}-2 \lambda-w$ de los Hildas, libra alrededor de cero $\left(\lambda_{J}\right.$ y $\lambda$ son las longitudes medias de Júpiter y los Hildas respectivamente y $w$ es la longitud del perihelio de los Hildas). De esta forma, cuando el asteroide está en conjunción con Júpiter $\left(\lambda=\lambda_{J}\right)$, el asteroide está cerca del perihelio $(\lambda \sim w)$, y lejos de Júpiter. Sin embargo existen vacíos o gaps en el cinturón principal en algunas resonancias con Júpiter como se aprecia en la figura 1.2, llamados gaps de Kirkwood en honor a su descubridor. En 1867, Kirkwood estudió la distribución en semieje mayor de las órbitas de $\sim 100$ asteroides y notó que existían regiones desprovistas de asteroides en algunas resonancias con Júpiter.

La concentración de objetos en unas resonancias y la falta en otras evidencia el hecho de que las resonancias pueden ser la fuente tanto de términos de gran estabilidad como de inestabilidad. Así, la dinámica de una resonancia juega un rol crítico en la comprensión de la distribución y el transporte de los cuerpos menores en las diferentes regiones del sistema planetario.

Por otro lado, como se observa en la figura 1.2, los límites interno y externo del cinturón principal de asteroides están asociados con las resonancias 4:1 y 2:1. Otra característica es la falta de asteroides observados (excepto el asteroide Thule en la resonancia 4:3) más allá de la resonancia 3:2. Esto es una consecuencia de la superposición de resonancias de primer orden con Júpiter en esa zona, ya que a medida que nos acercamos a Júpiter, las resonancias de primer orden se acercan entre sí. 


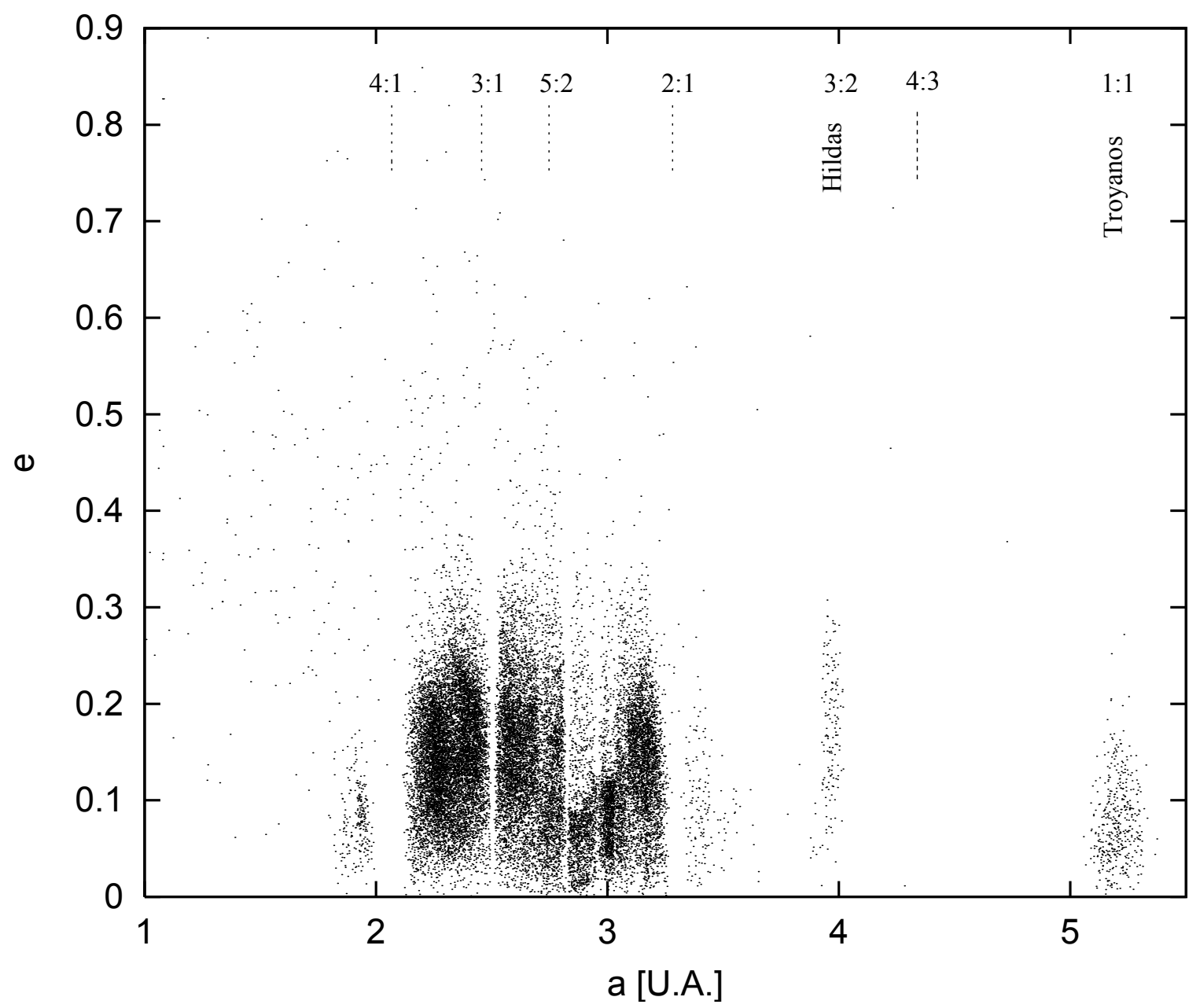

Figura 1.2: Distribución de asteroides en el cinturón principal y principales resonancias de movimientos medios con Júpiter

Una de las principales resonancias de movimientos medios con Júpiter de primer orden es la resonancia $2: 1$, en $a \sim 3,27$ UA llamada gap Hecuba.

La dinámica del gap Hecuba es muy similar a la de la resonancia $3: 2$. Por este motivo la falta de objetos en la resonancia 2 : 1 y el grupo de asteroides en la resonancia 3 : 2, ha sido ampliamente estudiado (por ej. Ferraz-Mello y otros, 1998a y 1998b, Nesvorný y Ferraz-Mello, 1997).

La resonancia 3 : 1 llamada gap Hestia en $\sim 2,5$ UA, es una región caótica fuente de Objetos Cercanos a la Tierra (NEOs) y meteoritos. Un objeto en la zona de esta 
resonancia alcanza excentricidades altas hasta cruzar las órbitas de Marte y la Tierra en escalas de tiempo de millones de años (Wisdom, 1983, 1985). Así es finalmente removido por perturbaciones de Marte e incluso la Tierra y Venus.

Las resonancias seculares también modelan la forma del cinturón en el espacio de los elementos orbitales. Las principales resonancias que son importantes en el cinturón de asteroides son las $\nu_{5}, \nu_{6}$ y $\nu_{16}$ (Scholl, y otros 1989). Estas resonancias se deben a la igualdad entre las frecuencias de variación del perihelio del asteroide y la frecuencia de variación del perihelio de Júpiter y Saturno y la igualdad de la frecuencia de variación del nodo del asteroide y la de Júpiter respectivamente. La resonancia $\nu_{16}$ produce principalmente grandes variaciones en la inclinación mientras que las $\nu_{5}$ y $\nu_{6}$ fuertes variaciones en la excentricidad. Están asociadas con regiones despobladas en el cinturón de asteroides. En particular, el corte abrupto en la concentración de asteroides observados en $\sim 2 \mathrm{UA}$ se debe a la resonancia secular con Saturno $\nu_{6}(a=2,06 \mathrm{UA})$. Su efecto es aumentar las excentricidades de los objetos en esa zona hasta que cruzan la órbita de Marte y la Tierra y finalmente son removidos de la resonancia por esos planetas. Esta resonancia junto con la resonancia de movimientos medios 3:1 son las principales fuentes de NEOs (Bottke y otros, 2002). Los mecanismos que alimentan de objetos estas resonancias son las colisiones de asteroides y el efecto Yarkowsky (fuerza de drag térmica que hace decaer a los asteroides en semieje mayor). Bottke y otros (2002) obtienen que los objetos que alcanzan la población de NEOs son colisionalmente evolucionados, por tanto el efecto Yarkowsky es el principal en inyectar asteroides en las resonancias que los transportan a la zona de los planetas terrestres.

\subsubsection{Objetos cercanos a la Tierra, Centauros y Trans - Neptu- nianos}

Además de los asteroides del cinturón principal, y de los asteroides de la zona externa entre 3,5 y 5,2 UA, existen otros grupos de objetos, los objetos cercanos a la Tierra, los Centauros y los Trans-Neptunianos, que se describen en las secciones siguientes. Cabe aclarar que en principio, todo objeto de apariencia estelar que se observa dentro del 
Sistema Solar, se lo designa como asteroide a menos que se demuestre lo contrario . Es decir, si se detecta actividad, es un cometa, si no es un asteroide. En virtud de su ubicación y de las observaciones y teorías sobre composición y origen de los grupos de objetos fuera del cinturón principal, es más apropiado llamarlos objetos en lugar de asteroides. También es discutible el status de los Hildas y Troyanos, como veremos a lo largo de esta tesis.

\section{Objetos cercanos a la Tierra (NEOs)}

Los Objetos cercanos a la Tierra (NEOs), se encuentran hacia dentro del cinturón principal, son los objetos (asteroides y cometas) que cruzan las órbitas de los planetas terrestres. Este grupo, representado en la figura 1.1 está definido como los objetos que tienen distancias perihélicas $q \leq 1,3$ UA y distancias afélicas $Q \geq 0,983$ UA (por ej. Bottke y otros, 2002). Esta población se subdivide en los objetos Amor $(q>1,0167$ UA), con órbitas cercanas a cruzar la Tierra, los Apollo ( $a \geq 1$ UA y $q \leq 1,0167$ UA) y Athenas $(a<1$ UA y $Q \geq 0,983)$ que cruzan la órbita de la Tierra. Son objetos pequeños provenientes principalmente del cinturón de asteroides, y en menor medida de los Cometas de la Familia de Júpiter (Bottke y otros, 2002).

\section{Objetos Centauros}

El grupo de objetos ubicados entre las órbitas de Júpiter y Neptuno son los Centauros. Se cree que han sido eyectados de la región transneptuniana a través de inestabilidades dinámicas (Morbidelli, 1997) o colisiones mutuas (Ip y Fernández, 1997). Los Centauros caen así bajo el control gravitatorio de los planetas gigantes, intersectando sus órbitas. Esto hace que sus órbitas sean altamente caóticas con tiempos de vida medios muy cortos. Se supone que conforman un eslabón dinámico entre los objetos Trans - Neptunianos y los Cometas de Corto Período. El primer Centauro descubierto fue 2060 Chiron en 1978 con semieje mayor $a=13,7$ UA. Es un ejemplo de un objeto catalogado en principio como asteroide pero que luego de su descubrimiento se le ha detectado actividad, evidenciando su condición de cometa. Tienen características espectrales muy diferentes entre sí, aunque se observa la presencia de materiales volátiles y orgánicos. 


\section{Objetos Trans - Neptunianos}

Más allá de Neptuno se encuentran los Objetos Trans-Neptunianos (TNO), también llamados objetos del Cinturón de Edgeworth-Kuiper(EKB), en honor a los dos científicos que propusieron su existencia en 1949 y 1951 respectivamente. Ellos postularon, que el disco de planetesimales que formó los planetas no tenía porqué terminar en Neptuno (o Plutón). Pero, la densidad de la Nebulosa Solar primitiva era demasiado baja a esas distancias o los tiempos de formación muy grandes como para llegar a formar planetas. Así, se debería encontrar más allá de Neptuno un disco de planetesimales.

Desde el primer TNO descubierto en 1992 por D. Jewitt y J. Luu se han descubierto hasta el presente más de 700 TNO. Se pueden dividir en tres categorías dinámicas (Jewitt y Luu, 2000), los objetos clásicos: $a \geq 42$ UA y $q>35$ UA, los plutinos en resonancia 3:2 con Neptuno ( $a=39,4 \mathrm{UA})$ y los objetos del scattered disk con órbitas con gran inclinación y excentricidad y perihelios $q \sim 35$ UA. Sin embargo son objetos que han sido dinámicamente dominados por Neptuno. Como los Centauros, estos objetos probablemente sean cometas, de hecho está ampliamente aceptado que el EKB es la fuente de cometas de corto período. Probablemente, son cuerpos congelados, remanentes del disco protoplanetario primitivo. También se ha observado la presencia de polvo en esa región, aunque su detección certera es técnicamente difícil.

La acreción de cuerpos grandes como Plutón y simulaciones numéricas que dan cuenta de gran pérdida de masa por colisiones, hacen pensar que el EKB fue mucho más masivo que lo que actualmente es. Por otro lado se han observado discos de polvo circunplanetarios en otras estrellas (por ej. $\beta$ Pictoris), con extensiones de entre 200 y 2000 UA de la estrella central y un hueco central "vacío" de entre 20 y 100 UA de extensión. Esta zona central donde no se observa polvo, se cree que podría deberse a la presencia de planetas orbitando la estrella central que barrerían el polvo del disco primitivo. En este sentido, el Cinturón de Edgeworth-Kuiper sería el disco de polvo y objetos primitivos remanentes de la formación del Sistema Solar. 


\subsubsection{Composición y taxonomía de asteroides}

La base para la taxonomía de asteroides son los datos obtenidos por telescopios: el albedo geométrico y los espectros de reflexión en el infrarrojo cercano y visible. El albedo geométrico (p) de un objeto se define como el cociente entre el brillo de un objeto y el brillo de un disco perfectamente difusor del mismo radio del objeto y a la misma distancia del Sol (Nelson y Domingue, 1999). Es decir que es igual a la fracción de luz reflejada por el objeto. Está dado por:

$$
p=\frac{d^{2} R^{2} C(0)}{S r^{2}}
$$

donde $S$ es el flujo de energía solar en la órbita terrestre, $R$ es la distancia al Sol del objeto, $r$ su radio, $d$ es la distancia del objeto a la Tierra y $C(0)$ es la intensidad de radiación observada cuando el ángulo de fase solar es igual a $0^{\circ}$ (el observador está exactamente en la línea Sol - objeto).

Estudios realizados sobre meteoritos muestran que las superficies muy oscuras (albedo bajo), provienen de materiales carbonosos, mientras que las superficies con un albedo alto se asocian con una composición de silicatos.

El Sol tiene su máximo de radiación en la región visible media del espectro. Por tanto los objetos iluminados por él tendrán un flujo incidente máximo en esta longitud de onda aunque la emisión máxima debida a procesos térmicos depende de la temperatura superficial del objeto. Para los asteroides la emisión máxima está entre 5 y $20 \mu m$ dependiendo del albedo, de la emisividad y de procesos térmicos. La interacción entre la radiación solar y la materia de un asteroide se da, en el infrarrojo medio $(\lambda>3 \mu m)$ a través de las frecuencias vibracionales fundamentales de las moléculas. Para las temperaturas de las superficies de los asteroides la emisión es despreciable en el visible y en el infrarrojo cercano $(\sim 0,35 a \sim 3 \mu \mathrm{m})$ y las absorciones son producidas por mecanismos vibracionales, teoría de cristales y de transferencia de carga (Burns, 1970 y 1981).

La espectroscopía de reflexión para la caracterización de las superficies de los asteroides se utiliza en el rango del visible y del infrarrojo cercano. Esto es por un lado, 
porque como ya mencionamos, el Sol tiene su máximo en el visible, pero por otro porque la atmósfera es relativamente transparente en esas longitudes de onda comparadas con el ultravioleta o infrarrojo medio. Pero además, en aquella región del espectro, la mineralogía es la que determina las propiedades del espectro.

Como la luz del Sol interactúa sólo con la superficie del asteroide, el espectro representa las propiedades de las partículas superficiales. Sin embargo, probablemente las características de la superficie y por tanto del espectro sean afectadas por el impacto de partículas solares y micrometeoritos (space weathering). Este proceso es ampliamente debatido actualmente y sus efectos no se conocen bien. A pesar de esto, se asume que esta capa superficial de material es representativa de la composición de todo el asteroide.

Más allá de la líneas que se puedan observar en los espectros de los asteroides, el objetivo principal de la espectroscopía de reflexión es determinar el cociente entre la luz solar reflejada y la incidente como función de la longitud de onda. De hecho, las dos características principales de un espectro de reflexión son su pendiente y la presencia o ausencia de líneas o bandas de absorción.

La clasificación de los asteroides según su composición química, derivada de su espectro y albedo, da lugar a lo que se conoce como taxonomía de asteroides. Desde la primera clasificación realizada por Chapmann y otros (1975), la taxonomía depende de las capacidades observacionales y está condicionada por ellas. Según han evolucionado las técnicas de observación, han evolucionado los algoritmos para la clasificación de asteroides. Sin embargo, el objetivo general de las diferentes taxonomías es agrupar los asteroides con características similares en clases taxonómicas, cada clase denotada por una letra o grupo de letras. Esto involucra definir un espacio de parámetros y agrupar los asteroides según ellos. Hasta la actualidad se han propuesto cuatro sistemas taxonómicos (Bus y otros 2002): la Taxonomía de Tholen (1984), de Barucci y otros (1987), de Tedesco y otros (1989) y de Howell y otros (1994). Las clases taxonómicas definidas por estos cuatro sistemas son esencialmente similares. En los sistemas más nuevos suelen aparecer algunas subclases del sistema de Tholen o las clases de Tholen pueden estar divididas. En el trabajo de Bus y otros, (2002) se describen los cuatro sistemas mencionados. Sin embargo, para focalizar nuestra atención en el concepto general que involucra la clasificación de los asteroides 
según su composición, describiremos aquí las clases taxonómicas de la clasificación de Tholen. La tabla 1.1 es una adaptación de las tablas I de los trabajos de Bell y otros, (1989), Tholen y Barucci, (1989) y Bus y otros, (2002) y la tabla III de Gaffey y otros (1989).

La clase B tiene albedos bajos entre 0,04 y 0,08, la C, la clase más abundante, tiene albedos en el rango 0,04 a 0,06. Las clases E, M y G, con espectros similares a la clase $\mathrm{C}$, tienen albedos altos de 0,38, 0,12 y 0,09 respectivamente. Los asteroides D tienen albedos entre 0,04 y 0,07 y los S entre 0,14 y 0,17. Las clases A, Q, R y V tienen albedos moderadamente altos mientras que para las clases $\mathrm{T}$ y $\mathrm{P}$ son bajos (Tholen y Barucci, 1989).

Las clases taxonómicas no están distribuidas uniformemente a través del cinturón de asteroides sino que tienen sus picos de abundancia a diferentes distancias del Sol. Además cada clase no se restringe a una zona dada sino que tiene una distribución de forma gausiana en semieje mayor cuya dispersión es de alrededor de $1 \mathrm{UA}$. La clase S domina el cinturón principal interno mientras que las clases $\mathrm{C}, \mathrm{P}$ y D son más abundante en la zona externa. Cada clase taxonómica y por ende cada lugar del Sistema Solar está caracterizado por diferente mineralogía. Probablemente esto es el resultado de la distribución primordial de los elementos en el Sistema Solar y su subsecuente evolución térmica y dinámica, condicionada a las condiciones iniciales de la nebulosa solar temprana. De acuerdo a los modelos de la condensación de la nebulosa solar, los minerales silicatos de altas a moderadas temperaturas tienden a dominar el Sistema Solar interior, mientras que los minerales carbonaceos de temperaturas más bajas son comunes en las regiones frías externas del Sistema Solar. 


\begin{tabular}{|c|c|c|}
\hline Clase taxonómica & Espectro & Mineralogía \\
\hline $\mathrm{D}$ & $\begin{array}{c}\text { Relativamente con pocas } \\
\text { características con } \\
\text { pendiente muy abrupta en el rojo }\end{array}$ & $\begin{array}{l}\text { materiales orgánicos (carbón) } \\
\text { silicatos enriquecidos en materiales } \\
\text { orgánicos y hielos. }\end{array}$ \\
\hline $\mathrm{P}$ & $\begin{array}{c}\text { pocas características, levemente } \\
\text { enrojecido entre } 0,3 \text { y } 1,1 \mu m \text { difiere } \\
\text { del espectro idéntico de las } \\
\text { clases E y M en el albedo (más bajo) }\end{array}$ & $\begin{array}{l}\text { materiales orgánicos (carbón), } \\
\text { silicatos enriquecidos en } \\
\text { materiales orgánicos y hielos }\end{array}$ \\
\hline $\mathrm{C}$ & $\begin{array}{l}\text { absorción débil a media en } \lambda<0,55 \mu \mathrm{m} \\
\text { y neutro o levemente enrojecido y sin } \\
\text { características más allá de } \lambda=0,55 \mu \mathrm{m}\end{array}$ & $\begin{array}{l}\text { materiales orgánicos y opacos, } \\
\text { arcillas, silicatos hidratados } \\
\text { más carbón. }\end{array}$ \\
\hline $\mathrm{Q}$ & $\begin{array}{l}\text { pendiente en el rojo moderadamente } \\
\text { abrupta }(\lambda<0,7 \mu m) \text { y } \\
\text { absorción profunda en } \lambda>0,75 \mu m\end{array}$ & $\begin{array}{l}\text { olivino }\left(M_{g}, F_{e}\right)_{2} \mathrm{SiO}_{4} \\
\text { piroxeno, metal }(\mathrm{NiFe})\end{array}$ \\
\hline $\mathrm{T}$ & $\begin{array}{c}\text { pendiente moderadamente enrojecida } \\
\text { para } \lambda<0,75 \mu \mathrm{m} \text { y generalmente } \\
\text { plana para } \lambda>0,75 \mu \mathrm{m} \\
\end{array}$ & $\begin{array}{c}\text { Probablemente similares } \\
\text { a las clases P y D }\end{array}$ \\
\hline $\mathrm{B}$ & $\begin{array}{l}\text { sin características con } \\
\text { pendiente neutra }\end{array}$ & $\begin{array}{l}\text { materiales orgánicos y opacos } \\
\text { silicatos hidratados más carbón. }\end{array}$ \\
\hline G & $\begin{array}{l}\text { pendiente neutra a levemente } \\
\text { enrojecida y sin características } \\
\text { más allá de } \lambda=0,55 \mu \mathrm{m} \text {,fuerte } \\
\text { absorción ultravioleta } \\
\text { para } \lambda<0,55 \mu \mathrm{m}\end{array}$ & $\begin{array}{l}\text { materiales orgánicos y opacos } \\
\text { silicatos hidratados } \\
\text { más carbón. }\end{array}$ \\
\hline $\mathrm{F}$ & $\begin{array}{l}\text { sin características con } \\
\text { pendiente neutra a levemente } \\
\text { azulada en todo el rango del } \\
\text { espectro entre } 0,3 a 1,1 \mu \mathrm{m}\end{array}$ & $\begin{array}{l}\text { materiales orgánicos y opacos } \\
\text { silicatos hidratados } \\
\text { más carbón. }\end{array}$ \\
\hline
\end{tabular}




\begin{tabular}{|c|c|c|}
\hline Clase taxonómica & Espectro & Mineralogía \\
\hline $\mathrm{V}$ & $\begin{array}{c}\text { pendiente en el rojo de } \\
\text { moderada a muy abrupta para } \\
\qquad \lambda<0,7 \mu \mathrm{m} \text { y con } \\
\text { una banda de absorción muy } \\
\text { profunda en } \lambda>0,75 \mu \mathrm{m}\end{array}$ & $\begin{array}{l}\text { piroxeno y feldespato (grupo mineral } \\
\left.\left.\qquad(\mathrm{Na}, \mathrm{Ca}) \mathrm{Al}(\mathrm{Si}, \mathrm{Al}) \mathrm{Si}_{2} \mathrm{O}_{8}\right)\right)\end{array}$ \\
\hline $\mathrm{R}$ & $\begin{array}{l}\text { pendiente en el rojo muy abrupta } \\
\qquad(\lambda<0,7 \mu m) \mathrm{y} \\
\text { absorción muy profunda para } \\
(\lambda>0,75 \mu m)\end{array}$ & piroxeno y olivino \\
\hline $\mathrm{S}$ & $\begin{array}{l}\text { absorciones fuertes a moderadas } \\
\text { para } \lambda<0,7 \mu m \\
\text { y absorciones de moderadas } \\
\text { a inexistentes para } \lambda>0,7 \mu m\end{array}$ & $\begin{array}{c}\text { metal }(\mathrm{NiFe}) \\
\text { olivino y piroxeno }\end{array}$ \\
\hline A & $\begin{array}{l}\text { pendiente de muy a extremadamente } \\
\text { abrupta en el rojo para } \\
\qquad \begin{array}{l}\lambda<0,75 \mu \mathrm{m} \text { y fuerte } \\
\text { absorción más alla de } \lambda=0,75 \mu \mathrm{m}\end{array}\end{array}$ & $\begin{array}{c}\text { olivino y } \\
\text { olivino metálico }\end{array}$ \\
\hline M & $\begin{array}{c}\text { pocas características, } \\
\text { plano a levemente enrojecido } \\
\text { entre } 0,3 \text { y } 1,1 \mu m, \\
\text { difiere del espectro idéntico } \\
\text { de las clases E y P en el albedo }\end{array}$ & metal $(\mathrm{NiFe})$ \\
\hline $\mathrm{E}$ & $\begin{array}{c}\text { pocas características, } \\
\text { plano a levemente enrojecido } \\
\text { entre } 0,3 \text { y } 1,1 \mu m, \\
\text { difiere del espectro idéntico } \\
\text { de las clases } \mathrm{M} \text { y P en el albedo } \\
\text { silicatos libres de hierro }\end{array}$ & $\begin{array}{c}\text { silicatos } \\
\text { libres de hierro }\end{array}$ \\
\hline
\end{tabular}

Tabla 1.1: Clasificación taxonómica de Tholen, sus características espectrales y composición mineral. 
Por otro lado es posible dividir la clasificación de Tholen en tres superclases (Bell, 1986 y Bell y otros, 1989) según el grado de metamorfosis por calentamiento que hayan sufrido los materiales en vez de su composición en si. Las clases D, P, C, K y Q serían objetos primitivos que han experimentado poco o ningún calentamiento. Las clases $\mathrm{T}, \mathrm{B}$, G y F, serían objetos metamórficos que han experimentado suficiente calentamiento como para evidenciar cambios en el espectro. Y finalmente los objetos igneos, las clases $\mathrm{V}, \mathrm{R}$, S, A, M y E cuyas superficies se formaron por la fusión de materiales. Según el trabajo de Bell, 1986, las clases igneas dominan la región interior a 2,7 UA, las clases metamórficas están en $\sim 3$ UA y las clases primitivas dominan la zona exterior a 3,4 UA (Bell 1986, Gaffey, 1989).

En la figura 1.3 se muestra la distribución en el Cinturón de asteroides de las clases taxonómicas y las tres superclases de Bell (Bell y otros, 1989).

Existen dos mecanismos para fundir o transformar los materiales originales de los meteoritos que son menos eficientes a medida que aumenta la distancia al Sol. Por un lado el proceso de acreción, atrapó radioisótopos de vida corta (probablemente ${ }^{26} \mathrm{Al}$ ), que decaen y calientan entonces el asteroide. Otro proceso de calentamiento puede ser la inducción magnetica producida por el campo magnético (intenso) del Sol en su etapa de T-Tauri. Por tanto los asteroides muestran un gradiente de composición más un patrón asociado con mecanismos que han transformado sus elementos originales (Bell y otros 1989).

Una evidencia directa de la composición de los asteroides, son los meteoritos. Se toman en laboratorio espectros de reflexión de los meteoritos y se los compara con los espectros obtenidos de los asteroides. Se encuentra que los espectros de los grandes grupos de meteoritos se corresponden, notablemente, con los diferentes tipos de asteroides del cinturón principal y objetos cercanos a la Tierra (NEOs). Así, es posible asignar a un tipo de meteorito dado un tipo de asteroide (clase taxonómica), de hecho, cada clase de meteorito proviene o es un fragmento que perteneció a algún asteroide. Sin embargo es importante tener en cuenta que las superficies de los asteroides que hoy vemos, han estado expuestas a la radiación solar, procesos de cráteres y fracturas. Esto puede afectar la comparación con los meteoritos, ya que estos serían fragmentos de los cuerpos origi- 


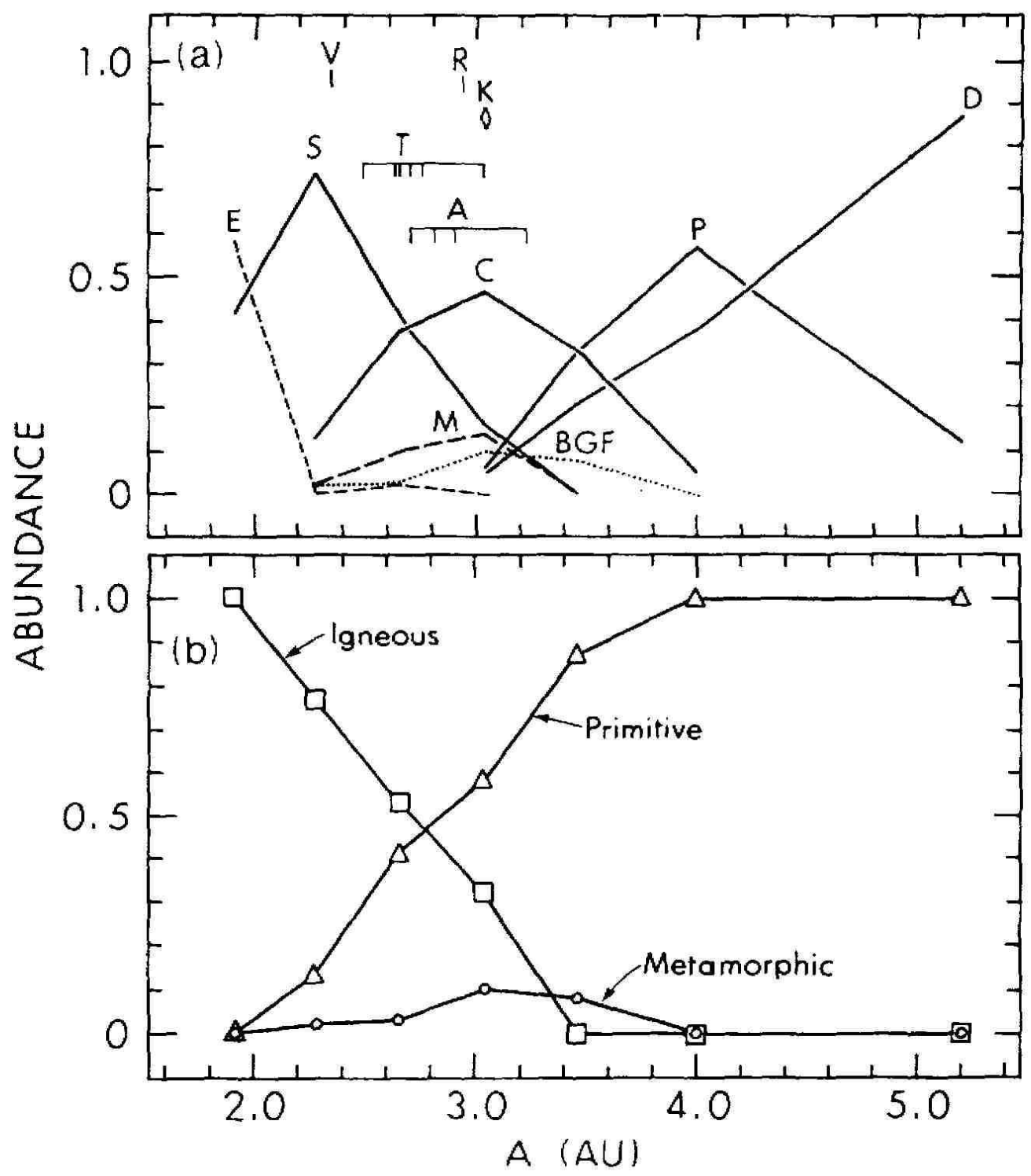

Figura 1.3: Abundancia de las clases taxonómicas y superclases de Bell versus el semieje mayor $A$. (De Bell y otros, 1989)

nales. En este sentido los meteoritos proveen un registro de la naturaleza y condiciones iniciales de las regiones del Sistema Solar donde fueron formados sus progenitores. Se han encontrado meteoritos que se pueden corresponder con todas las clases taxonómicas salvo las clases D y P (tabla 1 en Bell y otros 1989).

Un modelo, discutido, de asteroide consiste en un cuerpo formado por un nucleo central metálico transformado térmicamente a partir de su material original (por 
los procesos antes mencionados) y rodeado por capas cada vez menos transformadas por calentamiento. Para simplificar la idea, digamos que consiste de un nucleo metálico, un manto de material fundido y una corteza. Este tema es ampliamente discutido actualmente. Una de las causas es que la mayoría de los meteoritos encontrados en la Tierra son metálicos y solo una fracción muy pequeña son rocosos. La evolución colisional que experimentó el cinturón de asteroides explica en principio la existencia de meteoritos metálicos provenientes de asteroides primordiales que hubieran sufrido una colisión tal que fueron despojados de su manto y corteza basáltica. Sin embargo, no existe acuerdo en cuanto a porque la mayoría son metálicos. Otro problema es la inexistencia de meteoritos provenientes de los mantos de los asteroides. Esto condiciona fuertemente el modelo anterior.

Otro modelo de asteroide es el llamado rubble-pile es decir, de acumulación de rocas. Probablemente este modelo concuerde con los objetos de la zona externa del cinturón de asteroides, objetos Centauros y Trans-Neptunianos en los que el calentamiento no ha transformado los materiales primordiales.

\subsection{Cometas}

Los cometas son cuerpos del tamaño de algunos kilómetros, compuestos por una mezcla de polvo de silicatos, materiales orgánicos y materiales volátiles o hielos en su mayoría $\mathrm{H}_{2} \mathrm{O}$ pero también $\mathrm{CO}, \mathrm{CO}_{2}, \mathrm{H}_{2} \mathrm{CO}, \mathrm{CH}_{3} \mathrm{OH}$ y otros. El cuerpo propio de un cometa es su núcleo sólido. Tienen albedos superficiales de $\sim 0,04$ y un espectro visible típico desprovisto de características, similar al de los asteroides D. Cuando se aproximan al Sol, el núcleo se calienta y los hielos se subliman produciendo la característica coma o atmósfera difusa del cometa, rodeada por un halo de hidrógeno muy grande (visible sólo en el ultravioleta). La coma consiste de gases y granos de polvo. La interacción del polvo con la presión de radiación del Sol y de los átomos y moléculas con el viento y con el campo magnético solar produce una cola de polvo y una de plasma o iones respectivamente. Los cometas se caracterizan por sus moderadas a altas excentricidades e inclinaciones. Tienen desde órbitas elípticas moderadamente excéntricas hasta casi parabólicas e hiperbólicas. 
El modelo aceptado de formación de los cometas es el de rubble-pile es decir que están formados por la aglomeración de fragmentos pequeños unidos por gravedad o reacumulados por gravedad luego de sufrir una colisión (Weissman, P. 1986).

Los cometas, en general, pasan la mayor parte de sus vidas lejos del Sol, en estado "inerte". En este estado, están largamente expuestos a los rayos cósmicos galácticos y partículas energéticas solares. Esto provoca la formación de mantos de carbón en la superficie de los cometas llamados mantos de irradiación. Son sonas inactivas. Las imágenes del cometa Halley obtenidas por las naves Vega y Giotto, e incluso las recientes imágenes obtenidas por la zonda STARDUST del cometa Wild 2 muestran en sus superficies estas zonas inactivas y varios "jets" de gas y polvo que representa la actividad cometaria. Los sucesivos pasajes por el perihelio y el consecuente desarrollo de actividad, los van desgastando. En cada pasaje pierden probablemente entre el 0,01-0,1\% de su masa. Existen varios casos de cometas que han "desaparecido", es decir que no se los ha podido volver a observar. En principio, un cometa podría sublimar todos sus volátiles hasta quedar un núcleo remanente de materiales no volátiles o desaparecer por completo. Por otro lado, las imágenes cercanas de cometas sugieren que estos, efectivamente desarrollan mantos de carbón. Por tanto, podrían evolucionar en cometas dormidos (ya que el manto de irradiación los cubriría por completo). Fernández y otros, (1999), observan y analizan la población de Cometas de la Familia de Júpiter. En este trabajo, no encuentran cometas activos menores a 0,4 km de radio, y sugieren que la causa es su rápida desintegración.

Con el objeto de hacer más específica la terminología sobre cometas y también asteroides, Hartmann y otros (1987), proponen una definición más estricta sobre estos cuerpos, a continuación enunciamos algunas de sus definiciones:

- Un cometa activo, es un núcleo cometario que despliega coma por la pérdida de sus volátiles.

- Un cometa inactivo es un núcleo cometario que es activo durante parte de su órbita pero que está en una parte donde la pérdida de volátiles es despreciable y no se detecta coma.

- Un cometa dormido es un núcleo cometario sin actividad detectada pero que si 
decreciera su distancia perihélica o sufriera algún proceso de fragmentación por colisiones o efectos de marea, podría ser reactivado.

- Un cometa extinto se llama al cometa que ha perdido sus hielos y es por lo tanto incapaz de desplegar actividad.

\subsubsection{Clasificación de cometas}

Históricamente, la clasificación de cometas se ha basado en el período orbital:

- los cometas de largo período con períodos > 200 años,

- los cometas de período corto con períodos $<200$ años,

- cometas de la familia de Júpiter (JFC): períodos $<20$ años,

- cometas tipo Halley (HTC): períodos entre 20 y 200 años.

El límite principal se fija en $\sim 200$ años, ya que un cometa con período más grande, generalmente se ha observado sólo una vez en los tiempos modernos.

Los cometas de largo periodo ( $L P C$ ) tienen órbitas casi parabólicas o altamente elípticas y por tanto pasan la mayor parte del tiempo lejos de la zona planetaria. La distribución de los afelios de estos cometas es aproximadamente isotrópica alrededor del Sol. Estas características llevaron al astrónomo Jan Oort en 1950 a proponer que la fuente de los LPC era una nube de cometas rodeando el sistema planetario que se extendía a distancias casi estelares.

Se piensa que el origen de esta nube son los cometesimales formados en la región de los planetas gigantes en el Sistema Solar temprano. Estos objetos fueron adquiriendo grandes excentricidades e inclinaciones hasta que los afelios alcanzaron las 20000 o 30000 UA. En este punto la marea galáctica y los pasajes estelares perturban sus órbitas y entonces comienzan a desacoplarse de los planetas. Como los pasajes estelares son al azar, la distribución de cometas se va haciendo isotrópica formando el reservorio de LPC que se conoce actualmente como Nube de Oort. Fernández y Brunini (2000) demostraron que 
la Nube de Oort tiene un núcleo denso de cometas con semiejes entre algunos cientos y miles de UA producto de la formación del Sol dentro de un cúmulo denso de estrellas. Además, esta zona densa estaría rodeada por una región cada vez menos densa.

Everhart (1967) estudió la distribución intrínseca de perihelios y magnitudes absolutas para cometas de largo periodo. Basado en una lista de 256 cometas descubiertos entre 1840 y 1967, mostró que alrededor de 8000 cometas más brillantes que magnitud 11,0 pasaron dentro de 4 UA del Sol en ese periodo. Esto significa 16 cometas por UA por año, aunque sólo un cuarto de ellos serían cometas nuevos (Weissman, 1983). Weissman (1982) estudió la evolución dinámica de las órbitas cometarias en la Nube de Oort y estimó un población actual de 1,2 a $2 \times 10^{12}$ cometas. Considerando la masa típica de un cometa $\sim 4 \times 10^{15}$ gr., Weissman obtiene una masa actual de la Nube de Oort de $\sim 1$ masa terrestre $\left(M_{T}\right)$.

Los mecanismos por los que los cometas dejan la Nube de Oort son las perturbaciones de estrellas cercanas, de nubes moleculares interestelares o fuerzas de marea galáctica. Este último, es el mecanismo más eficiente en injectar cometas hacia la zona planetaria (Byl, 1983).

En 1980, Fernández (1980) fue el primero en sugerir que el Cinturón de Edgeworth Kuiper es la fuente de los cometas de corto período ( $S P C)$. Duncan y otros, 1988 confirmaron este argumento mediante simulaciones numéricas que mostraron que una fuente alrededor de Neptuno con una distribución de inclinaciones inicialmente baja, era más consistente con las bajas inclinaciones observadas para estos cometas.

Una clasificación de los cometas basada en cuestiones dinámicas se obtiene a través de la constante de Tisserand con respecto a Júpiter (Carusi y Valsecchi, 1987, Levison, 1996). El parámetro de Tisserand T, es una aproximación de la constante de Jacobi del problema restringido de los tres cuerpos y está dada por la ecuación:

$$
T=\frac{1}{a}+2 \sqrt{a\left(1-e^{2}\right)} \cos i,
$$

donde $a, e$ e $i$ son el semieje mayor, excentricidad e inclinación del cometa ( $a$ se expresa en las unidades normalizadas del problema). 
La clasificación usando la constante de Tisserand propuesta por Levison (1996) es la siguiente:

- cometas eclípticos: cuerpos con $T>2$ :

- cometas de la familia de Júpiter: $2<T<3$,

- cometas tipo Encke: $T>3$ y $a<a_{J}$,

- cometas tipo Chiron: $T>3$ y $a>a_{J}$,

- cometas casi isotrópicos: cuerpos con $T<2$, principalmente provienen de la Nube de Oort.

En esta clasificación se usa, como ya mencionamos, la constante de Tisserand con respecto a Júpiter, sin embargo, para los cometas tipo Chirón podría ser más apropiado considerar la constante de Tisserand respecto a Saturno.

Hay que notar que los cometas eclípticos cuyas órbitas son inestables están en la región transneptuniana, cuyos objetos son estables en escalas de tiempo comparables con la edad del Sistema Solar. Por lo tanto hay que distinguir entre objetos estables del EKB y cometas en órbitas inestables (Levison y Duncan, 1997). Además, los cometas tipo Chiron son probablemente Centauros, evidenciando el hecho de que la distinción entre asteroides y cometas en esta parte del Sistema Solar no es muy clara.

Una diferencia entre los cometas casi isotrópicos y los eclípticos es la distribución de inclinaciones. Los cometas eclípticos con inclinaciones cercanas a la eclíptica se originan en la región transneptuniana. Mientras que los cometas casi isotrópicos, que agrupan en general a los LPC y HTC, provienen de la Nube de Oort. Levison y Duncan, (1997), encuentran que los HTC que provienen del EKB (y pasan de JFC a HTC), serían la mayoría extintos y por tanto contribuirían en un número despreciable.

Los JFC, como subgrupo de los cometas eclípticos, tienen inclinaciones bajas, es decir que se mueven en órbitas directas.

La mayoría de los JFC tienen constante de Tisserand entre 2,5 y 3, que corresponden a distancias perihélicas menores y por tanto más fácilmente observables. 
La expresión de la integral de Jacobi $\left(C_{j}\right)$ en el problema restringido de los tres cuerpos con respecto a Júpiter es:

$$
C_{j}=2 U-v^{2},
$$

donde $v$ es la velocidad de la partícula relativa a Júpiter y $\mathrm{U}$ es la función potencial, dada por :

$$
U=\frac{x^{2}+y^{2}}{2}+\frac{1-\mu}{r_{1}}+\frac{\mu}{r_{2}}
$$

que depende de las masas principales: $\mu$ y $1-\mu$, de sus distancias a la partícula: $r_{2}$ y $r_{1}$ y al centro de masas del sistema $(x, y)$.

En el problema restringido Sol - Júpiter - cometa, podemos despreciar la masa de Júpiter frente a la del Sol y si el cometa está cerca de Júpiter, su distancia al Sol $r_{1} \sim r$, que es su distancia al centro de masas del sistema. Así, la integral de Jacobi del cometa queda:

$$
C_{j}=-v^{2}+x^{2}+y^{2}+\frac{2}{r},
$$

Considerando que la constante de Tisserand es un caso particular de la constante de Jacobi, tenemos que

$$
T=-v^{2}+x^{2}+y^{2}+\frac{2}{r},
$$

Por lo tanto, la velocidad relativa entre un cometa y Júpiter durante un encuentro cercano con el planeta será:

$$
v=\sqrt{3-T},
$$


Esto muestra que los encuentros con Júpiter son posibles si $T<3$. Así, los JFC, con $2<T<3$, están dominados gravitatoriamente por Júpiter. Además, los cometas con $\mathrm{T}$ levemente menor que 3 tienen velocidades relativas muy bajas y por tanto encuentros muy fuertes con Júpiter.

Los JFC descubiertos tienen períodos menores que 20 años. Por lo tanto sufren la evaporación de sus hielos mucho más frecuentemente que los LPC. Esto determina que su vida física, es decir, el tiempo que el cometa puede ser activo es entonces mucho menor. Levison y Duncan (1997), estiman un tiempo de vida físico de 12000 años. Este tiempo es mucho menor que el tiempo de vida dinámico de $2,7 \times 10^{5}$ años (tiempo hasta que es eyectado del Sistema solar o impacta el Sol o un planeta).

\subsection{La Familia de los Hildas}

En contraposición con otras resonancias con Júpiter, en la resonancia de movimientos medios 3:2, se concentra una importante población: el grupo de los asteroides Hildas. Se encuentran dentro de una fina franja en semieje mayor de 0,1 UA de ancho centrada en $\sim 3,97$ UA (Ferraz Mello y otros, 1998 b). Tienen excentricidades en un amplio rango que alcanzan el valor de $\sim 0,62$, aunque la gran mayoría se concentra en $0,1<e<0,3$ siendo la excentricidad media del grupo $<e>\sim 0,2$. Las inclinaciones de los Hildas llegan hasta los $\sim 45^{\circ}$ siendo la media $\left\langle i>\sim 6,6^{\circ}\right.$. Las distribuciones de los elementos orbitales de los Hildas observados hasta el presente se muestran el la figura 1.1. El asteroide más grande del grupo es el 153 Hilda con 170,6 km de diámetro, descubierto en 1875.

La población de los Hildas se caracteriza por una zona central de gran estabilidad dinámica donde un asteroide puede sobrevivir por la edad del Sistema Solar (Nervorný y Ferraz Mello (1997), Ferraz Mello y otros (1998b)). Sin embargo esta delgada zona está rodeada por regiones inestables hasta alcanzar una región límite muy caótica, donde los tiempos característicos de permanencia son muy cortos. Así, un asteroide que entra en estas zonas es rápidamente eyectado de la resonancia.

Al igual que para los asteroides Troyanos, el intercambio de impulso durante las colisiones mutuas es actualmente, el mecanismo más eficiente para inyectar Hildas en 
las regiones inestables de los bordes de la resonancia. Una colisión en la que el trozo resultante más grande contiene el $50 \%$ o menos de la masa original del blanco se conoce como una colisión catastrófica. El resultado de tal colisión, es un número de fragmentos, cuyos tamaños están distribuidos en una ley de potencias incremental (Davis y otros, 1989). Sólo una fracción de estos fragmentos puede escapar de la atracción gravitatoria del cuerpo más grande, y eventualmente si el impulso adquirido durante la colisión es suficiente, podrían escapar también de la resonancia (Davis y otros, 1989). Este tema se desarrolla en el siguiente capítulo.

Como objetos de la zona externa del cinturón de asteroides, los Hildas podrían contener volátiles. De hecho, estudios espectroscópicos revelan clases taxonómicas principalmente D y P (Dahlgren y Lagerkvist 1995, Dahlgren y otros, 1997). Sin embargo, no es posible decir, a partir de las observaciones, si los hielos se encuentran separados de los otros materiales como en los cometas o integrados a ellos. Dahlgren y otros (1997) obtuvieron que un $36 \%, 28 \%$ y un $2 \%$ son de clases D, P, y C respectivamente. Un resultado adicional de estos trabajos es una relación entre la pendiente del espectro (que identifica la clase taxonómica) y el tamaño de los Hildas, lo que implica que la composición superficial depende del tamaño del asteroide. Hay más objetos de menor tamaño de tipo D. Esta correlación se encontró también en los asteroides Troyanos (Jewitt y Luu, 1990) y en asteroides tipo D observados por Fitzsimmons y otros (1994). Sin embargo, este efecto no fue observado entre asteroides pequeños del cinturón principal (Xu y otros 1995), de manera que sólo debe ocurrir en clases taxonómicas primitivas (Dahlgren y otros 1997). De acuerdo al modelo descripto por Bell y otros (1989), Las clases taxonómicas D, P y C están al comienzo de la secuencia de condensación en la nebulosa solar. Este orden está correlacionado con la distancia al Sol. Dahlgren y otros (1997), sugieren dos posibles explicaciones para la dependencia tamaño - espectro. En primer lugar, discuten mecanismos de calentamiento dependientes del tamaño, que explica cómo el calentamiento metamórfico actúa para diferentes tamaños. Pero estos procesos no parecen explicar cómo el calentamiento afecta diámetros más grandes, y consecuentemente favorece asteroides P y C más grandes. La otra explicación está basada en el hecho de que las colisiones mutuas afectan la distribución de tamaños. Por un lado, siendo los asteroides D los más 
primitivos, son más frágiles, y por tanto más fáciles de fragmentar. En este sentido, uno podría esperar más asteroides D más pequeños que $\mathrm{P}$ o C. Por otro lado, las colisiones de asteroides P o C producen fragmentos pequeños de las capas superiores menos calentadas. Estos fragmentos son probablemente más parecidos al tipo D, y por tanto esto también contribuye a la población de asteroides D pequeños.

\subsubsection{Distribución de tamaños}

El 31 de Octubre de 2002, se encontraron catalogados 814 Hildas en la base de datos de asteroides del Observatorio Lowell (http:// asteroid.lowell.edu). De esta muestra, una submuestra de 35 asteroides tienen sus diámetros estimados. La figura 1.4 muestra la relación entre el diámetro $D$, y la magnitud absoluta catalogada $\mathrm{H}$, de esta submuestra.

También se muestra en esta figura un ajuste por mínimos cuadrados de la forma:

$$
\log D(k m)=s \times H+b,
$$

donde $s=-0,189 \pm 0,01$ and $b=3,673 \pm 0,14$.

Extrapolando este ajuste a toda la muestra (asumiendo que el albedo geométrico medio no cambia con el tamaño), es posible estimar los diámetros de la población entera. El número acumulativo de objetos con diámetro mayor que $D_{0}, N\left(>D_{0}\right)$, se muestra en la figura 1.5 .

Aunque los objetos de tamaño muy grande no se deben incluir, ya que no están afectados por la evolución colisional, es posible realizar un único ajuste de ley de potencia al número acumulativo de la muestra, para $D \geq 12 \mathrm{~km}$, de la forma

$$
N(>D)=\alpha D^{q}
$$

mostrando que la muestra observada está completa hasta este diámetro, un resultado ya reportado por Davis y otros (2002). El mejor ajuste se obtiene para $q=-2,11 \pm 0,008$ 


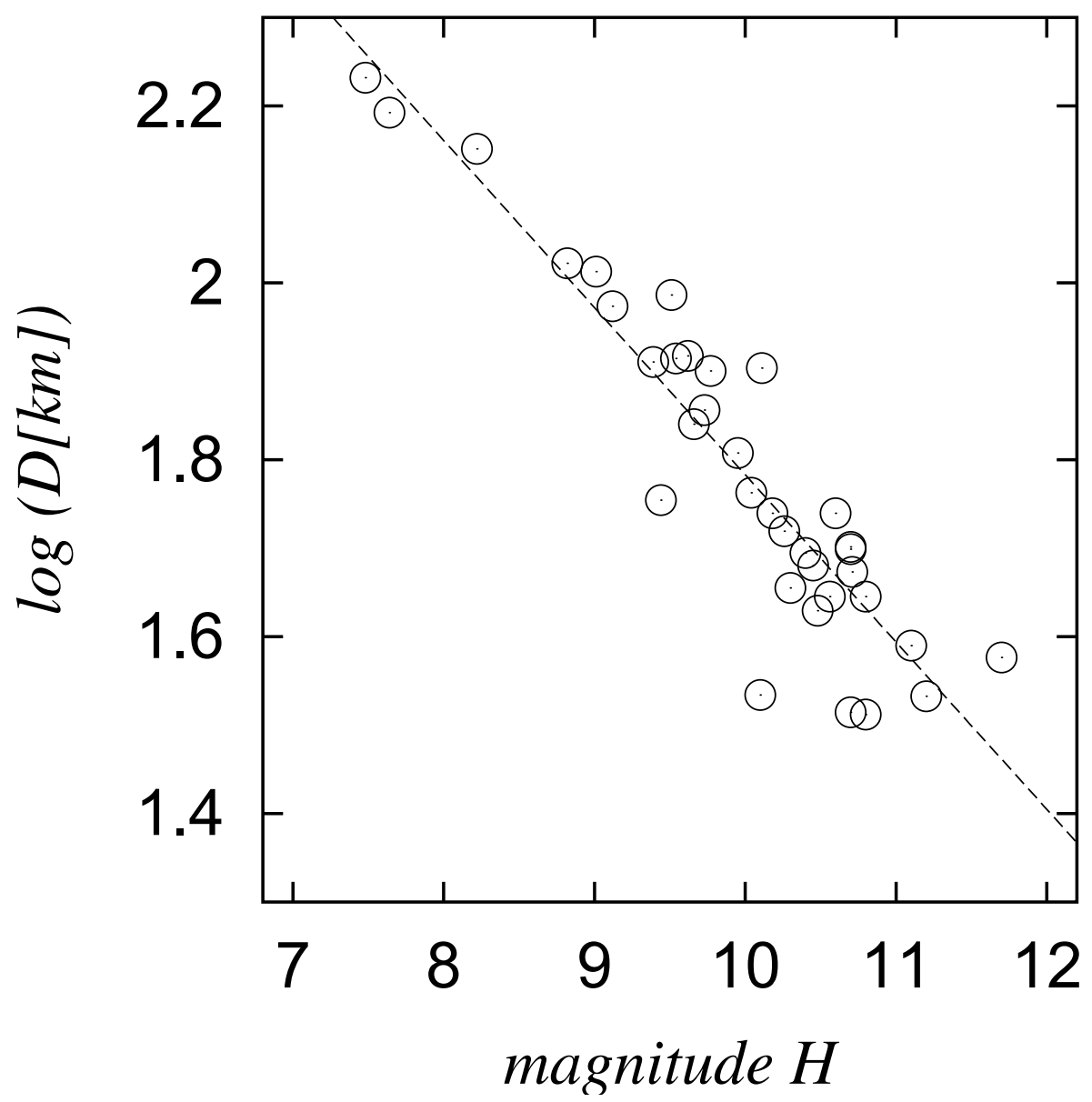

Figura 1.4: Asteroides Hildas con diámetros bien determinados y el ajuste por mínimos cuadrados a la relación entre magnitud absoluta H y el diámetro en Km.

y $\alpha=107922,8$, lo que está de acuerdo con un resultado de cascada colisional. Roig y otros (2002), llevaron a cabo un estudio similar encontrando $q=-2,17$. Es notable que $q$ no es muy sensible al límite superior incluido en la muestra.

Extrapolando a diámetros menores con este exponente, obtenemos una población total de Hildas mayores que $D_{0}=2 \mathrm{~km}$ de alrededor de 25000 asteroides, esto es alrededor de un $8 \%$ de la población de Troyanos estimada en los puntos L4 y L5, que es de alrededor de $3,2 \times 10^{5}$ objetos (Jewitt \& Trujillo 2000). Como para los asteroides Troyanos, no hay un consenso generalizado acerca de la población de Hildas para diámetros pequeños, y es posible una población menor que la calculada anteriormente ( Davis et al. 2002 ). No obstante, son necesarias más observaciones para resolver esta cuestión. 


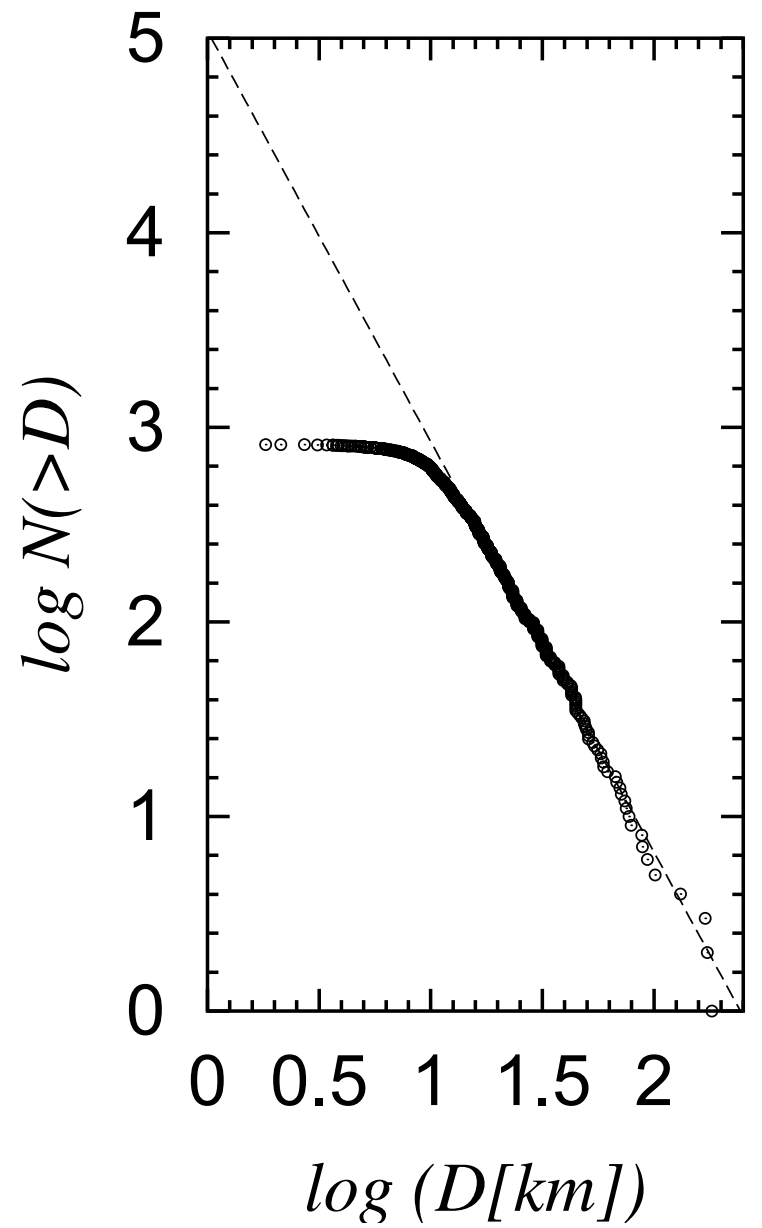

Figura 1.5: Población de todos los asteroides Hildas conocidos. La pendiente del ajuste por mínimos cuadrados a la relación $\log (N)$ y $\log (D)$ es $q=-2,11 \pm 0,008$.

A partir de la ecuación (1.10), el número de Hildas en el intervalo $d r$ centrado en $r$ está dado por la ecuación:

$$
n(r) d r=C r^{-3,11} d r,
$$

donde $C=26375$ 


\section{Capítulo 2}

\section{Simulación numérica, evolución colisional y análisis estadístico}

\subsection{Simulación numérica y Condiciones iniciales}

Para investigar la evolución dinámica de los asteroides Hildas que escapan de la resonancia, llevamos a cabo la integración numérica de 500 asteroides Hildas ficticios bajo la influencia gravitatoria del Sol y los planetas desde Mercurio a Neptuno, con el integrador simpléctico híbrido EVORB realizado por el Dr. Adrián Brunini y colaboradores (Fernández y otros 2002). Este código numérico consiste en un integrador simpléctico de segundo orden con una rutina Bulirsch-Stoer para calcular los encuentros cercanos de las partículas con los planetas. Las condiciones iniciales de los objetos en semieje mayor, excentricidad, inclinación, longitud del nodo ascendente, argumento del perihelio y anomalía media fueron generadas al azar, a partir de la distribución actual de los parámetros or-

bitales de los asteroides Hildas reales que se conocen hasta ahora, tomados de la base de datos del Observatorio Lowell. La muestra se integró durante $1 \times 10^{9}$ años. Las partículas se integran hasta que colisionan con algún planeta o con el Sol o hasta que son eyectadas en órbita hiperbólica.

El objetivo de esta simulación es obtener la evolución dinámica que los asteroides siguen luego de que salen de la resonancia, para luego analizar las diferentes rutas. 
No estamos interesados a estos efectos en estudiar la estabilidad de los asteroides dentro de la resonancia 3:2, ni en la tasa de evaporación dinámica de estos objetos, ya que como veremos es despreciable frente a la evaporación por colisiones. Gil Hutton y Brunini (2000) mostraron que las colisiones pueden cambiar los elementos orbitales de los asteroides Hildas estables, moviéndolos hacia regiones inestables, donde poco después escapen. Además una colisión también cambia el ángulo crítico. Por esta razón, los elementos orbitales angulares fueron generados al azar, de manera que nuestras partículas no son, en general, objetos resonantes, pero sí representativos de fragmentos recientemente desplazados de sus lugares originales estables. La representatividad de la muestra de las partículas de prueba, fue corroborada al repetir nuestros cálculos dividiendo la muestra de las partículas escapadas en dos submuestras. La primera con las partículas escapadas durante los primeros $500 \times 10^{6}$ años y la segunda con las escapadas durante los restantes $500 \times 10^{6}$ años (partículas en regiones más estables). Analizamos los resultados de ambas muestras, que serán mostrados en los capítulos siguientes, y no observamos diferencias estadísticas significativas.

En la figura 2-1 se representan los elementos orbitales de los Hildas reales y ficticios.

Los archivos de salida obtenidos en nuestra simulación son:

- archivo con el tiempo, número de las partículas que quedan en la integración y elementos orbitales de las mismas impresos cada 1000 años.

- archivo de encuentros, donde se imprimen los datos correspondientes a los encuentros entre partícula y planeta, esto es, tiempo, distancia pericéntrica, velocidad y energía planetocéntrica, planeta y partícula.

- archivo de colisiones, donde se imprimen tiempo, distancia al Sol, la velocidad de colisión, la energía, el planeta y la partícula.

- archivo correspondiente a las partículas eyectadas y colisionadas, con el tiempo, la distancia heliocéntrica, los elementos orbitales previos al encuentro, el planeta y la partícula. 

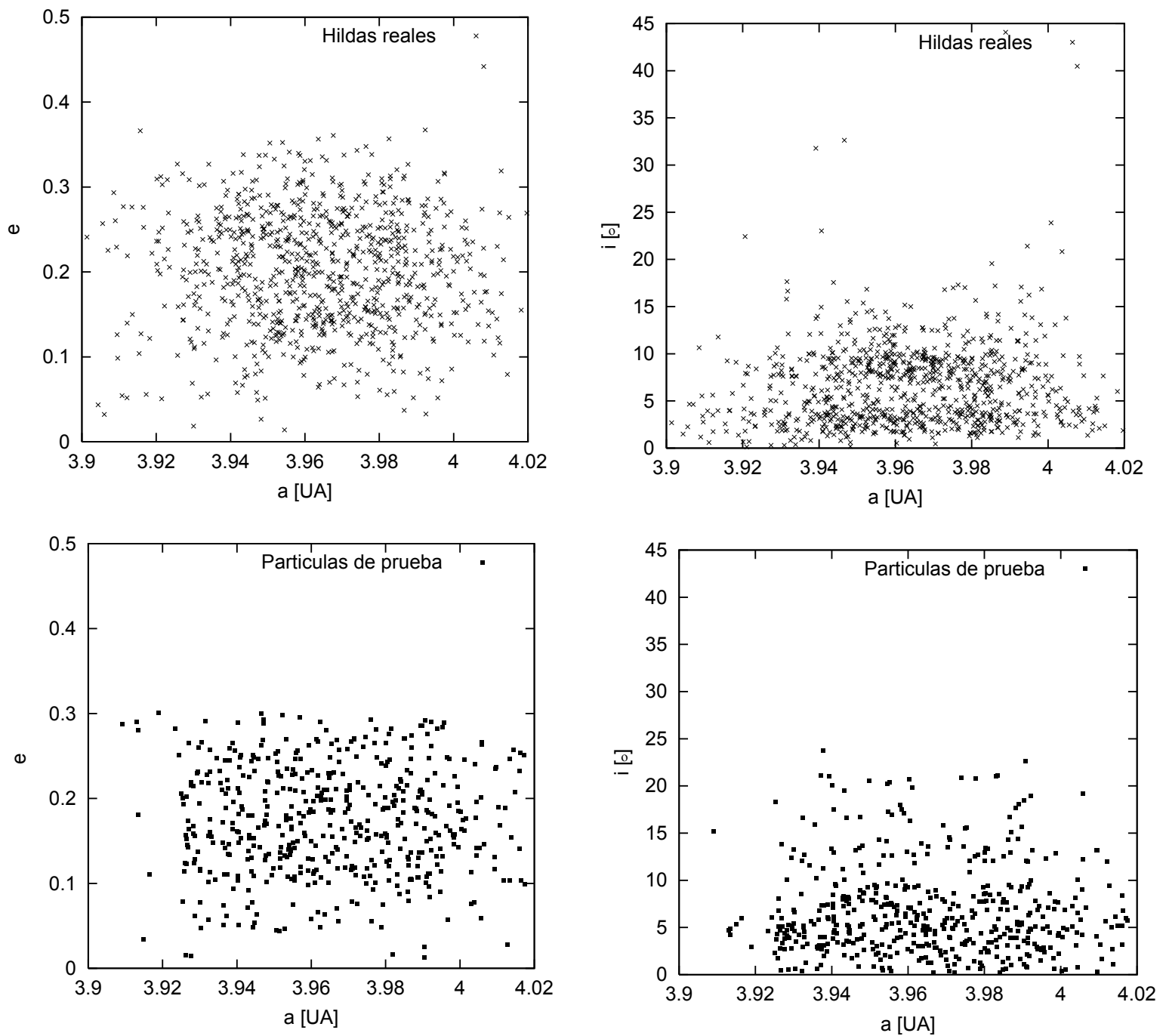

Figura 2.1: Elementos orbitales de los Hildas reales y distribución de los mismos elementos de las partículas de prueba.

\subsection{Resultados y análisis estadístico}

Se analizaron los resultados obtenidos de las simulaciones numéricas, obteniendo una estadística general para diferentes aspectos.

En primer lugar, de las 500 partículas iniciales, quedan en la resonancia, sólo 109, esto es un $21,8 \%$, el resto, o sea el $78,2 \%$ es eyectado de la resonancia. Estos resultados son un producto del modelo utilizado. Para obtener datos más precisos sobre lo que ocurre con las particulas en la resonancia y como evolucionan hasta salir de ella, es necesario considerar un modelo más detallado teniendo en cuenta interacciones entre particulas como las 
colisiones y su evolución. Dado que nuestro interés es estudiar la evolución dinámica post escape de los Hildas, los resultados relevantes son los relativos a las partículas eyectadas de la resonancia. En este caso, obtuvimos que de las partículas que salen de la resonancia, 360 son eyectadas en órbitas hiperbólicas $(92,1 \%)$ y 31 partículas colisionan con Júpiter, es decir un $7,9 \%$.

En general los asteroides que escapan de la resonancia lo hacen aumentando su excentricidad y su semieje mayor, de manera que en su evolución dinámica van transitando el Sistema Solar exterior, teniendo sucesivos encuentros con los planetas gigantes, mayormente con Júpiter. Es decir que tienen varios encuentros con un planeta y luego con otro y tal vez nuevamente con el primero y así sucesivamente. Esto es evidente de los resultados mostrados en la tabla 2.1 obtenida de nuestra simulación, donde se muestra el número total de encuentros con cada planeta, el número de partículas que encuentran cada planeta y su porcentaje con respecto al total de las partículas que escapan.

\begin{tabular}{|l|c|c|c|}
\hline Planeta & $N_{e}$ & $N_{p}$ & $P$ \\
\hline Venus & 55 & 21 & $5,4 \%$ \\
Tierra & 182 & 33 & $8,4 \%$ \\
Marte & 137 & 43 & $11 \%$ \\
Júpiter & 248360 & 392 & $100 \%$ \\
Saturno & 42492 & 368 & $94 \%$ \\
Urano & 9259 & 326 & $83 \%$ \\
Neptuno & 10115 & 295 & $75 \%$ \\
\hline
\end{tabular}

Tabla 2.1: Para cada planeta, $N_{e}$ es el número de encuentros, $N_{p}$ es el número de partículas que tienen encuentros con cada planeta y $\mathrm{P}$ es el porcentaje de $N_{p}$ con respecto al total de las partículas escapadas.

Consideramos que una partícula tiene un encuentro con un planeta si su distancia pericéntrica es menor que 3 veces el radio de Hill. El radio de Hill $\left(R_{H}\right)$ de un planeta está definido por la curva de velocidad cero correspondiente al punto de Lagrange L2 (ubicado entre las masas principales) del problema restringido de los 3 cuerpos. Por tanto, a primer 
orden esta curva será un círculo de radio:

$$
R_{H}=a_{p}\left[\frac{m_{p}}{3\left(m_{p}+M\right)}\right]^{1 / 3}
$$

donde $m_{p}$ es la masa del planeta, $a$ su semieje mayor y $M$ es la masa del Sol.

El número total de encuentros que todas las partículas tienen con los planetas es 310600 , por tanto, el $80 \%$ de los encuentros se dan con Júpiter, el $14 \%$ con Saturno, el 5,9\% con Urano y Neptuno y el $0,1 \%$ con los planetas terrestres. En relación a los planetas terrestres, en el apéndice B se realiza un análisis sobre la contribución de los Hildas al agua en la Tierra. También se analiza la contribución a la población de NEOs. En ambos casos, como es de esperar, según los resultados mostrados en la tabla 2.1, la contribución de los Hildas es despreciable.

En la figura 2.2 se muestran las partículas que son eyectadas por cada planeta. El criterio que adoptamos para reconocer el planeta eyector es el que tuvo el último encuentro. Se puede observar claramente de estos resultados que la dinámica general de las partículas eyectadas está dominada por la acción gravitatoria de Júpiter.

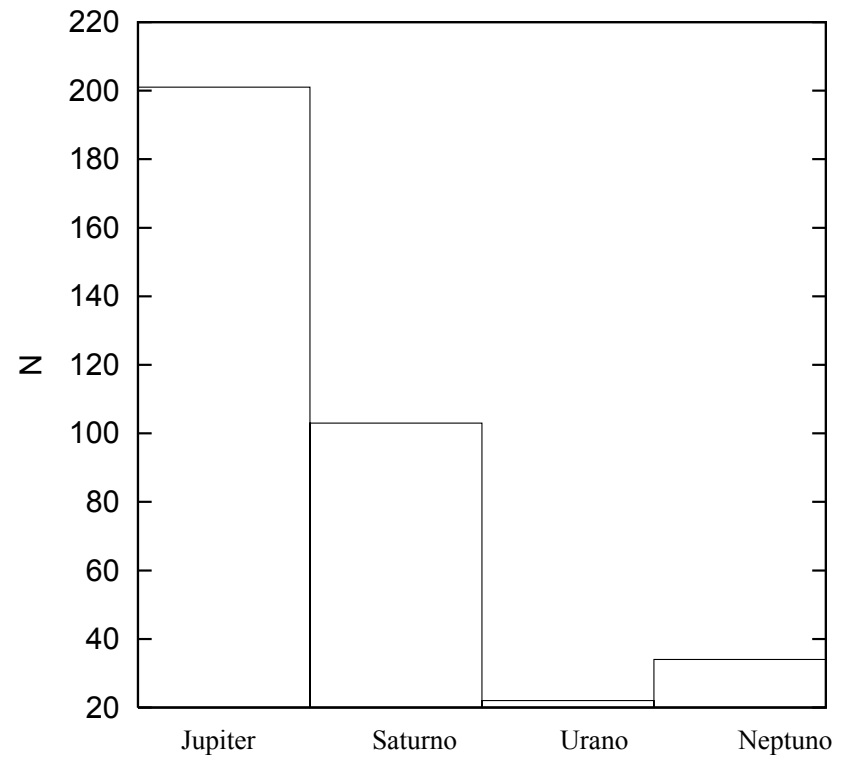

Figura 2.2: Número de partículas eyectadas por planeta

Por otro lado a partir del archivo de salida en el que se imprime el tiempo y el 
número de partículas que quedaron para seguir integrando, se confeccionó un gráfico del número de objetos que quedan en la resonancia versus el tiempo. Además se realizó un ajuste por mínimos cuadrados de estos datos obteniéndose la siguiente relación:

$$
N(t)=\frac{\beta}{(t+\alpha)^{q}}
$$

donde $N(t)$ es el número de partículas que quedan en la resonancia en el instante de tiempo $t$ y los parámetros del ajuste son:

$$
\begin{gathered}
\beta=3994,4 \\
\alpha=64872,6 \\
q=0,18104
\end{gathered}
$$

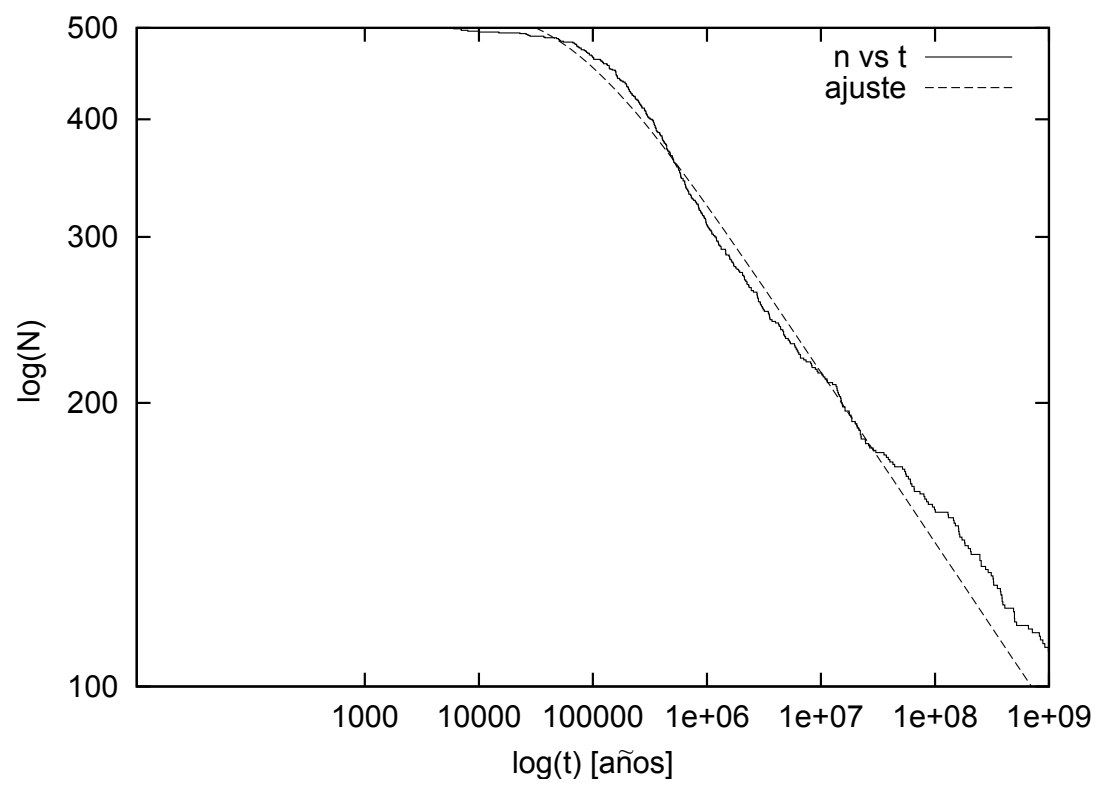

Figura 2.3: Partículas que quedan en la resonancia versus el tiempo.

Esta relación da la forma en que se va despoblando nuestra población por evolución dinámica. Estos resultados representados en la figura 2.3 nos permiten observar que la mayoría de las partículas se pierden al principio relativamente rápido. Luego la tasa de evaporación de la población va disminuyendo. 


\subsection{Algunas rutas dinámicas y evoluciones típicas}

- Las partículas que escapan de la resonancia, como ya dijimos están dominadas por el control gravitatorio de Júpiter. Por lo tanto una característica usual en la evolución dinámica post-escape de un Hilda es el paso a través de una resonancia de movimientos medios con Júpiter. Esto puede observarse en las evoluciones temporales del semieje mayor de tres partículas en las figuras 2.4, 2.5 y 2.6. Las tres partículas de las figura son eyectadas por Júpiter. En particular, en las figuras 2.5 y 2.6 las partículas transitan la resonancia 1:1 con Júpiter por $\sim 150000$ y $\sim 100000$ años respectivamente. Sin embargo, no están excactamente en los puntos de Lagrange L4 y L5.

- En la figura 2.7 se muestran el semieje mayor y el tiempo versus la longitud media del Hilda ficticio relativa a la longitud media de Júpiter de la partícula correspondiente a la figura 2-6. Se observa que en el lapso de tiempo en que el asteroide está exactamente en resonancia 1:1 con Júpiter, la longitud media relativa oscila alrededor de un valor medio de $\sim-85^{\circ}$.

- Hay una partícula que se comporta como un objeto trans-neptuniano. Tiene sucesivos encuentros con Júpiter, Saturno y Urano, hasta que entra bajo el control gravitatorio de Neptuno. Vive como objeto del Scattered Disk por 3,6 $\times 10^{8}$ años. La evolución dinámica luego del escape del grupo de los Hildas se muestra en la figura 2.8 .

- Un estado frecuente de las partículas escapadas es el pasaje por una resonancia de Kozai por relativamente mucho o poco tiempo. En la figura 2.9 se muestra la evolución temporal de un objeto que sale de la resonancia 3:2 y entra en resonancia de Kozai hasta que es eyectado por Júpiter a $\operatorname{los} \sim 5 \times 10^{6}$ años. Este objeto permanece con un valor medio del semieje mayor $a=3,575$. En la figura 2.9 se muestra la evolución temporal del argumento del perihelio y el comportamiento opuesto de la excentricidad e inclinación característico de objetos que transitan por este estado (ver Apéndice A, sección A.0.2). 


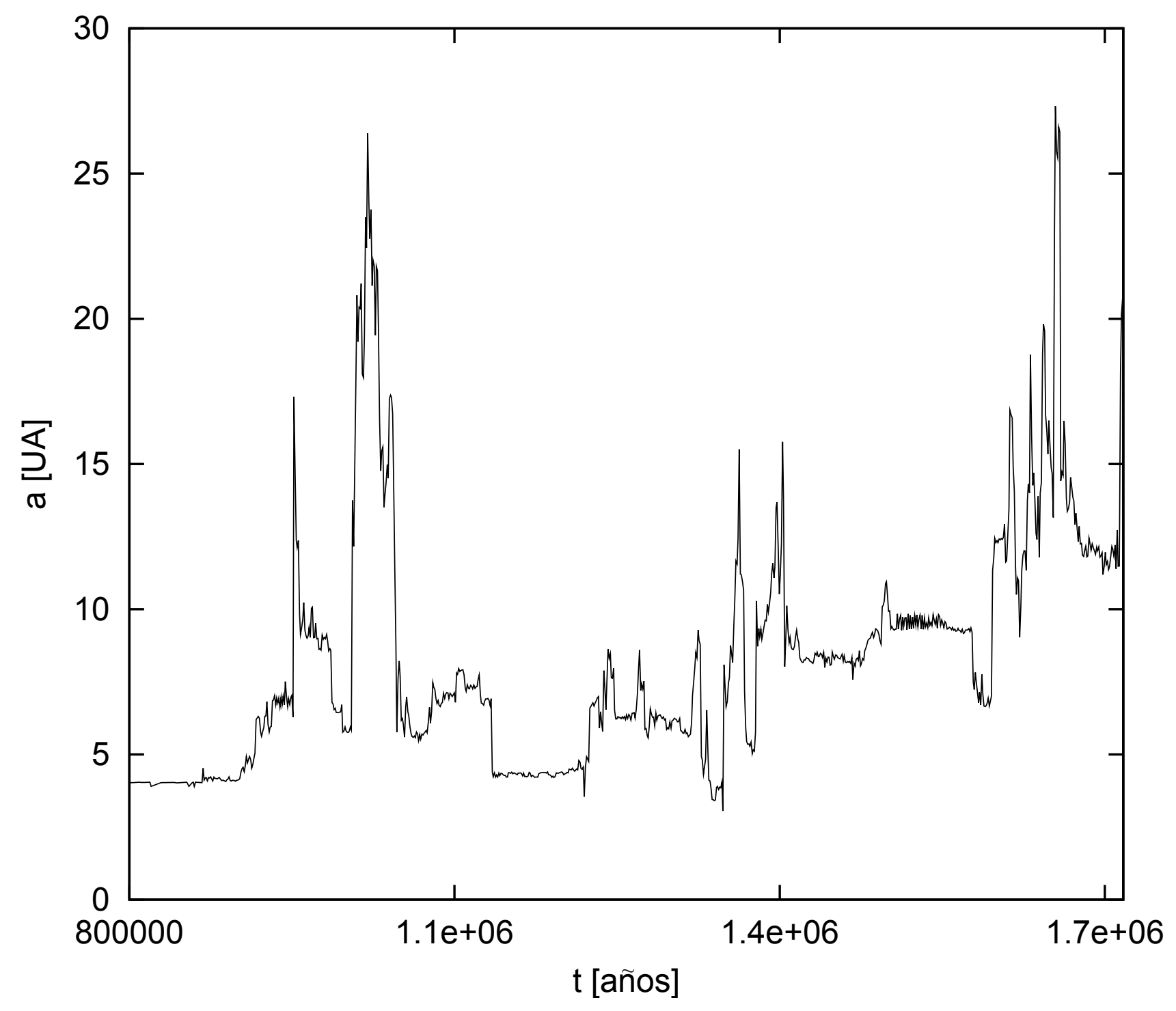

Figura 2.4: Evolución temporal post escape del semieje mayor de una partícula. 


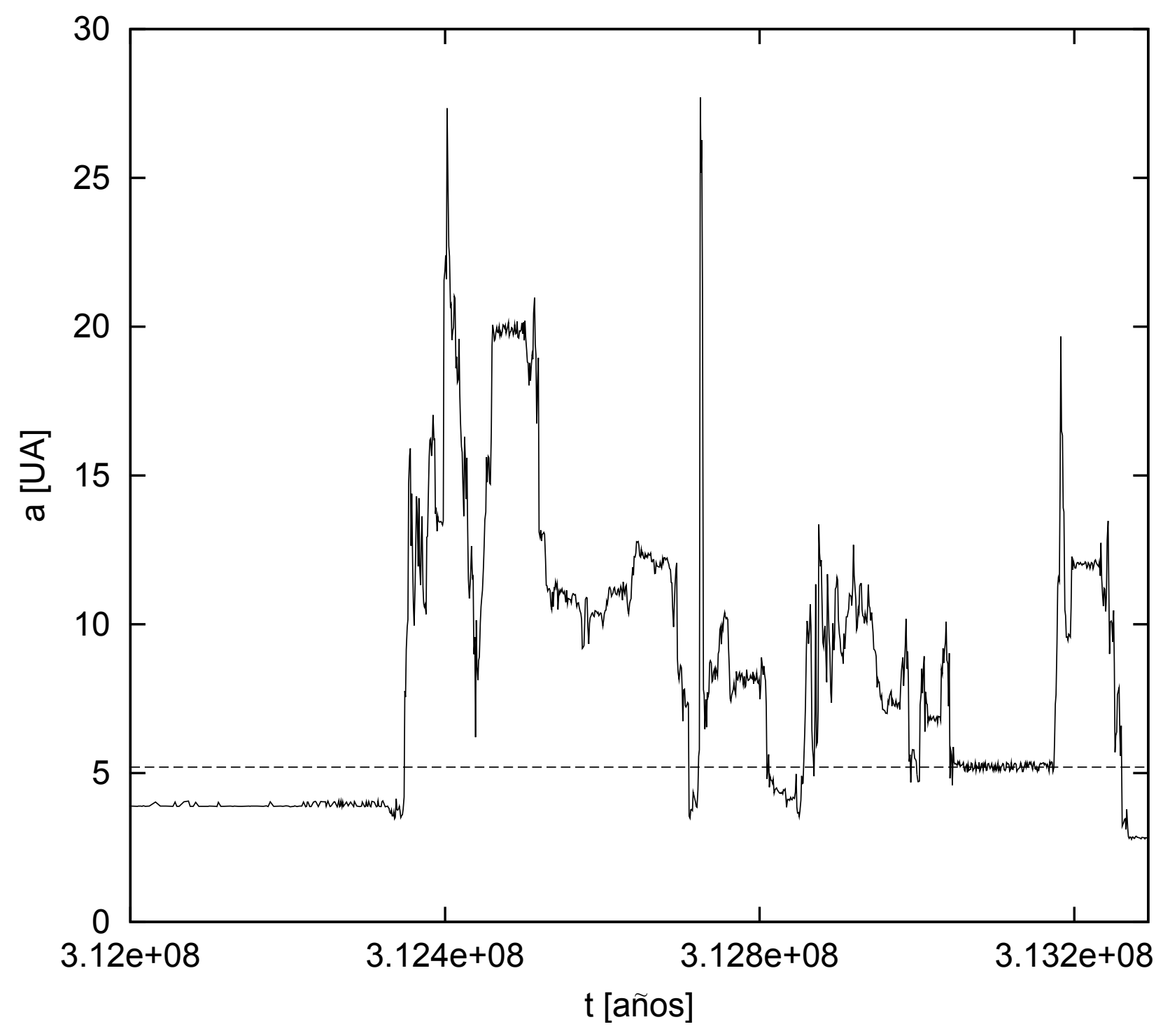

Figura 2.5: Evolución temporal post escape del semieje mayor de una partícula. 


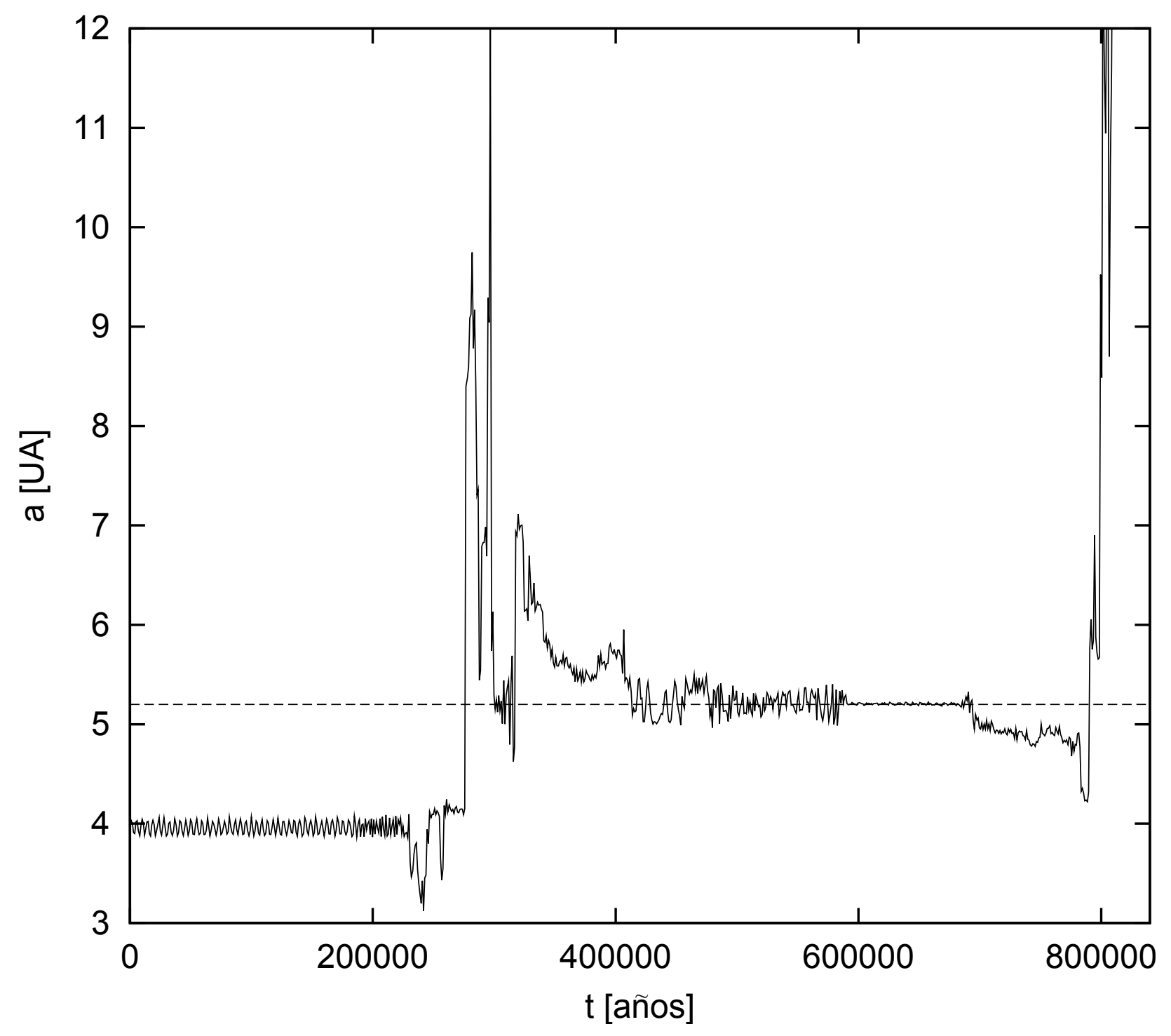

Figura 2.6: Evolución temporal post escape del semieje mayor de una partícula. 

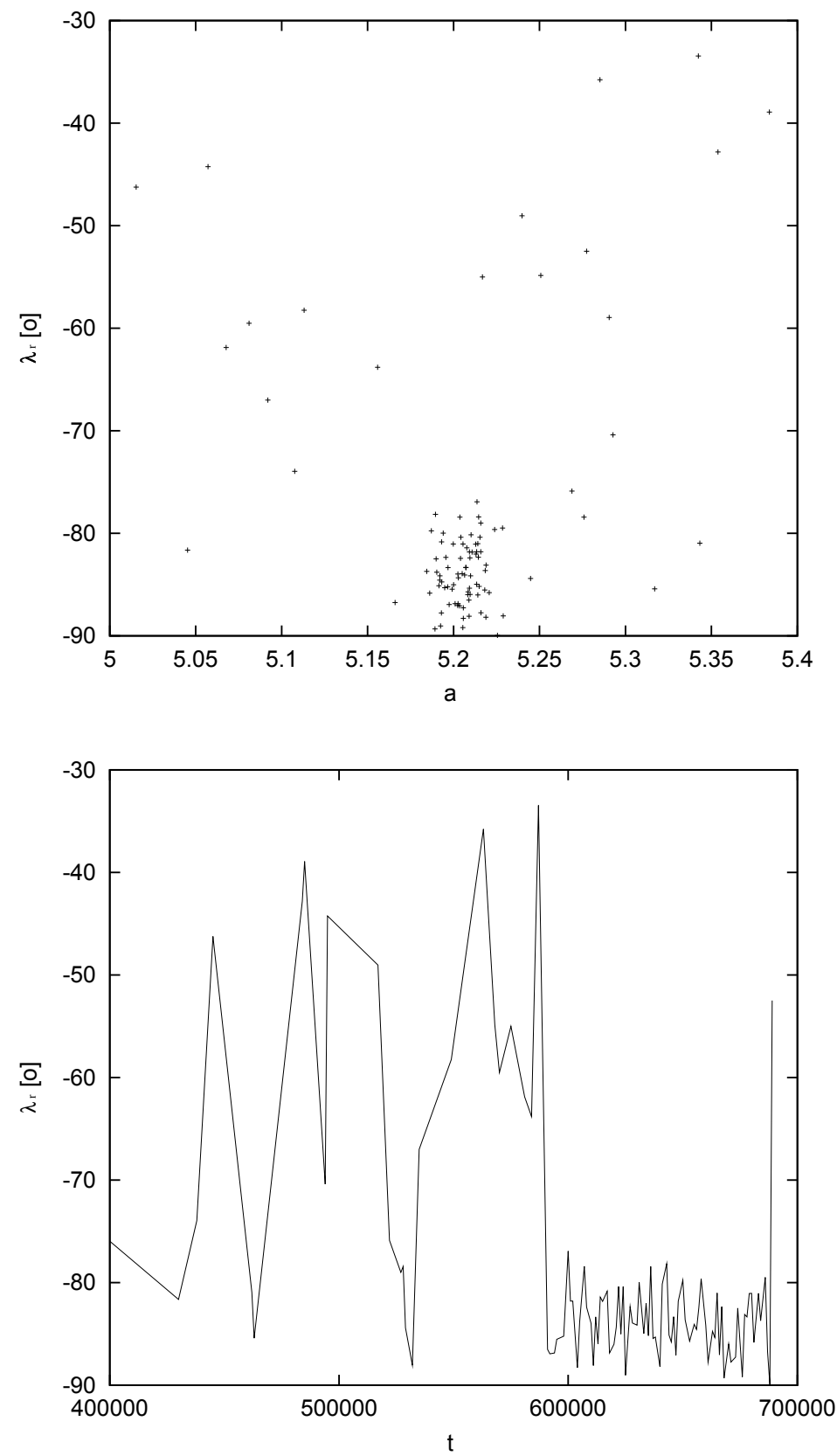

Figura 2.7: Evolución temporal y del semieje mayor de la longitud media relativa a la longitud media de Júpiter para la partícula de la figura 2.6 




Figura 2.8: Evolución temporal del semieje mayor de una partícula que se escapa de la resonancia 3:2 y permanece un tiempo como un objeto trans-neptuniano. En la parte superior izquierda se muestra una ampliación del gráfico correspondiente a los momentos de los encuentros con los planetas Saturno, Urano y Neptuno. 

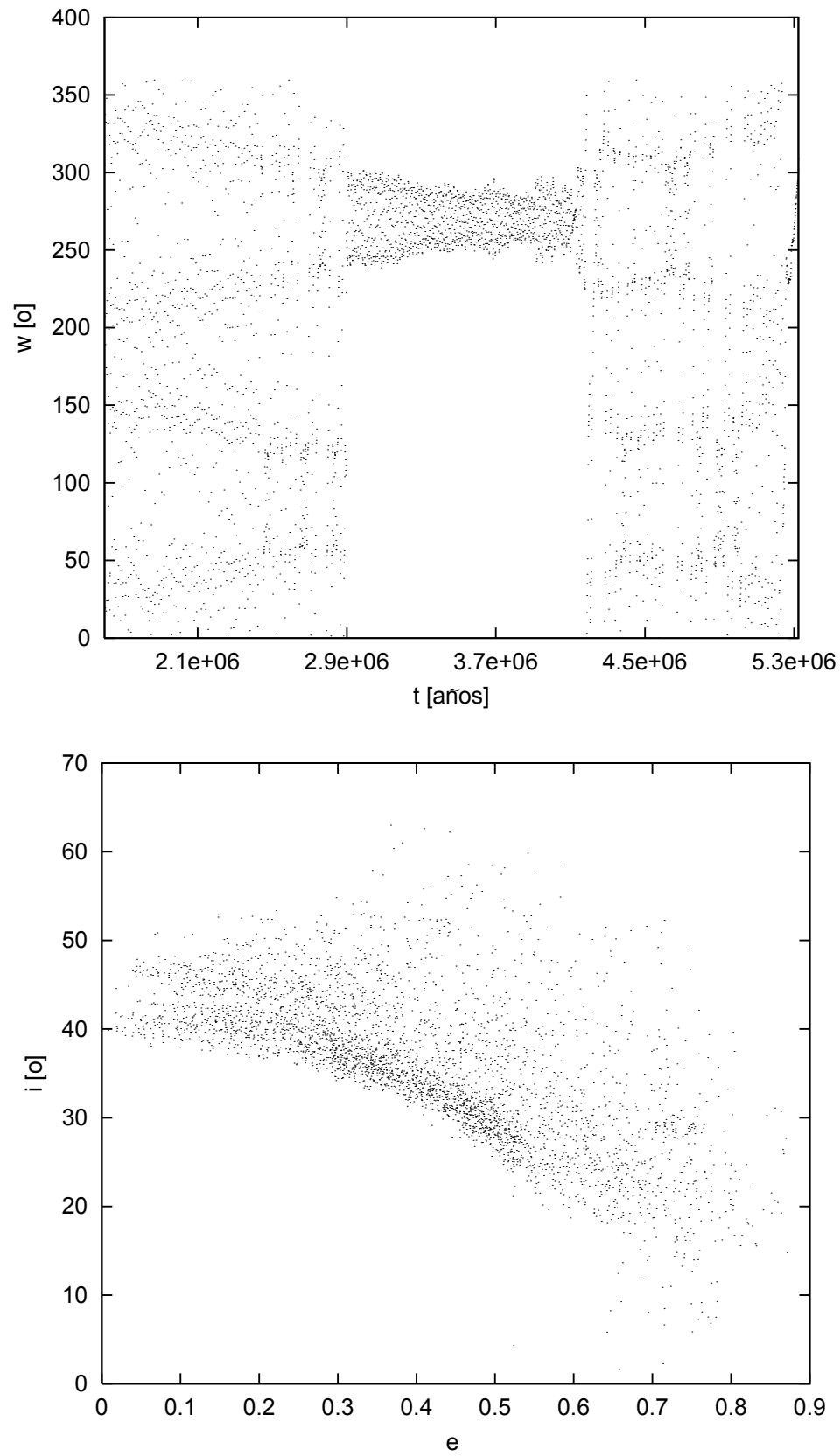

Figura 2.9: Evolución temporal del argumento del perihelio y excentricidad versus inclinación de una partícula en resonancia de Kozai 


\subsection{Evolución colisional: cálculo de la tasa de evapo- ración por colisiones}

Un asteroide Hilda, que se encuentra en la zona estable de la resonancia, puede alcanzar la zona externa inestable, siguiendo alguna ruta dinámica. En general, estas rutas de difusión son muy lentas, produciendo una tasa de evaporación de la resonancia también lenta. Sin embargo, los Hildas son una población sujeta a una fuerte evolución colisional, siendo las colisiones el mecanismo más eficiente para alcanzar las regiones inestables de la zona límite de la resonancia y escapar de ella. La evaporación dinámica es entonces mucho menor que la colisional. Por lo tanto, para calcular la tasa de evaporación del grupo Hilda, debe estudiarse un modelo de evolución colisional. Como nuestro interés se limita a calcular la tasa actual de evaporación, sólo llevamos a cabo un paso en el proceso de evolución colisional de la población siguiendo las prescripciones de Davis y otros (2002) y Gil Hutton y Brunini (2000), esto es, una " pseudo evolución colisional" en la que la población se considera en estado estacionario. En una evolución colisional real, la población evoluciona, por tanto, estamos considerando que esta evolución es realmente menor que las escalas de tiempo relevantes involucradas en nuestro problema.

Para estudiar la evolución colisional de la población de Hildas, nos concentraremos en colisiones catastróficas, las cuales se definen como la colisión donde la pieza resultante más grande contiene el $50 \%$ o menos de la masa inicial del blanco. El radio $r_{p}$ del menor proyectil capaz de fragmentar un blanco de radio $r_{a}$ es (Davis y otros 1989)

$$
r_{p}=r_{a} \times\left(\frac{4 S}{\rho_{a} v^{2}}\right)^{1 / 3}
$$

donde $\rho_{a}$ es la densidad del asteroide, $v=4,6 \mathrm{~km} \mathrm{~s}^{-1}$ es la velocidad de colisión (Gil Hutton y Brunini, 2000) entre Hildas, y $S$ es la energía por unidad de volumen necesaria para fragmentar un cuerpo. Para este último parámetro, usamos el algoritmo de escala de energía recomendado por Davis y otros (1994) 


$$
S=S_{0}+\frac{4 \pi k G \rho_{a}^{2} r_{a}^{2}}{15}
$$

donde $S_{0}=3 \times 10^{7} \mathrm{erg} \mathrm{cm}^{-3}, G$ es la constante gravitacional y $k$ es un parámetro adimensional, que adoptamos igual a uno, siguiendo a Davis y otros (2002). Reemplazando la ecuación (2.4) en la $(2.3)\left(\left[r_{a}\right]=k m\right)$, podemos obtener el radio del proyectil.

La probabilidad de una colisión catastrófica por unidad de tiempo, de un asteroide de radio $r_{a}$ es

$$
P\left(r_{a}\right)=P_{i} \int_{r_{p}}^{r_{\max }}\left(r_{a}+r\right)^{2} n(r) d r
$$

donde $r_{\max }$ es el mayor objeto de la población, $P_{i}$ es la probabilidad de colisión intrínseca y $n(r)$ es la distribución diferencial de tamaños de la población (ecuación (1.11)). Para los Hildas adoptamos $P_{i}=0,65 \times 10^{-18} \mathrm{~km}^{-2}$ año ${ }^{-1}$ (Gil Hutton y Brunini 2000). Integrando numéricamente la ecuación anterior obtenemos la probabilidad de una colisión catastrófica.

Entonces, el número de asteroides de radio $r_{a}$, que recibe una colisión catastrófica por unidad de tiempo está dado por:

$$
N_{c o l}\left(r_{a}\right)=n\left(r_{a}\right) \times P\left(r_{a}\right),
$$

donde $n\left(r_{a}\right)$ es el número de objetos con radio $r_{a}$ dado por la ecuación (1.11).

El resultado de una colisión catastrófica es un número de fragmentos con una distribución de masas $m$ dada por (Greenberg y otros 1978, Zapalá y otros 1984, y otros 1989):

$$
N(>m)=F m^{-f}
$$

donde $N(>m)$ es el número de fragmentos que tienen masas mayores que $m$ y $F$ es una constante a determinar. El exponente y la constante $F$ se calcula de la siguiente manera teniendo en cuenta la masa del fragmento más grande y la condición de conservación de la masa. En una colisión catastrófica a un blanco de radio $r_{a}$, la masa del fragmento más grande es a lo sumo $m_{a} / 2$. Por lo tanto $N\left(>m_{a} / 2\right)=1$, entonces:

$$
1=F\left(m_{a} / 2\right)^{-f}
$$


Ahora, de la ecuación (2.7), el número de fragmentos de masa $m$ producidos en una colisión catastrófica será:

$$
n(m)=f F m^{-f-1} .
$$

Por lo tanto la masa del blanco $m_{a}$ será igual a la masa de todos los fragmentos, es decir:

$$
m_{a}=\int_{0}^{m_{a} / 2} n(m) m d m .
$$

Reemplazando (2.9) en (2.10) e integrando, obtenemos:

$$
\frac{f F}{1-f}\left(m_{a} / 2\right)^{1-f}=m_{a}
$$

y combinando esta ecuación con la ecuación (2.8), obtenemos:

$$
f=2 / 3
$$

y

$$
F=\left(m_{a} / 2\right)^{2 / 3}
$$

Entonces, la función distribución de masas queda:

$$
N(>m)=\left(m_{a} / 2\right)^{2 / 3} m^{-2 / 3}
$$

o en términos del radio $r$ :

$$
N(>r)=2^{-2 / 3}\left(r_{a} / r\right)^{2}
$$

Por tanto, el número total de fragmentos de radios mayores que $r$ producidos en la zona de los Hildas está dado por:

$$
N_{f}=\int_{0}^{r_{\max }} N_{c o l}\left(r_{a}\right) N(>r) d r_{a}
$$

Una vez que se produce una colisión catastrófica, los fragmentos pueden escapar de la atracción gravitatoria del cuerpo mayor y eventualmente, si la velocidad es suficiente, 
escapar de la resonancia. La distribución acumulativa de velocidad la modelamos con la formulación usual, (Gault y otros 1963)

$$
\begin{array}{ll}
f(>V)=\left(V / V_{0}\right)^{-k} & \left(\text { si } V>V_{0}\right) \\
f(>V)=1 & \left(\text { si } V<V_{0}\right)
\end{array}
$$

donde $f(>V)$ es la fracción de objetos que se mueven más rápido $V, V_{0}$ es la velocidad mínima de eyección de los fragmentos y k es un exponente característico aproximadamente igual a $9 / 4$.

Además, cada fragmento de masa $m$ es eyectado con una velocidad:

$$
V(m)=W\left(m / m_{a}\right)^{-r}
$$

donde $W$ es una constante (con dimensión de velocidad) y el exponente $r$ es:

$$
r=(1-b / k)
$$

donde $b$ es el exponente de la distribución de masas de los fragmentos (ecuación 2.14); para nuestro caso que consideramos colisiones catastróficas, $b=2 / 3$ como demostramos anteriormente.

Después de la colisión los fragmentos reciben como energía cinética una fracción $f_{k e}$ de la energía de la colisión .Usualmente se toma $f_{k e}$ entre $1 \%$ y $10 \%$. Nosotros adoptamos el valor conservador de $2 \%$, aunque realizamos experimentos explorando todos los rangos posibles obteniendo resultados similares. Entonces,

$$
\sum \frac{1}{2} m_{i} v_{i}^{2}=\frac{1}{2} \sum m_{i} W^{2}\left(m_{i} / M\right)^{-2 r}=f_{k e} E,
$$

de donde se obtiene:

$$
W^{2}=2 f_{k e} E / \sum\left[m_{i}\left(m_{i} / M\right)^{-2 r}\right]
$$

Como se conoce la distribución de masas, podemos obtener $W$. Así es posible calcular $V_{0}$ que corresponde a la velocidad del fragmento mayor eyectado:

$$
V_{0}=W(1 / 2)^{-r}
$$


Para calcular el número de fragmentos que escapan de la resonancia, adoptamos las mismas prescripciones que Gil Hutton y Brunini (2000). Si el fragmento adquiere un pequeño impulso, su velocidad orbital cambia una pequeña cantidad $\Delta V$. En esta situación podemos escribir, por medio de las ecuaciones de Gauss

$$
\Delta a=\frac{2}{n} \Delta V_{T}
$$

donde $\Delta V_{T}$ es la componente de $\Delta V$ en la dirección del movimiento, a es el semieje mayor, $n$ es el movimiento orbital medio. De Ferraz Mello y otros (1998b) se obtiene $\Delta a \sim 0,05 \mathrm{UA}$ como el ancho medio de la región estable, así, un fragmento originalmente ubicado en el centro de la resonancia, puede alcanzar el límite inestable si su velocidad se incrementa en una cantidad $\Delta V_{T}>0,094 \mathrm{~km} / \mathrm{s}$. Si se supone que las velocidades relativas de las colisiones entre proyectiles y el blanco son igualmente particionadas entre las tres componentes, la velocidad de eyección necesaria para escapar de la resonancia es $\Delta V>0,163 \mathrm{~km} / \mathrm{s}$. Esta debe compararse con la velocidad de eyección obtenida por el mismo procedimiento para los asteroides Troyanos, que es de 0,65 km/s, o sea, cuatro veces mayor que para los Hildas, revelando que la población de Troyanos es más estable con respecto a las colisiones. La fracción de objetos que escapan, será entonces:

$$
f\left(>V_{e s}\right)=\left(\frac{0,163}{V_{0}}\right)^{-9 / 4}
$$

donde $V_{e s}=0,163 \mathrm{~km} / \mathrm{s}$.

Entonces, la tasa de escape de objetos con radio mayor que $r$ será: $N e(>r)=f(>$ $\left.V_{e s}\right) \times N_{f}$. Por ejemplo, objetos mayores de $0,5 \mathrm{~km}$ de radio escapan cada 9000 años, y objetos mayores que $1 \mathrm{~km}$ de radio lo hacen cada 50000 años.

También deberían considerarse colisiones no catastróficas, aunque el intercambio de impulso durante esta clase de eventos es menos efectivo para producir eyección de la resonancia. Además es notable que en este caso sólo un objeto (si es que alguno), puede escapar de la resonancia en cada colisión, entonces la contribución de este régimen a la tasa total de escape de los Hildas no es importante. 


\section{Capítulo 3}

\section{Contribución de los Hildas a la}

\section{producción de cráteres en los satélites}

\section{galileanos}

Los cráteres de impacto han sido un proceso natural y usual en el Sistema Solar. Durante la acreción planetaria, la colisión de cuerpos fue un mecanismo frecuente y fundamental. Aunque la tasa de impactos ha ido decreciendo a medida que el Sistema Solar se fue estabilizando, tenemos gran cantidad de evidencia de intensos procesos de impactos en el pasado, a través de todos los cuerpos del Sistema Solar. Los procesos de impactos en el Sistema Solar interior ha sido vastamente estudiado, principalmente, mediante los registros de los cráteres lunares, y existe la idea que la historia de cráteres en el Sistema Solar interior y exterior son muy similares.

Para estudiar la historia de cráteres de los cuerpos del Sistema Solar exterior, tenemos un escenario natural y apropiado: los cuatro satélites Galileanos: Io, Europa, Ganymede y Callisto. Io no tiene cráteres de impacto conocidos. Europa, es un cuerpo congelado cruzado por una red de fracturas oscuras. La existencia de pocos cráteres de impacto sugiere que los procesos geológicos están actualmente activos, y que tiene una superficie joven. El satélite galileano más grande, la luna congelada Ganymede, tiene un terreno oscuro, repleto de cráteres con surcos brillantes más recientes. También presen- 
ta evidencia de actividad geológica, pero su superficie es muy vieja. Su superficie está completamente saturada por cráteres. Una característica que es propia de Callisto es la estructura remanente de numerosos cráteres de impacto. Las imágenes recientes obtenidas por la misión Galileo plantean cuestiones cruciales acerca de la naturaleza de las poblaciones impactoras en el sistema Joviano.

Zahnle y otros (1998) estudian la producción de cráteres sobre los satélites galileanos por algunas poblaciones. Discuten en detalle la producción de los Cometas de la Familia de Júpiter (JFC), usando el estudio numérico hecho por Levison y Duncan (1997). También consideran otras fuentes como los Cometas de Largo Período, los asteroides Troyanos y los asteroides del cinturón principal. Además analizan la producción de cráteres de 10 y $20 \mathrm{~km}$ y estiman edades para las superficies de Europa y Ganymedes.

Levison y Duncan (1997) evolucionan 2200 partículas sin masa por $10^{9}$ años, bajo la acción gravitatoria del Sol y los cuatro planetas gigantes, desde su origen en el Cinturón de Edgeworth - Kuiper. Como subproducto, calculan las tasas de impacto de los cometas eclípticos sobre los planetas. En particular, encuentran para impactos sobre Júpiter una colisión cada 400 años; este número fue encontrado directamente contando los impactos durante la simulación. Zahnle y otros (1998) usan estos datos para caracterizar las órbitas de los JFC que tienen encuentros con Júpiter, y usando un modelo Monte Carlo, y a partir de esta distribución orbital, simulan la interacción de cometas con Júpiter y sus satélites, determinando las velocidades de impacto y las probabilidades relativas de impacto respecto de Júpiter. Obtienen que al menos un $90 \%$ de los cráteres sobre los satélites galileanos se deben a impactos por JFCs. Posteriormente, Levison y otros (2000) reevaluaron las tasas de impacto de los cometas eclípticos sobre los planetas. Encontraron que las tasas de impacto sobre los planetas gigantes son en realidad alrededor de cuatro veces menores que en Levison y Duncan (1997). Para Júpiter calcularon un valor de $6,3 \times 10^{-4}$ colisiones por año o una colisión cada 1600 años. Entonces, las estimaciones hechas por Zahnle y otros (1998) para los satélites galileanos deben ser corregidas por ese factor. Una incerteza para aquellas estimaciones es la importancia relativa de cometas inactivos. En este sentido, debe hacerse otra corrección a las tasas de impactos tomando en cuenta una nueva estimación del número de JFCs con $q<2,5$ UA dada por Bottke y otros 
(2002). Ellos obtienen, basándose en escalear el número de cometas inactivos, en vez de cometas activos, un número de cometas del tamaño de kilómetros en la región de los JFCs, un factor tres veces menor que las estimaciones hechas por Levison y otros (2000). Este factor afecta directamente las tasas de impactos sobre los satélites galileanos, reduciendo tres veces los impactos por JFCs obtenidos anteriormente. Por lo tanto, la corrección total a los primeros valores es de 12 veces menos.

Para los asteroides Troyanos, Zahnle y otros (1998) consideran el hecho de que luego de que escapan de la resonancia, siguen una evolución orbital similar a la de los JFC. Ellos afirman que el cociente entre Troyanos y todos los JFC es de 1/40, así, dependiendo de la distribución de masa de los Troyanos, estos contribuyen con un $1-10 \%$ de los cráteres de los satélites galileanos.

Con respecto a los asteroides del cinturón principal, Zahnle y otros (1998) usan el análisis de Gladman y otros (1997) que estudiaron la evolución orbital de asteroides escapados de resonancias inestables. Relacionando los impactos sobre los satélites galileanos con la tasa de impactos de los asteroides cercanos a la Tierra (NEA) sobre la Tierra, Zahnle y otros (1998) encuentran que la contribución de los asteroides del cinturón principal a la tasa de cráteres sobre el sistema galileano es despreciable con respecto a los JFCs. Probablemente, el motivo para este valor tan bajo, es el bien conocido hecho de que la región del cinturón principal interior a la resonancia 3:1 no envía asteroides hacia la región externa del Sistema Solar. Sin embargo, la contribución a los cráteres sobre los satélites galileanos por el cinturón externo de asteroides no fue analizada por Zahnle y otros (1998), por tanto nosotros focalizamos nuestra atención a esta zona.

Como ya mencionamos en el capítulo 1, el grupo de asteroides Hildas está localizado en el cinturón externo de asteroides en la resonancia 3:2 con Júpiter. Se caracteriza por una zona central dinámicamente estable rodeada por regiones inestables hasta alcanzar en el límite una zona muy caótica. Así, un asteroide de la población que entra en esta zona, es eyectado rápidamente de la resonancia.

En este capítulo, estudiamos la evolución dinámica de los Hildas que escapan a fin de calcular su contribución a la historia de cráteres de los satélites galileanos. 


\subsection{Cálculo de las velocidades y tasas de impacto sobre los satélites galileanos}

Una información extraida de nuestra simulación es la velocidad relativa de impacto entre las velocidades de los objetos que escapan de la región de los Hildas y los satélites galileanos. En vez de usar alguna aproximación, fue posible calcularla directamente de la simulación. Tenemos la posición y velocidad relativa a Júpiter de los encuentros cercanos a menos de 3 radios de Hill, a pasos de tiempo muy pequeños. Así, fue posible obtener la velocidad relativa de los objetos con respecto a Júpiter cuando estuvieran a una distancia del planeta comparable al semieje mayor orbital de los satélites galileanos. Definimos cáscaras centradas en el semieje mayor orbital de cada satélite galileano con un ancho medio de alrededor de un $5 \%$ de su radio. Como la geometría de los encuentros dentro de 3 radios de Hill de Júpiter es casi isotrópica, la velocidad media de todos los objetos que entran en estas cáscaras, son representativas de la velocidad relativa típica cuando los objetos intersectan la órbita de cada uno de los satélites galileanos. Los valores así obtenidos se muestran en la tabla 3.1. Variar el umbral del 5\% de 1 a $10 \%$ solo afecta la dispersión de los valores pero el valor medio en sí varía en menos de un $3 \%$.

La velocidad de impacto sobre los satélites galileanos se calculó suponiendo que la geometría de las colisiones es isotrópica. En esta situación, si la velocidad orbital del satélite es $v_{s}$, la velocidad de colisión más probable puede calcularse como

$$
v_{i m p}=\sqrt{v_{s}^{2}+v_{0}^{2}}
$$

donde $v_{0}$ es la velocidad media de los asteroides Hildas cuando intersectan la órbita del satélite galileano.

Los valores de las velocidades de colisión, que figuran en la Tabla 3.1, son muy similares a los calculados por Zahnle y otros (1998) para impactos de los JFC sobre los satélites galileanos, y difieren sólo en alrededor de un $10 \%$.

Ahora es posible obtener la probabilidad de impacto sobre cada satélite galileano, 


\begin{tabular}{|l|c|c|c|c|}
\hline & Io & Europa & Ganymede & Callisto \\
\hline$a_{s}$ & 5.9 & 9.4 & 15.0 & 26.4 \\
$r_{s}$ & 1820 & 1570 & 2630 & 2400 \\
$v_{s}$ & 17.3 & 13.7 & 10.9 & 8.2 \\
$v_{0}$ & $24,3 \pm 0,5$ & $19,6 \pm 0,4$ & $15,7 \pm 0,1$ & $12,0 \pm 0,1$ \\
$v_{\text {imp }}$ & 29.6 & 23.7 & 19.1 & 14.5 \\
$\dot{N}_{\text {sat }} / \dot{N}_{\text {Jupiter }}$ & $1,32 \times 10^{-4}$ & $6,32 \times 10^{-5}$ & $1,17 \times 10^{-4}$ & $5,93 \times 10^{-5}$ \\
$\mathrm{JFC}$ & $1,4 \times 10^{-4}$ & $6,2 \times 10^{-5}$ & $1,2 \times 10^{-4}$ & $6,1 \times 10^{-5}$ \\
\hline
\end{tabular}

Tabla 3.1: $a_{s}$ : semieje mayor del satélite [radio joviano]. $r_{s}$ : radio geométrico del satélite $[\mathrm{km}] . v_{s}$ : velocidad orbital del satélite $\left[\mathrm{km} \mathrm{s}^{-1}\right] . v_{0}$ : velocidad media de los asteroides Hildas cuando intersectan las órbitas de los satélites galileanos $\left[\mathrm{km} \mathrm{s}^{-1}\right] . v_{i m p}$ : velocidad media de impacto sobre cada satélite galileano. $\left[\mathrm{km} \mathrm{s}^{-1}\right] \cdot \dot{N}_{\text {sat }} / \dot{N}_{\text {Jupiter }}$ : tasa de impactos sobre cada satélite galileano / tasa de impactos sobre Júpiter. La última fila son las probabilidades de impacto sobre cada satélite galileano, relativas a la probabilidad de impacto sobre Júpiter de los JFC obtenidas por Zahnle y otros (1998).

relativa a la probabilidad de impacto sobre Júpiter. En principio, hay varias posibilidades para calcular estos valores, y nosotros hemos seguido el sencillo procedimiento derivado por Harris y Kaula (1975). La tasa de impacto relativa está dada por

$$
\frac{\dot{N}_{\text {sat }}}{\dot{N}_{\text {planet }}}=\left(\frac{r_{s}}{r_{p}}\right)^{2}\left(\frac{1+\frac{7 \theta r_{p}}{3 a_{s}}}{1+2 \theta}\right)
$$

donde $r_{s}$ y $r_{p}$ son los radios del satélite y planeta respectivamente, $a_{s}$ es el semieje mayor del satélite y $\theta$ es un parámetro adimensional, introducido por primera vez por Safronov (1972), cuya expresión es:

$$
\theta=\frac{G m_{p}}{r_{p} v_{\infty}^{2}}
$$

donde $m_{p}$ es la masa planetaria, $\mathrm{G}$ es la constante de Gravitación, y $v_{\infty}$ es la velocidad relativa de los objetos cuando entran en la esfera de Hill del planeta. Al igual que para $v_{0}$, 
fue posible calcular esta velocidad relativa, a partir de nuestra simulación. Del archivo de encuentros extrajimos los encuentros con Júpiter y calculamos la velocidad más probable. Obtuvimos $v_{\infty}=5,45 \mathrm{~km} / \mathrm{s}$, que es muy similar al valor para los JFC obtenido por Zahnle y otros (1998), de $v_{\infty} \sim 5 \mathrm{~km} / \mathrm{s}$. Así, como el único parámetro de la ecuación (3.2) para estas dos poblaciones es la velocidad relativa, deberíamos esperar resultados muy similares para las tasas de impacto relativas a Júpiter para los Hildas y para los JFCs.

Los valores de $\dot{N}_{\text {sat }} / \dot{N}_{\text {Jupiter }}$ se muestran en la Tabla 3.1. En la última fila, también se muestran las probabilidades de impacto de los JFC sobre cada satélite galileano, relativas a la probabilidad de impacto sobre Júpiter obtenidas por Zahnle y otros (1998) con un método más sofisticado, el formalismo de Öpik. Se puede observar que las diferencias relativas entre nuestros valores y los de Zahnle y otros (1998) son de menos de un $6 \%$.

\subsection{Tasa de producción de cráteres}

Con toda esta información podemos calcular ahora el diámetro de un cráter simple producido por objetos de la región de los Hildas. Hemos usado las mismas expresiones generales recomendadas por Schmidt y Housen (1987) para blancos de roca o hielo. Ellos proponen usar la relación de escala:

$$
D_{s}=1,4\left(\frac{m_{a}}{2 \rho_{s}}\right)^{0,26}\left(\frac{\rho_{a}}{\rho_{s}}\right)^{0,073} g_{s}^{-0,22} v_{i m p}^{0,44} \mathrm{~cm}
$$

donde $m_{a}$ y $\rho_{a}$ son la masa y densidad del impactor, que hemos supuesto de $2,5 \mathrm{gr} / \mathrm{cm}^{3}$, $\rho_{s}$ es la densidad del blanco, y $g_{s}$ su gravedad superficial. Esta expresión se evalúa en unidades cgs. Hay que notar que la incerteza en el tamaño del cráter para un impactor dado es alrededor de un $30 \%$. Hemos incluido una correción adicional para cráteres complejos, ya que los cráteres más grandes son considerablemente más superficiales y extendidos que los cráteres simples descriptos por la ecuación (3.4). Para cráteres de diámetros $D_{s}>D_{c}$ predichos por la ecuación (3.4), el diámetro final del cráter es según Mc Kinnon y otros (1991).

$$
D=D_{s}^{1,13} D_{c}^{-0,13}
$$




\begin{tabular}{|l|c|c|c|}
\hline satlite & $m_{a}$ & $D_{a}$ & $N\left(>D_{a}\right)$ \\
\hline Io & $1.86 \mathrm{E}+14$ & 0.522 & $4 \times 10^{5}$ \\
Europa & $3.68 \mathrm{E}+13$ & 0.304 & $13 \times 10^{5}$ \\
Ganymede & $5.72 \mathrm{E}+13$ & 0.352 & $10 \times 10^{5}$ \\
Callisto & $8.10 \mathrm{E}+13$ & 0.396 & $8 \times 10^{5}$ \\
\hline
\end{tabular}

Tabla 3.2: Población de los Hildas capaces de producir cráteres de $D>10 \mathrm{~km}$ calculada a partir de la función acumulativa de tamaños (ecuación (1.10)) $m_{a}$ es la masa mínima [gr] de un asteroide Hilda capaz de producir un cráter de $10 \mathrm{~km}$ sobre cada satélite galileano. $D_{a}$ es el diámetro correspondiente del asteroide $[\mathrm{km}]$, suponiendo una densidad de 2,5 $\mathrm{gr} / \mathrm{cm}^{3} . N\left(>D_{a}\right)$ es el número de Hildas más grandes que ese diámetro.

donde $D_{c}$ es la transición entre cráteres simples y complejos. Siguiendo a Chapman y Mc Kinnon (1986), quienes recomiendan un valor de $D_{c}=4 \mathrm{~km}$ para cráteres sobre Ganymede, nosotros adoptamos este valor. El coeficiente numérico 1,4 en la ecuación (3.4) fue calculado considerando el ángulo de incidendia más probable de $45^{\circ}$.

Para cráteres de $10 \mathrm{~km}$, a partir de la ecuación (3.4), podemos obtener la masa de los objetos impactores y por tanto sus diámetros. Por tanto, objetos mayores de un dado diámetro producirán cráteres mayores de $10 \mathrm{~km}$. La Tabla 3.2 muestra el tamaño mínimo $\left(D_{a}\right)$ y la población de los Hildas capaces de producir cráteres de $D>10 \mathrm{~km}$ sobre cada uno de los satélites galileanos.

Ahora, es posible calcular la tasa de producción de fragmentos que escapan de la zona de los Hildas y que son capaces de producir cráteres más grandes que un dado diámetro sobre cada uno de los satélites galileanos. Suponemos que después de escapar de la resonancia por evolución colisional, los asteroides tendrán una evolución dinámica similar a la predicha por nuestra simulación (capítulo 2). Así, el $8 \%$ de los fragmentos que escapan impactará a Júpiter, y de éstos sólo una pequeña fracción que está dada en la tabla 3.1, impactarán un dado satélite. En el capítulo 2 calculamos la tasa de escape de los Hildas por evolución colisional $\left(N_{e}(>r)\right)$, entonces la tasa de impacto de los asteroides Hildas mayores que un cierto radio r estará dada por: 


$$
N i(>r)=0,08 \frac{\dot{N}_{\text {sat }}}{\dot{N}_{\text {Jupiter }}} N e(>r)
$$

La tasa de producción de cráteres mayores de $10 \mathrm{~km}$ estará dada por $N i(>r)$ donde $r=D_{a} / 2$ dado en la tabla 3.2. Ahora, dado que la función de distribución de diámetros obtenida para los Hildas es el factor de mayor incerteza en nuestros cálculos, mostramos los resultados en cuanto a la producción de cráteres en términos del blanco de menor tamaño, $r_{\min }$, al cual se puede extrapolar la función de distribución. De este parámetro depende la producción de fragmentos $N_{f}$ en la zona de los Hildas (y por tanto la tasa de escape) es decir:

$$
N_{f}=\int_{r_{\min }}^{r_{\max }} N_{c o l}\left(r_{a}\right) N(>r) d r_{a}
$$

Los resultados de estos cálculos se muestran en la tabla 3.3 en términos entonces de $r_{\min }$.

Hay que notar que nosotros estamos considerando que la población de Hildas sigue la misma función de distribución acumulativa de tamaños hasta diámetros muy pequeños. No sólo para los diámetros de los blancos pequeños sino, los de los proyectiles más pequeños capaces de destruirlos. Por ejemplo, el diámetro del menor proyectil capaz de destruir un asteroide de $D=400 \mathrm{~m}$ es de alrededor de $D=20 \mathrm{~m}$.

Sin embargo, la función de distribución acumulativa observacional real de tamaños de los Hildas muestra un quiebre de la pendiente en $D=12 \mathrm{~km}$ (ver figura 1.5). Este hecho se explica tradicionalmente como una incompletitud observacional. El estrecho ancho en semieje mayor de la resonancia, y la baja velocidad de escape de ésta, hacen que los fragmentos producidos por colisiones cercanas al límite de la resonancia puedan escapar fácilmente. Esto podría producir una reducción de la distribución de tamaños de los Hildas para diámetros pequeños y una pérdida permanente de proyectiles (Gil-Hutton y Brunini, 


\begin{tabular}{|c|c|c|c|c|}
\hline$r_{\min }(\mathrm{km})$ & $\dot{C}_{I}^{-1}$ & $\dot{C}_{E}^{-1}$ & $\dot{C}_{G}^{-1}$ & $\dot{C}_{C}^{-1}$ \\
\hline 0.4 & $2,1 \times 10^{7}$ & $1,5 \times 10^{7}$ & $1,1 \times 10^{7}$ & $2,6 \times 10^{7}$ \\
0.6 & $6,9 \times 10^{7}$ & $4,9 \times 10^{7}$ & $3,6 \times 10^{7}$ & $8,9 \times 10^{7}$ \\
0.8 & $1,6 \times 10^{8}$ & $1,2 \times 10^{8}$ & $8,4 \times 10^{7}$ & $2,1 \times 10^{8}$ \\
1.0 & $3,2 \times 10^{8}$ & $2,3 \times 10^{8}$ & $1,6 \times 10^{8}$ & $4,1 \times 10^{8}$ \\
1.5 & $1,1 \times 10^{9}$ & $7,7 \times 10^{8}$ & $5,5 \times 10^{8}$ & $1,4 \times 10^{9}$ \\
$(\mathrm{JFC})$ & $2,6 \times 10^{7}$ & $1,5 \times 10^{7}$ & $1,0 \times 10^{7}$ & $2,6 \times 10^{7}$ \\
\hline
\end{tabular}

Tabla 3.3: $\dot{C}^{-1}$ : Intervalo medio entre impactos sobre los satélites galileanos en años, capaces de producir cráteres con $D>10 \mathrm{~km}, r_{\text {min }}$ es el radio del mínimo blanco considerado como miembro del grupo Hilda. La última fila son los intervalos medios entre cráteres de $d>10 \mathrm{~km}$ calculados por Zahnle y otros (1998) para los JFC y corregidos por el factor 12.

2000). Por otro lado, el proceso colisional produce objetos pequeños a partir de objetos grandes, lo cual podría balancear la reducción de objetos pequeños.

No obstante, una actividad colisional alta actual no parece ser compatible con una población colisionalmente relajada. Por tanto, siguiendo Davis y otros (2002), asumimos que el cambio en la pendiente observado en $D \sim 12 \mathrm{~km}$, se debe a una selección observacional.

Europa tiene sólo 27 cráteres conocidos con $D>4 \mathrm{~km}$ (Moore y otros 2001). Aunque Bierhaus y otros (2001) afirman que la gran mayoría de los cráteres pequeños son secundarios, probablemente todos los cráteres mayores que $2 \mathrm{~km}$ son primarios. Así, $D>4 \mathrm{~km}$ parece ser una elección segura para los cráteres primarios. En la tabla 3.4, damos la misma información que en la tabla 3.3 pero para cráteres con $D>4 \mathrm{~km}$. Es posible ver que consideraciones diferentes con respecto a la población del grupo Hilda de diámetros pequeños, pueda cambiar substancialmente la determinación de la edad de la superficie de Europa, aunque en cualquier caso es muy joven.

En las dos últimas filas en las tablas 3.3 y 3.4, los intervalos de tiempo son muy grandes como para despreciar la evolución de los Hildas debido a su evolución colisional, 


\begin{tabular}{|c|c|c|c|c|}
\hline$r_{\text {min }}(\mathrm{km})$ & $\dot{C}_{I}^{-1}$ & $\dot{C}_{E}^{-1}$ & $\dot{C}_{G}^{-1}$ & $\dot{C}_{C}^{-1}$ \\
\hline 0.2 & $2,5 \times 10^{5}$ & $2,3 \times 10^{5}$ & $1,6 \times 10^{5}$ & $4,1 \times 10^{5}$ \\
0.4 & $2,0 \times 10^{6}$ & $1,8 \times 10^{6}$ & $1,3 \times 10^{6}$ & $3,3 \times 10^{6}$ \\
0.6 & $6,7 \times 10^{6}$ & $6,2 \times 10^{6}$ & $4,4 \times 10^{6}$ & $1,1 \times 10^{7}$ \\
0.8 & $1,6 \times 10^{7}$ & $1,5 \times 10^{7}$ & $1,0 \times 10^{7}$ & $2,6 \times 10^{7}$ \\
1.0 & $3,1 \times 10^{7}$ & $2,9 \times 10^{7}$ & $2,0 \times 10^{7}$ & $5,1 \times 10^{7}$ \\
2.0 & $2,5 \times 10^{8}$ & $2,3 \times 10^{8}$ & $1,6 \times 10^{8}$ & $4,1 \times 10^{8}$ \\
3.0 & $8,3 \times 10^{8}$ & $7,7 \times 10^{8}$ & $5,5 \times 10^{8}$ & $1,4 \times 10^{9}$ \\
\hline
\end{tabular}

Tabla 3.4: $\dot{C}^{-1}$ : Intervalo medio entre impactos sobre los satélites galileanos capaces de producir cráteres con $D>4 \mathrm{~km}$.

de manera que sólo serían una estimación a un primer orden debido al modelo colisional utilizado.

\subsection{Comparación con Troyanos y Cometas de la Fa- milia de Júpiter}

Bajo la suposición de que los Hildas siguen la misma distribución de tamaños hasta radios pequeños, la producción de cráteres producida por los asteroides Hildas es comparable a la tasa de producción producida por los JFC (tabla 3.2).

La diferencia más importante entre las tasas de producción de cráteres de los Hildas y los JFC se dá con respecto a las escalas de tiempo involucradas en el proceso. Como se observa en la figura (3.1), cerca del $75 \%$ de los objetos que impactan sobre Júpiter lo hacen en menos de $5 \times 10^{4}$ años luego de que escapan de la resonancia. Esto representa un tiempo muy corto comparado con los $40 \times 10^{6}$ años que tarda un cometa típico en viajar desde el Cinturón de Kuiper hasta la región de los JFC (Levison y Duncan, 1997). Podríamos especular que luego de una colisión catastrófica, varios fragmentos escapan de la región de los Hildas y un número considerable de ellos (el $\sim 8 \%$ ) termina colisionando con Júpiter durante un intervalo de tiempo relativamente corto de $\sim 10^{4}$ años. Tal proceso 
podría quedar marcado en la superficie de los satélites Galileanos y por tanto aportaría importantes claves con respecto a la historia de los Hildas.

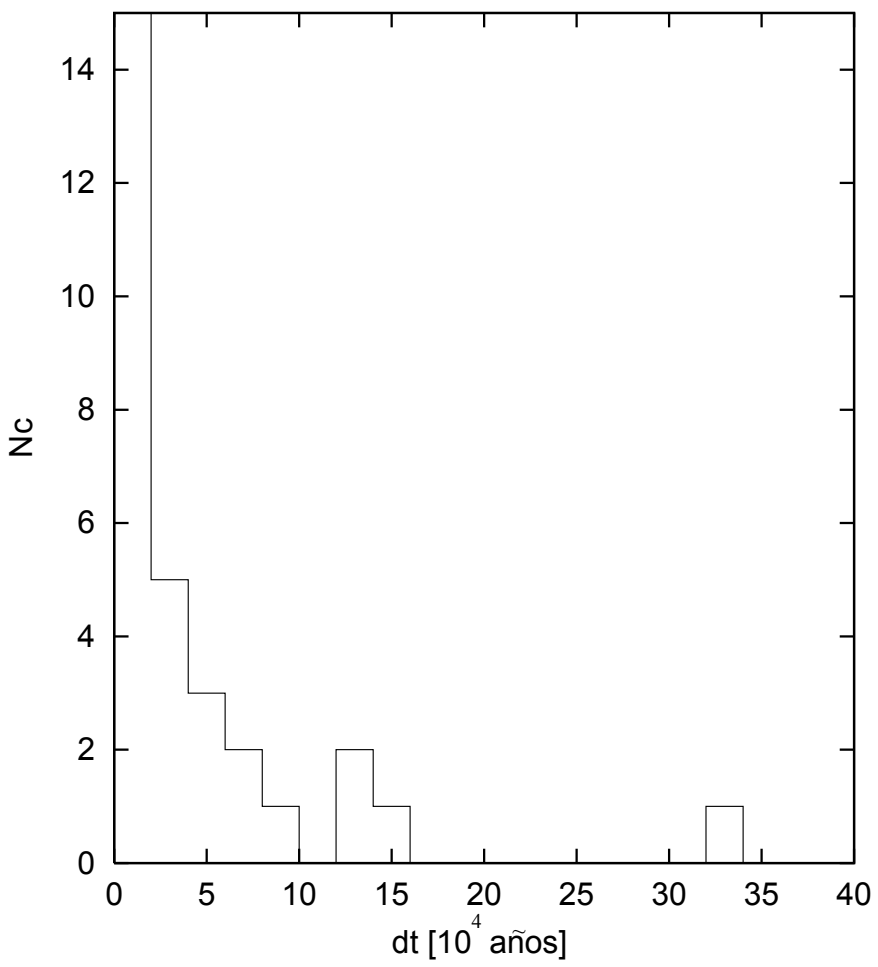

Figura 3.1: Distribución del intervalo de tiempo entre los escapes de la resonancia 3:2 y los impactos con Júpiter de las 31 partículas de la simulación que colisionan con Júpiter.

Como ya mencionamos, los asteroides Troyanos contribuyen con un $1-10 \%$ de la contribución de los JFC a los cráteres de los satélites galileanos (Zahnle y otros 1998). Dado que la producción de cráteres de los JFC es del mismo orden que la producción de los Hildas, la tasa de producción de cráteres de los Troyanos es bastante menor a la de los Hildas.

Es notable que dos poblaciones estables, los asteroides Troyanos y los Hildas, relativamente aislados del cinturón principal, que tendrían características comunes, tengan contribuciones tan diferentes a la tasa de cráteres de los satélites galileanos. La población de Troyanos (en L4 y L5) es probablemente 13 veces la población de los Hildas, sin embargo:

- La probabilidad de colisión intrínseca para los Hildas es 2 veces mayor que para los 
Troyanos (Gil-Hutton y Brunini, 2000), por tanto, aunque la región de los Hildas está 13 veces menos poblada que la de los Troyanos, las colisiones son sólo $13 / 2=6$ veces menos frecuentes que entre Troyanos.

- Debe agregarse otro factor $\sim 2$, ya que los Troyanos están separados en dos grupos (los puntos L4 y L5).

- El hecho de que la velocidad de escape de los Troyanos es cuatro veces la de los Hildas hace más difícil que un fragmento se escape de la resonancia (los Troyanos son más estables que los Hildas en relación a la evaporación por evolución colisional).

- Simulaciones numéricas de la evaporación de los Troyanos (Fernández y Mallada, 2002, comunicación personal) han dado como resultado que sólo el $2 \%$ de los Troyanos que escapan, impactan sobre Júpiter. Éste es un valor pequeño comparado con el $8 \%$ de los Hildas.

Todos estos factores juntos, hacen que la contribución de los Hildas a la tasa de cráteres sobre los satélites galileanos sea de 4 a 5 veces más importante que la debida a asteroides Troyanos. 


\section{Capítulo 4}

\section{Contribución de los Hildas a la}

\section{población de Cometas de la Familia de}

\section{Júpiter}

Los cometas y los asteroides representan partes distintas del espectro de planetesimales formados y procesados en la Nebulosa Solar Primitiva.

La distinción entre asteroides y cometas, está basada en sus cualidades observacionales y características orbitales más que en las diferencias en sus propiedades o composición química. Los cometas están caracterizados por su coma de gas sublimado y polvo que les da su característica apariencia en el cielo. Los asteroides, en cambio, tienen apariencia estelar. Actualmente, la designación de un nuevo objeto como cometa o asteroide, se remite a la presencia o ausencia de coma. Sin embargo los cometas muestran su característica cola cuando entran en el Sistema Solar interior y se calientan lo suficiente como para sublimar los hielos atrapados, esto sucede a una distancia de alrededor de 4 UA del Sol (Weissman y otros 2002). Los asteroides con semieje mayor más allá de las 4 AU, pueden estar compuestos de los mismos volátiles, polvo y moléculas orgánicas que los cometas, pero sus órbitas no son lo suficientemente excéntricas como para acercarse al Sol y por lo tanto no subliman sus hielos lo suficiente como para mostrar la actividad observada en los cometas. En este sentido, Hartmann y otros (1987), analizan la posibi- 
lidad de que los asteroides Troyanos y algunos Hildas puedan ser cometas dormidos. Por lo tanto, desde el punto de vista de la composición, es algo arbitrario, o al menos difícil, distinguir entre asteroides de la zona externa del cinturón y cometas.

Los modelos sobre la composición de ambos cuerpos están basados en observaciones indirectas a través del espectro de reflexión. Los objetos de la zona externa del cinturón de asteroides, con semieje mayor $a>3,3$ UA tienen un albedo bajo y clase taxonómica C, P, y D. Los asteroides de tipo P y D tienen una mezcla de materiales orgánicos, silicatos anhídridos, polvo y hielo (Bell y otros 1989; Gaffey y otros 1989; Vilas y otros 1994). Fitzsimmons y otros (1994), realizaron una campaña observacional tomando espectros de asteroides tipo D para investigar sus propiedades de reflectancia y su composición. Ellos encuentran que la mayoría de estos asteroides tienen la pendiente de reflexión o color y albedo dentro de los mismos rangos. Pero los núcleos cometarios, aunque tienen albedos muy similares a los de los asteroides D, muestran un amplio rango de colores. Esta diferencia podría deberse a la historia dinámica de los cometas y a los procesos que han afectado sus superficies, mientras que los asteroides, que están en órbitas más estables, conservan sus superficies primordiales. Así, concluyen que los asteroides tipo D pueden considerarse como análogos espectrales a los cometas. En este sentido, el hecho de distinguir entre cometas y asteroides de la zona externa del cinturón, podría limitarse a la cuestión de la evolución orbital, más que de composición química.

Los asteroides Hildas, están a 4 UA del Sol, las clases taxonómicas D y P dominan el grupo (Dahlgren y otros 1997). Es una población estable (Ferraz Mello y otros 1998b), pero, como los Troyanos, uno podría esperar que luego de escapar de la resonancia, evolucionen dinámicamente como JFC, contribuyendo en alguna medida a la población de JFC.

Los asteroides y los JFC son, de hecho, dos poblaciones dinámicamente diferentes. Pero, aunque los asteroides del cinturón externo, Hildas o Troyanos, están protegidos de los encuentros con Júpiter, una vez que escapan de la resonancia, están dominados gravitatoriamente por Júpiter semejando entonces el comportamiento dinámico de los JFC.

Actualmente hay evidencia substancial de que los JFC han evolucionado desde 
la región transneptuniana (Duncan y otros 1998, Levison y Duncan 1997, Bottke y otros 2002). Los JFC tienen órbitas muy inestables sujetas a fuertes perturbaciones de Júpiter. Las integraciones numéricas han sugerido que los asteroides Troyanos también han contribuido a la población de JFC con menos de un $10 \%$ (Marzari y otros 1995, Levison y otros 1997).

En este capítulo estudiamos la familia de los Hildas como una fuente probable más de los JFC. A partir de las simulaciones numéricas realizadas, seguimos la evolución dinámica de los Hildas escapados de la resonancia, con el objeto de determinar si pasan algún tiempo como cometas, en particular de la Familia de Júpiter. Determinamos cuántos de los cometas actuales serían Hildas escapados y estudiamos algunos casos especiales.

\subsection{La región de los JFC}

Los JFC están controlados gravitatoriamente por Júpiter, por lo tanto, tienen que pasar en algún momento a través de su esfera de Hill. Esta condición es satisfecha si los afelios $(Q)$ son mayores que 4,61 UA y los perihelios $(q)$ son menores que 5,82 UA. Graficando todos los cometas observados hasta hoy se ve que tienen en realidad perihelios menores a 5,42 UA. Por otro lado las condiciones $q<5,42$ UA y $Q>4,61$ UA son casi equivalentes a la clasificación de los JFC propuesta por Levison (1996) en la que el rango de la constante de Tisserand $2<T<3$. Hasta el presente hay 245 JFC descubiertos (tomados de la base de datos http://ssd.jpl.nasa.gov/), que cumplen con las condiciones de $q<5,42$ UA y $Q>4,61$ UA. El $95 \%$ de ellos, esto es 233 cometas, tienen semiejes mayores, $a$, en el rango $2 U A<a<9 U A$. Éstos tienen, además, excentricidades $e<0,9$. Por lo tanto definimos la región de los JFC como la zona limitada por:

$$
\begin{aligned}
& \text { - } q<5,42 \text { UA y } Q>4,61 \mathrm{UA}, \\
& \text { - } 2 \mathrm{UA}<a<9 \mathrm{UA}, \\
& \text { - } 0<e<0,9 \\
& \text { - } a>4,02 \mathrm{UA} \text { y } a<3,9 \mathrm{UA} .
\end{aligned}
$$


Este último ítem significa que las partículas están fuera de la resonancia 3:2 (Ferraz-Mello et al. 1998b), ya que como dijimos, ésta es ocupada por los Hildas, y lo que nos interesa es el destino de los objetos que escapan de allí.

Esta región junto con los JFC observados hasta la actualidad se muestran en la figura 1-1.

\subsection{Método y resultados}

A partir de las simulaciones numéricas, se extrajeron las partículas que escapan de la resonancia 3:2 y viven al menos 1000 años como JFC. De las 391 partículas que dejan la zona de la resonancia, 386 (esto es el 98.7\%) viven al menos 1000 años como JFC. El tiempo total que la zona de los JFC es ocupada por las 386 partículas es $5,403 \times 10^{8}$ años. La vida media de un Hilda escapado en esta zona es entonces $t m=1,4 \times 10^{6}$ años. Por tanto, el número de Hildas escapados que están en la región de los JFC se calcula mediante la siguiente ecuación:

$$
N_{H C}=N_{e}(>r) 0,987 t m
$$

donde $N_{e}(>r)$ es la tasa de escape de la población de los Hildas por evolución colisional. Esta cantidad, junto con el número de Hildas escapados en la zona de los JFC se muestran en la tabla 4.1 También se muestra el número de Troyanos esperado en la misma situación. De los Hildas escapados, 302, pasan en promedio $1,1 \times 10^{5}$ años con distancias perihélicas, $q$, menores que 2,5 UA donde los cometas son activos y fácilmente detectables. En la región $q>2,5 \mathrm{UA}, 383$ de los Hildas escapados que pasan por la zona de los JFC, pasan en promedio $1,33 \times 10^{6}$ años. De la misma manera, es posible estimar el número de Hildas escapados en esas zonas. Esto se muestra también en la tabla 4.1. Todos los números se dan para partículas de diámetro mayor que un valor dado $D_{0}$.

Por otro lado, es interesante conocer de que manera los Hildas escapados pueblan la zona de los JFC. Para esto, calculamos y mostramos en las figuras 4.1 y 4.2 , la probabilidad de distribución de los tiempos de residencia de los asteroides Hildas escapados 


\begin{tabular}{|l|c|c|c|c|c|}
\hline$D_{0}[\mathrm{~km}]$ & $N_{e}\left(D>D_{0}\right)\left[a o^{-1}\right]$ & $N_{H, q<2,5}$ & $N_{H, q>2,5}$ & $N_{H C}$ & $N_{T C}$ \\
\hline 0.5 & $5,7 \times 10^{-4}$ & 48 & 742 & 787 & 21 \\
1. & $1,1 \times 10^{-4}$ & 9 & 143 & 152 & 5 \\
1.5 & $4,0 \times 10^{-5}$ & 3 & 52 & 55 & 2 \\
2. & $2,0 \times 10^{-5}$ & 2 & 26 & 27 & 1 \\
\hline
\end{tabular}

Tabla 4.1: Tasa de escape de la región de los Hildas de asteroides más grandes que un dado diámetro $D_{0}$, y el número de Hildas estimado dentro de la zona de los JFC. A modo de comparación, la última columna muestra el número de Troyanos dentro de la misma zona.

en la región de los elementos orbitales que ocupan los JFC. Estos mapas se obtuvieron de la siguiente manera: subdividimos la zona de los JFC en celdas de $0.1 \mathrm{UA}$ en semieje mayor, 0.01 en eccentricidad y $1^{\circ}$ en inclinación. Luego, estimamos el tiempo $\delta t_{i}$ que cada partícula visita cada celda. Entonces, el tiempo total que cada celda es ocupada está dado por:

$$
\delta t=\sum_{i=1}^{386} \delta t_{i}
$$

Finalmente el tiempo de residencia en cada celda fue normalizado al tiempo total que todas las partículas están en la región de los JFC. Este valor es lo que se plasma en las figuras 4.1 y 4.2 según la escala de colores allí explicada. También se muestran en esta figura los JFC observados (círculos rojos). Las partículas pasan un tiempo considerable justo en los límites de la resonancia, van incrementando sus excentricidades, y sus semiejes mayores, hasta que dejan la región de los JFC. En esta ruta pasan más tiempo en la zona de excentricidades medias, hasta que adquieren valores relativamente grandes cruzando rápidamente la zona hacia la eyección hiperbólica. Puede observarse que la mayoría de los cometas se encuentran en la zona donde los tiempos de residencia de los Hildas escapados son mayores, localizados cerca de la resonancia. 


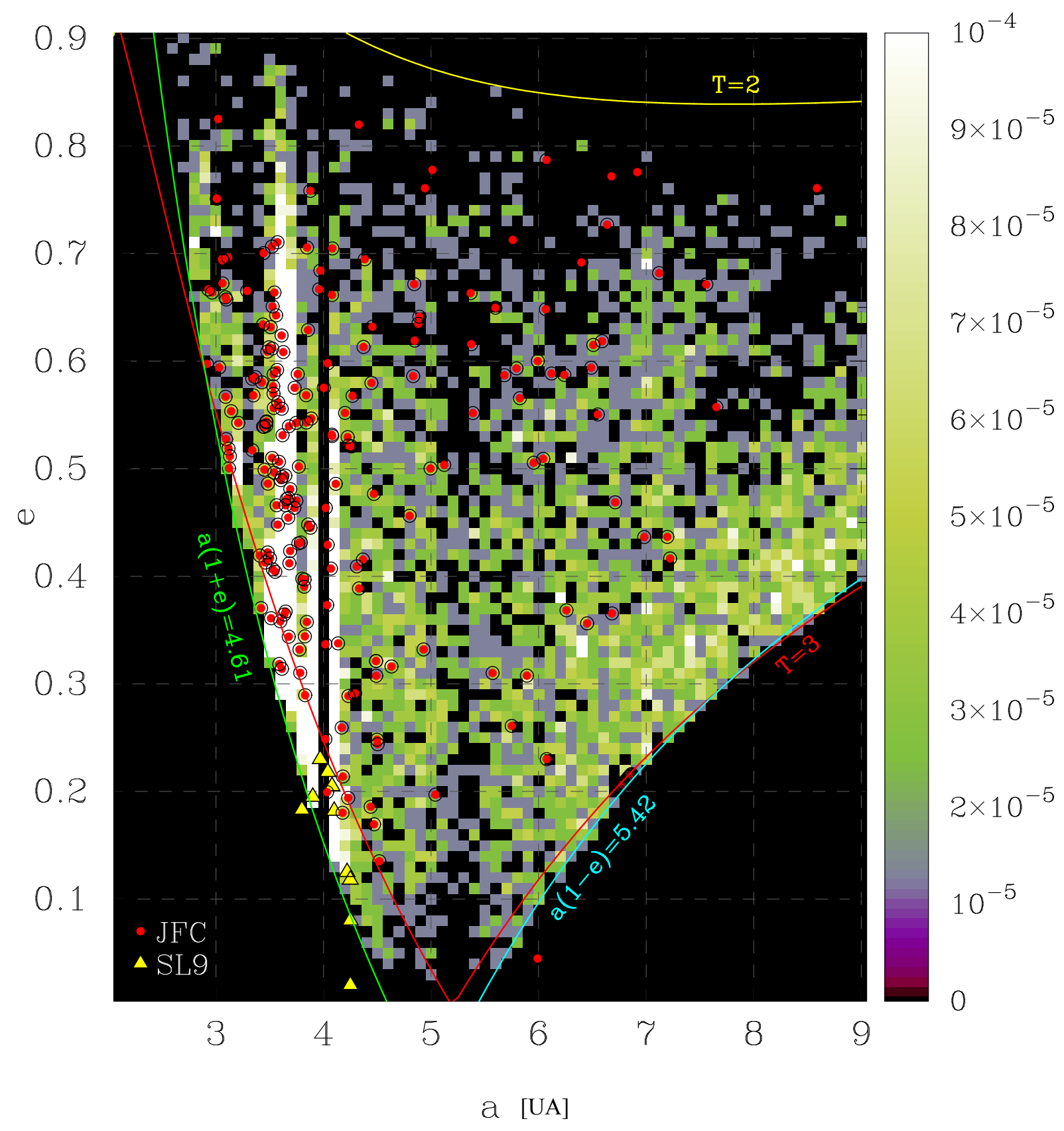

Figura 4.1: Distribución de probabilidades de tiempos de residencia de asteroides Hildas escapados en la región de elementos orbitales también ocupados por los Cometas de la Familia de Júpiter. Los círculos rojos son los JFC conocidos. Los triángulos amarillos son elementos orbitales pre-captura probables de los fragmentos del SL9 (Benner y Mc. Kinnon, 1995). 


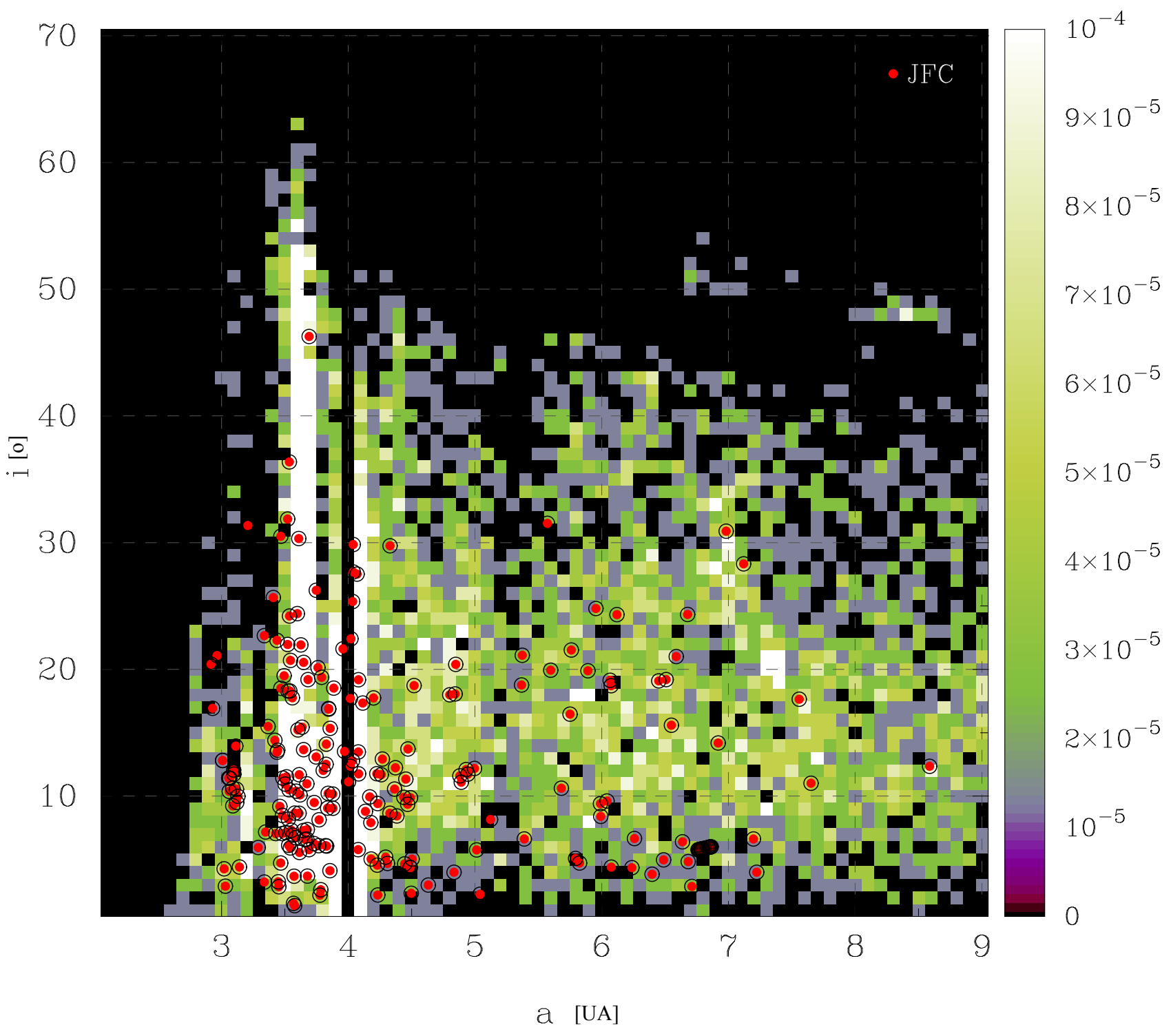

Figura 4.2: Distribución de probabilidades de tiempos de residencia de asteroides Hildas escapados en la región de elementos orbitales también ocupados por los Cometas de la Familia de Júpiter. Los círculos rojos son los JFC conocidos. 


\subsection{El número de JFC y la contribución de los Hildas}

Fernández y otros (1999) estimaron el número de JFC activos para diferentes valores de $q$. Obtienen una población de 800 JFC activos con $q<2,5$ UA y magnitud absoluta total $H_{N}<18,5$ o equivalentemente objetos de tamaño kilométricos $(D>\sim 1,4$ km). Levison y Duncan (1997) sugieren que el cociente entre el número de cometas extintos y el número de cometas activos es 3,5, entonces el número total de JFC (activos y extintos) será:

$$
N_{J F C}=N_{a}(1+3,5)
$$

donde $N_{a}$ es el número de cometas activos.

Por lo tanto, el número de JFC con $q<2,5$ UA y más brillantes que $H_{N}<18,5$ será 3600, de los que 2800 serán extintos. Los JFC vienen de la región transneptuniana y son inyectados hacia la región interna del Sistema Solar por las perturbaciones de Júpiter. Esta acción reduce las distancias perihélicas de esos objetos hasta que se hacen detectables por el despliegue de actividad. La sublimación de los hielos de los cometas es mayor cuanto menor es la distancia al Sol, así, los JFC pierden sus volátiles y por ende la capacidad de desarrollar actividad más rápido cuanto menor es $q$. De esta manera, el cociente entre cometas extintos y activos debería ser una función de $q$. Es muy difícil obtener tal función a partir de los datos observacionales disponibles actualmente, sin embargo, en principio parece razonable esperar que el número de cometas extintos aumente a medida que nos acercamos al Sol. Por lo tanto en una primera aproximación, en la zona con $q>2,5 \mathrm{UA}$ la población de cometas extintos podría ser despreciable frente a los activos. Más aún, probablemente, la gran mayoría de los JFC con $q>2,5$, sean cometas dormidos. Por

consiguiente, tomamos como el número total de JFC en la región con $q>2,5 \mathrm{UA}$, la estimación de Fernández y otros (1999) de 10000 .

De la figura 4.1 y de la tabla 4.1, es evidente que los Hildas escapados pueblan principalmente la zona de los JFC con $q>2,5 \mathrm{UA}$, y que la contribución a la zona interna es despreciable. Podemos esperar que 143 asteroides Hildas con diámetros mayores que 
$1 \mathrm{~km}$ estén entre la población de JFC con $q>2,5$ UA. Sin embargo, los cometas deben ser activos sólo durante una fracción de su vida dinámica (5 - 20\% de su vida dinámica), entonces el número de Hildas que se puedan reconocer como cometas activos debería ser menor. Por tanto, podría ser que casi todos los Hildas en esa zona sean cometas dormidos. Que esto ocurra depende del tiempo de vida físico de los Hildas, del instante de escape de la resonancia y de si los Hildas contienen suficientes volátiles como para desarrollar actividad.

\subsection{El caso del Shoemaker - Levy 9}

El cometa Shoemaker - Levy 9 (SL9), colisionó con Júpiter en 1994 luego de fragmentarse en 1992, 2 horas después de su pasaje por el pericentro de su órbita alrededor de Júpiter (a una distancia menor a 1.62 radios jovianos). No hay un consenso generalizado acerca de su composición química. Podría haber sido un cometa o un asteroide. Se han observado colas de polvo en los fragmentos pero también hay alguna evidencia indirecta de gases. Dejando este aspecto a un lado, centraremos nuestra atención en el aspecto dinámico del problema. Benner y Mc. Kinnon (1995) calcularon los elementos pre-captura del SL9. Ellos encuentran dos posibles órbitas debido a la naturaleza caótica del encuentro con Júpiter. Los elementos orbitales extraidos del trabajo de Benner y Mc. Kinnon (1995) de estas 2 posibles trayectorias pre-captura se muestran en la figura 4.3. Con el fin de referirnos a ambos grupos hemos denominado Z1 al grupo en la zona de $\sim 4$ UA (cuadrados llenos) y Z2 al grupo en $~ 6,5$ UA (cuadrados vacíos). En el gráfico también se muestran las curvas que delimitan la zona de los JFC y los asteroides Hildas (puntos).

En la figura 4-1 se muestra el grupo Z1 de elementos orbitales pre-captura del SL9. Puede observarse que esta trayectoria se superpone con el espacio de elementos orbitales de los Hildas escapados. El otro conjunto de elementos, Z2, está fuera de la región de los JFC. De este modo, en principio, en virtud de la superposición del grupo Z1, un Hilda escapado podría haber sido el objeto madre de los fragmentos que chocaron con Júpiter. Así, hay una cierta probabilidad de que el SL9 sea un asteroide Hilda escapado, y si realmente lo fuera, los elementos pre-captura serían los correspondientes a la zona Z1. 


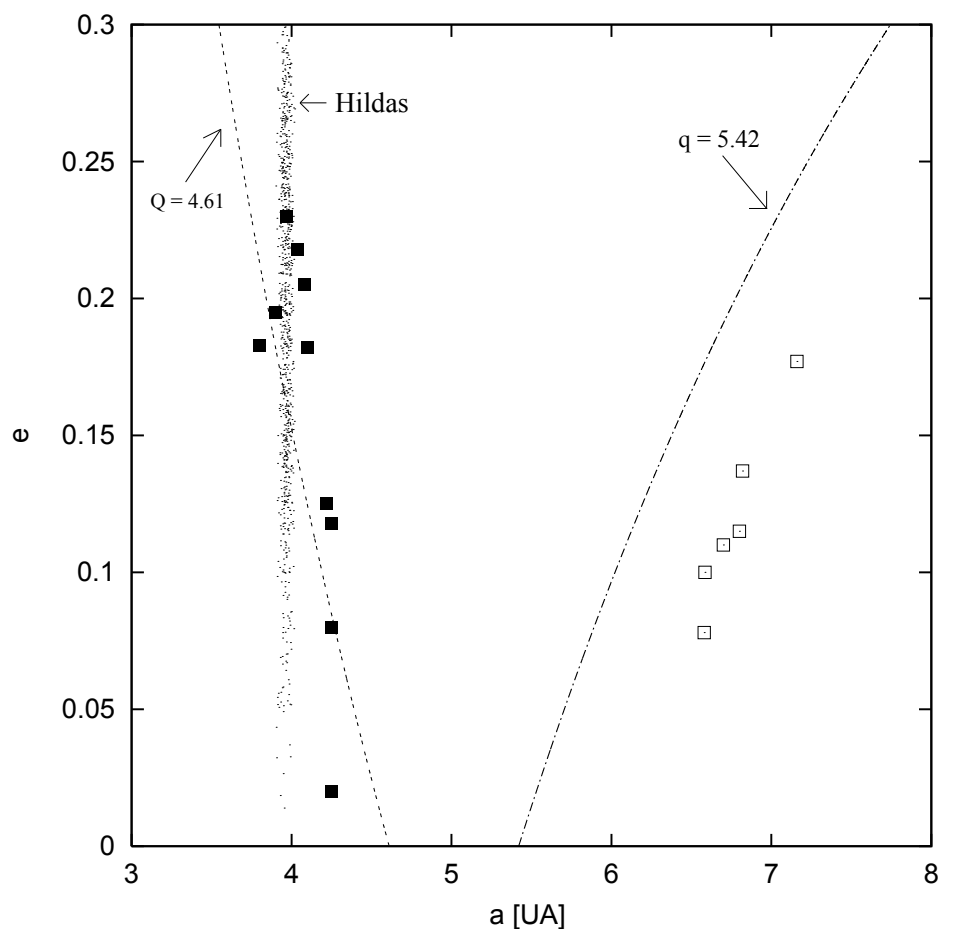

Figura 4.3: Elementos orbitales pre-captura del cometa SL9. Los cuadrados llenos corresponden al grupo Z1 de elementos en la zona de $\sim 4$ UA y los cuadrados vacíos al grupo Z2 en $\sim 6,5$ UA. En el gráfico también se muestran las curvas que delimitan la zona de los JFC y los asteroides Hildas (puntos).

En nuestra simulación, el $8 \%$ de los Hildas escapados impactan sobre Júpiter. Entonces, la tasa de colisión de un asteroide Hilda de diámetro mayor que $1 \mathrm{~km}$ sobre Júpiter es de $8,8 \times 10^{-6}$ año ${ }^{-1}$, esto es, un impacto cada 110000 años. Para objetos más grandes que 0,5 km, se daría un impacto cada 22000 años. Sin embargo, si un objeto pasa dentro del radio de Roche de Júpiter, esto es a una distancia del planeta menor que 2,5 radios jovianos, como lo hizo el SL9, la fuerza de marea del planeta podría fragmentarlo. Entonces por disipación de mareas aquellos objetos reducirían su semieje mayor planetocéntrico cayendo hacia el planeta hasta colisionar con él. De nuestra simulación, hay 55 Hildas escapados que tienen en algún momento distancias pericéntricas menores que 2,5 radios jovianos. Son el $14 \%$ del total de las partículas escapadas. Así, en realidad, los Hildas mayores que $1 \mathrm{~km}$ podrían impactar a Júpiter cada 65000 años y los mayores que $0.5 \mathrm{~km}$ cada 12500 años. Los JFC impactan Júpiter cada $\sim 1200$ años (Zahnle y otros 
1998 corregido por el factor 12), por lo tanto su probabilidad de impacto sobre Júpiter es mayor que la de los Hildas.

\subsection{Discusión}

Hay dos formas posibles de atacar el problema de si un objeto es un asteroide o un cometa. Una es desde el punto de vista de la composición química, y la otra por su comportamiento dinámico. Como se describe en el capítulo 1, el espectro de los cometas y los asteroides tipo D son muy similares, pero ésto no es concluyente. El hecho de que no tengamos meteoritos provenientes de la zona externa del cinturón de asteroides es un obstáculo para verificar la presencia de hielos. Por otro lado, como los asteroides tienen órbitas relativamente estables y los cometas inestables, la cuestión desde el punto de vista dinámico favorece la distinción entre ellos, pero esta es una visión incompleta. Como demostramos, los asteroides Hildas, tienen un comportamiento dinámico como el de los JFC una vez que escapan de la resonancia. Por lo tanto, desde este punto de vista, no hay distinción entre ellos. Las similitudes espectrales los ponen también en igualdad de condiciones, aunque, como ya dijimos, no sabemos con certeza que cantidad de volátiles tienen los Hildas y si son capaces de desplegar actividad.

Otra posible conexión entre los JFC y los asteroides Hildas son los cometas que están justo en los bordes de la resonancia. Este es el caso de los cometas P/Gehrels 3, P/Oterma, P/Helin-Roman-Crockett y P/Smirnova-Chernykh. Estos cometas han sido o serán satélites temporarios de Júpiter (Tancredi et al. 1990). Este grupo fue llamado quasi-Hilda por Kresák (1979). Como se observa en la figura 4.1 el tiempo de vida de los Hildas escapados es mayor cerca de los bordes de la resonancia, así, la probabilidad de encontrar objetos en esa zona es alta y por tanto, es probable que los cometas observados en esa zona sean en verdad asteroides Hildas o fragmentos que han dejado la zona estable de la resonancia. Si realmente lo fueran, la actividad detectada en ellos reforzaría la idea de la presencia de hielos en estos asteroides.

Por otro lado, la resonancia 3:2 con Júpiter es una zona muy estable, por tanto, los Hildas han estado allí por mucho tiempo y aunque muy lentamente, podrían haber 
perdido sus hielos superficiales por la acción distante del Sol. Otro fenómeno que se podría dar es la formación de mantos de irradiación sobre su superficie. De cualquier manera, los Hildas son una población colisionalmente activa y por tanto las colisiones entre ellos producen fragmentos que exponen los hielos atrapados bajo la superficie del asteroide madre. Dado que los escapes de la resonancia se dan por este mecanismo, los objetos escapados tendrían la capacidad para desplegar actividad si se acercan al Sol y por tanto tendrían la característica de potenciales cometas. Pueden ser activos o dormidos, dependiendo de la composición química real y del tiempo que han estado expuestos a la radiación solar antes de alcanzar la región cometaria observable. 


\section{Capítulo 5}

\section{Conclusiones}

En esta tesis hemos realizado una simulación numérica y una pseudo - evolución colisional para estudiar la evolución dinámica post - escape de los asteroides de la familia de los Hildas. Hemos demostrado que el planeta Júpiter domina las rutas dinámicas de los Hildas escapados, a tal punto que una cantidad considerable de partículas terminan colisionando con este planeta. El efecto general sobre las partículas escapadas es el aumento de la excentricidad y semieje mayor, hasta ser eyectadas del Sistema Solar. Este mecanismo hace que las partículas escapadas pasen un tiempo considerable en la zona exterior a Júpiter y muy poco tiempo en la zona interna del Sistema Solar. Como resultado de esta evolución post - escape, es de esperar, como hemos demostrado, que los efectos que los Hildas producen en el Sistema Solar exterior sean importantes, no así, los efectos en el Sistema Solar interior. Este hecho es diferente de los mecanismos que operan en otras resonancias de movimientos medios con Júpiter. Para los objetos en resonancias del

cinturón principal exteriores a la resonancia 3:1 (2,5 UA), los planetas interiores son los que sacan a las partículas de las resonancias mediante encuentros cercanos. Esto produce el aumento de las excentricidades hasta que cruzan la órbita de Júpiter, teniendo entonces encuentros cercanos con este planeta que los remueve definitivamente del Sistema Solar interior (Gladman y otros, 1997). En cambio, casi el $80 \%$ de los objetos en las resonancias 3:1 y $\nu_{6}$, terminan colisionando con el Sol (Gladman y otros, 1997).

A continuación presentamos, entonces los resultados y conclusiones de este estudio 
punto por punto.

- Como resultado de la evolución dinámica de 500 Hildas ficticios a través de una simulación numérica, obtuvimos que de las partículas que escapan de la resonancia, el $92,1 \%$ son eyectadas en órbitas hiperbólicas y el 7,9\% colisionan con Júpiter. Esta es una fracción significativa que debe compararse con la fracción de Troyanos de Júpiter que, luego de dejar los puntos $L 4$ y L5, terminan colisionando con Júpiter, que es sólo de un $2 \%$ (Fernández y Mallada 2002, comunicación personal). También es significativo comparado con el $2 \%$ de los Cometas de la Familia de Júpiter que colisionan con Júpiter en la simulación de Levison y Duncan (1997).

- Aunque los Hildas pueden tener la composición apropiada para haber transportado el agua a los planetas terrestres, demostramos que su contribución es despreciable así como su contribución a la población de NEOs (Ver apéndice B).

- Una característica común de las evoluciones de las partículas escapadas es la captura momentánea en una resonancia de movimientos medios con Júpiter. En particular, encontramos dos partículas que están 100000 años en resonancia 1:1 con Júpiter, aunque no exáctamente en los puntos Lagrangianos equiláteros. Otro estado frecuente es el pasaje por una resonancia de Kozai.

- Encontramos que la población de los asteroides Hildas podría ser la fuente más importante de cráteres de impactos pequeños sobre los satélites de Júpiter, incluso, superando a la contribución de los JFC. Dado que la mayoría de los objetos impacta sobre Júpiter en una escala de tiempo mucho menor que la de los JFC, y que los objetos que escapan son principalmente fragmentos de una colisión catastrófica, podríamos esperar entonces, que este proceso quede marcado en la superficie de los satélites Galileanos, por ejemplo produciendo cadenas o grupos de cráteres.

Zahnle y otros (1998), basados en simulaciones numéricas realizadas por Gladman y otros (1997) sobre la evolución dinámica de objetos en resonancias del Cinturón de asteroides interiores a 3,5 UA, demuestran que los asteroides del cinturón principal contribuyen en una fracción despreciable a los cráteres de los satélites galileanos. En principio, entonces, se podría decir que la historia de cráteres del Sistema Solar 
interior y exterior es diferente. Además, el hecho de que una población compacta y aislada como los Hildas pueda ser la fuente principal responsable de la producción de cráteres pequeños en la zona de Júpiter, nos hace pensar que la historia de cráteres de los cuerpos del Sistema Solar exterior tienen que ser analizadas separadamente.

Los Hildas contribuyen en un factor de 4 a 5 veces mayor que los Troyanos a los cráteres sobre los satélites galileanos

- Nuestro estudio revela que 143 asteroides Hildas con diámetros mayores que $1 \mathrm{~km}$. escapados de la resonancia pueblan la zona de los JFC con $q>2,5$ UA. En esa región tienen una vida media de $1,33 \times 10^{6}$ años. Casi todos los Hildas escapados pasan a través de la región dinámica de los JFC, siendo la vida media en esa zona de $1,4 \times 10^{6}$ años. La clase taxonómica D es la más abundante en el grupo de los Hildas, con mayor proporción de asteroides D para tamaños menores. Por lo tanto, como los Hildas que escapan son fragmentos que resultan de colisiones catastróficas, es más probable que los objetos escapados sean de tipo D. Esta es la clase de objetos más primitiva y más similar a los cometas. Aunque no se ha detectado actividad en los Hildas, la presencia de los cometas quasi-Hildas, en los bordes de la resonancia representa una conexión entre Hildas y cometas. Probablemente sea más conveniente llamar a los Hildas cometas dormidos que asteroides, en virtud de su composición y de la evolución dinámica post -escape que presentan.

Uno de los dos conjuntos de elementos orbitales pre-captura del Shoemaker Levy 9 obtenido por Benner y Mc. Kinnon (1995) se superpone con los elementos orbitales de los Hildas en la zona de los JFC, apoyando la idea de que el SL9 podría ser un Hilda. Si realmente lo fuera, quedarían definidos sus elementos orbitales precaptura. 


\section{Apéndice A}

\section{Resonancias}

En esta sección se presenta una descripción breve del fenómeno de resonancia con el objetivo de dar una idea general del tema y las definiciones utilizadas a lo largo de esta tesis.

En general las fuerzas perturbativas que actúan sobre la órbita de un cuerpo del Sistema Solar, son pequeñas. Sin embargo perturbaciones pequeñas pueden producir grandes efectos si la frecuencia de la fuerza es conmensurable o casi conmensurable con la frecuencia natural de oscilación de los elementos correspondientes. Bajo estas circunstancias, las perturbaciones se van sumando a lo largo del tiempo. Esto es un ejemplo del fenómeno de resonancia que ocurre en una gran cantidad de sistemas físicos.

En el Sistema Solar existen tres tipos generales de fenómenos resonantes que involucran movimientos orbitales. La resonancia spin - órbita en cuyo caso existe una conmensurabilidad entre el período (o la frecuencia) de rotación de un cuerpo y su período (o frecuencia) orbital. Las resonancias de movimientos medios en las que las frecuencias de traslación orbital de dos cuerpos son conmensurables. Y por último las resonancias seculares en las que las frecuencias de precesión orbital dadas por la variación de las longitudes del perihelio o nodo de ambas órbitas son iguales. También existe en el Sistema Solar un ejemplo de resonancia "hibrida"en el sistema de anillos y lunas de Saturno que involucra la conmensurabilidad de una frecuencia de precesión secular con un movimiento orbital medio (Malhotra 1998). 


\section{A.0.1. Resonancias de movimientos medios}

Si consideramos el problema restringido de los tres cuerpos, en este caso aplicado al sistema Sol - planeta - asteroide, en el que el planeta en una órbita externa perturba al asteroide (de masa despreciable) en órbita interna, los primeros términos de la expresión general de la función perturbadora (consideramos bajas excentricidades e inclinaciones) son (Murray y Dermott, (1999)) :

$$
R=\frac{G m_{p}}{a_{p}}\left[A(\alpha) e^{2}+B(\alpha) e \cos (\varphi)\right]
$$

donde

$$
\varphi=(p+q) \lambda_{p}-p \lambda-w
$$

es el ángulo crítico, $\alpha=a / a_{p}$ ( $a$ es el semieje mayor del asteroide y $a_{p}$ el del planeta) y $A(\alpha)$ y $B(\alpha)$ son funciones de $\alpha$ y de los coeficientes de Laplace $b_{s}^{(j)}(\alpha), \lambda_{p}$ y $\lambda$ son las longitudes medias del planeta y asteroide y $w$ la longitud del perihelio del asteroide.

Las longitudes medias $\lambda$ y $\lambda_{p}$ son ángulos que varían con velocidades $n$ y $n_{p}$ respectivamente, mientras que $w$ varía muy lentamente.

\section{$\mathrm{Si}$}

$$
(p+q) \lambda_{p}-p \lambda=0
$$

donde p y q son enteros entonces los movimientos medios del planeta y del asteroide son conmensurables y se dice que estos objetos están en resonancia de movimientos medios $p+q: p$. Equivalentemente se puede expresar:

$$
\frac{n}{n_{p}}=\frac{p+q}{p}
$$


Mientras el planeta completa $p$ vueltas alrededor del Sol, el asteroides completa $p+q$ vueltas. Por la tercera ley de Kepler, la conmensurabilidad de movimientos medios o períodos "localiza" en semieje mayor los términos resonantes de la función perturbadora.

El ángulo $\varphi$ mide el desplazamiento de la longitud de conjunción desde el pericentro del planeta. El fenómeno de resonancia lleva entonces a que el asteroide y el planeta tengan encuentros repetidos en el mismo lugar de sus órbitas y de esta forma el efecto de sus interacciones se va repitiendo y por tanto acumulando.

Dado que en esta tesis estudiamos el caso de los Hildas en la resonancia $3: 2$, vamos a considerar resonancias de primer orden, es decir: $p+1: p$ :

Si calculamos la derivada segunda del ángulo crítico, teniendo en cuenta que las variaciones de $w$, de las longitudes medias de la época $L$ y $L_{p}(\lambda=n t+L)$ son despreciables frente a los movimientos medios, y que en el problema restringido $\dot{n}_{p}=0$, se puede obtener la expresión para $\ddot{\varphi}$ (Murray y Dermott, 1999):

$$
\ddot{\varphi}=K \sin \varphi
$$

donde $K=3 p^{2} C_{T}$ ne y $C_{T}=\left(m / m_{p}\right) n \alpha B(\alpha)$. La ecuación (A.5), es la ecuación de movimiento de un péndulo simple con movimiento estable alrededor de $\varphi=0$. Las soluciones de esta ecuación diferencial son una libración de $\varphi$, es decir que oscila alrededor de cero o una circulación. Esto depende de la energía $E$ del sistema que está dada por:

$$
E=\frac{\dot{\varphi}^{2}}{2}-2 K \sin ^{2}(\varphi / 2)
$$

En la figura A.1 se muestran las curvas de igual energía en el plano $(\varphi, \dot{\varphi})$. Las curvas internas cerradas (energías $E 1$ y E2) corresponden al régimen oscilatorio del péndulo o a la libración del ángulo $\varphi$. Este tipo de movimiento se da para $-\pi<\varphi<\pi$. La curva con energía $E 3$, corresponde al límite entre los dos regímenes y se denomina separatriz. Las curvas con energía mayor ( $E 4$ y $E 5)$ corresponden a la circulación de $\varphi$.

La variación de los elementos orbitales del asteroide dependen del ángulo $\varphi$ (a través de la función perturbadora) y por tanto se puede obtener la variación de los 


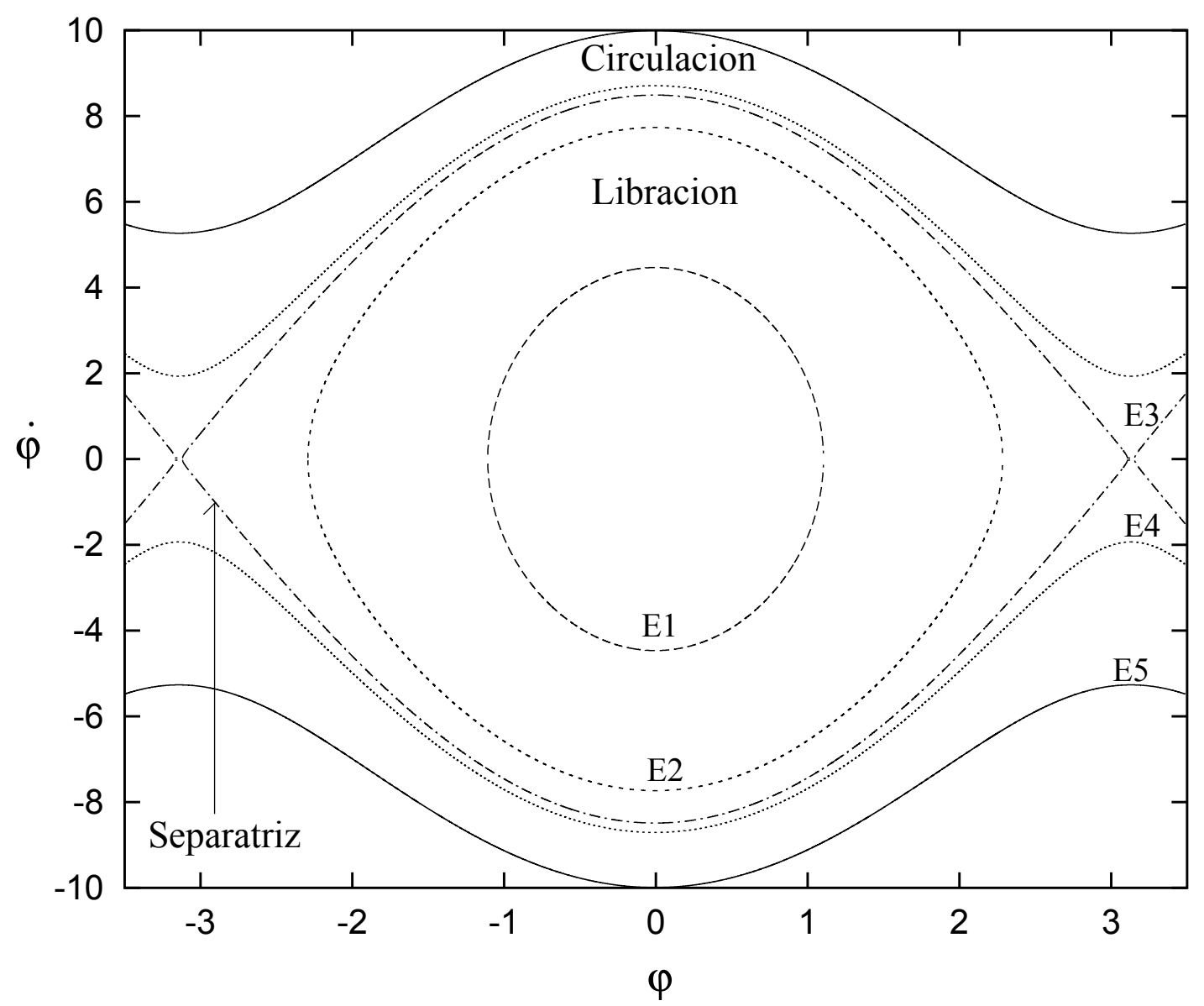

Figura A.1: Curvas de Energía constante en el espacio de las fases $(\varphi, \dot{\varphi})$

parámetros orbitales del asteroide causados por una resonancia. De la figura A.1, es evidente que la región de máxima libración de $\varphi$ se obtiene para $\dot{\varphi}=0$ en $\varphi=\pi$. Por tanto, la energía asociada a esta libración máxima será : $E_{\max }=-6 p^{2} C_{T} n e$. A partir de esta relación, de la expresión de la energía (ec. (1.6)) y de la ecuación de Lagrange para $\dot{a}$ (para bajas excentricidades e inclinaciones), se puede obtener la variación de $a$ con $\varphi$ :

$$
a=a_{0} \pm \sqrt{\frac{8\left|C_{T}\right| e}{3 n}} a \cos (\varphi / 2)
$$

Por lo tanto $a$ oscila alrededor del centro de la resonancia, $a_{0}\left(a_{0}=(p /(p+1))^{2 / 3} a_{p}\right)$ en contrafase con $\varphi$ y la amplitud máxima de oscilación vale: 


$$
\delta a=\sqrt{\frac{8\left|C_{T}\right| e}{3 n}} a
$$

Este valor determina el ancho de la resonancia. En un sistema físico como el Sistema Solar, en el que tenemos el cinturón de asteroides y los planetas, se dan varias configuraciones resonantes, en particular entre los asteroides y Júpiter. Cuando la separación entre resonancias vecinas es menor que el ancho de las resonancias, se da la superposición de resonancias. Estas regiones son muy inestables y un asteroide en esta zona es rápidamente removido.

En el Sistema Solar existen un gran núnero de objetos en resonancias de movimientos medios. Entre los planetas, Neptuno y Plutón están exáctamente en resonacia 3:2, mientras que Júpiter y Saturno están cerca de la resonancia 5:2 (the Great Inequality), Urano y Neptuno, cerca de la resonancia 2:1 y Saturno y Urano cerca de la 3:1. En cambio los sistemas de satélites de los planetas gigantes Júpiter y Saturno exhiben varias configuraciones resonantes exactas. Por ejemplo entre los satélites galileanos Io y Europa (resonancia 2:1) y entre Europa y Ganímedes (2:1), o la resonancia 4:3 entre Titán e Hyperion en el sistema de satélites de Saturno. Los sistemas de anillos de los planetas gigantes exhiben también características dinámicas asociadas con fenómenos resonantes (Goldreich y Tremaine (1982)).

\section{A.0.2. Resonancias seculares}

Consideremos un planeta en una órbita elíptica con semieje mayor $a_{p}$, excentricidad $e_{p}$ y una tasa de precesión del perihelio $\dot{w}_{p}=\nu_{p}$ y de precesión del nodo ascendente $\dot{\Omega}$. Un asteroide describe una órbita elíptica que es perturbada por las masas planetarias. De esta manera la órbita precesiona lentamente. El asteroide está en una resonancia secular cuando se da conmensurabilidad entre su tasa de precesión del perihelio o precesión del nodo ascendente y $\dot{w}_{p}$ o $\dot{\Omega}$.

Un tipo de resonancia secular particular es la resonancia de Kozai en la que la tasa de variación del argumento del perihelio $\dot{w}=0$. Kozai (1962) mostró que un asteroide 
en órbita circular alrededor de Júpiter cambiará su excentricidad $(e)$ e inclinación $(i)$ manteniendo constante la cantidad:

$$
H_{k}=\sqrt{1-e^{2}} \cos i
$$

Además su semieje mayor no variará.

Por lo tanto, la excentricidad e inclinación de un objeto están acopladas de manera que cuando una es máxima la otra es mínima y viceversa.

La teoría de Kozai fue extendida por Michel y Thomas (1995) para incluir los 4 planetas gigantes. La teoría muestra que para órbitas de baja inclinación $w$, libra en forma estable alrededor de $w=0^{\circ}$ y $w=180^{\circ}$. Para inclinaciones mayores que $30^{\circ}$ los puntos de libración estables son $w=90^{\circ}$ y $w=270^{\circ}$. Un ejemplo de este mecanismo es el caso de Plutón cuyo argumento del perihelio libra alrededor de $90^{\circ}$ (Malhotra y Williams 1997). 


\section{Apéndice B}

\section{Hildas en la región de los planetas terrestres}

El problema de estudiar un origen extraterrestre del agua en la Tierra, consiste en identificar reservorios potenciales en la región planetaria, que puedan haber sido fuentes de proyectiles. En este sentido, las fuentes más plausibles se encuentran en el cinturón de asteroides externo, la región de los planetas gigantes y el cinturón de Edgeworth Kuiper. Sin embargo, el momento de la formación de los planetas terrestres es una cuestión relevante y marca un límite en cuanto al tiempo de vida dinámico de los objetos de interés. La acreción de los planetas terrestres fue esencialmente completada en $10^{8}$ años, quedando entonces libres de megaimpactos que pudieran volatilizar el material de hielos previamente acretados. Presumiblemente el material de hielos que colisionó con la Tierra durante los primeros pocos $10^{8}$ años se perdió mientras que el que llegó luego, podría haber sido acretado.

El parámetro central que permite reconstruir el origen del agua en el Sistema Solar es el cociente del isótopo Deuterio/Hidrógeno $(D / H)$. Se ha sugerido que los cometas podrían ser una fuente importante del agua terrestre. Se ha medido el cociente $D / H$ en 3 cometas encontrándose un valor promedio de $3,16 \times 10^{-4}$ (Delsemme 1999), mientras que para los océanos terrestres $D / H=1,56 \times 10^{-4}$, la mitad que lo observado en los cometas. Si los 3 cometas son representativos de los demás, entonces debemos buscar otra fuente 
de volátiles para la Tierra.

Morbidelli y otros (2000b) estudiaron numéricamente la formación de los planetas terrestres asumiendo embriones planetarios entre 0.5 y 4 UA. Obtienen algunos planetas formados en la región de los planetas terrestres y en particular sostienen que la mayor parte del agua actual en la Tierra fue producto de la acreción en las últimas etapas de su formación de algunos pocos embriones planetarios originalmente formados en el cinturón externo de asteroides.

Delsemme (1999) sugirió que en la zona de Júpiter, las altas temperaturas han provocado que el agua se vuelva reducida en Deuterio hasta el valor observado en la Tierra. Esto está parcialmente de acuerdo con los datos de $D / H$ encontrados en los meteoritos carbonaceos que se supone que provienen del cinturón externo de asteroides. Por tanto, podriamos considerar reservorios con una composición isotópica apropiados en la zona de Júpiter que hayan sobrevivido por varios $10^{8}$ años.

Se tienen tres fuentes posibles: los objetos en la region de Júpiter y Saturno, los asteroides troyanos y objetos en el límite externo del cinturón de asteroides. En este punto estudiamos la contribución de los Hildas.

De nuestras simulaciones obtuvimos el número de partículas que escapan de la resonancia y tienen encuentros con los planetas a distancias menores que 3 veces el radio de Hill (ver tabla 2.1). En general, el número de partículas que tienen encuentros con un planeta $\left(n_{e}\right)$ a una distancia menor que $\mathrm{R}$, en un intervalo de tiempo $\Delta t$ y a una velocidad relativa $\mathrm{v}$, está dado por:

$$
n_{e}(d<R)=\pi R^{2} v n \Delta t
$$

donde $\mathrm{n}$ es la densidad volumétrica de partículas.

Entonces el número de colisiones con un planeta de radio $R_{p}$, será:

$$
n_{c}=\pi R_{p}^{2} v_{c} n \Delta t
$$


donde $v_{c}$ es la velocidad de colisión.

Dado que queremos hacer una estimación de las colisiones con los planetas terrestres, podemos considerar que $v_{c}$ es aproximadamente igual a la velocidad media relativa de las partículas en los encuentros, entonces, el número de colisiones con un planeta lo podemos obtener de:

$$
n_{c}=n_{e}\left[\frac{R_{p}}{3 R_{H}}\right]^{2}
$$

donde $n_{e}$ es el número de partículas que tienen encuentros con el planeta a una distancia menor a $3 R_{H}$ mostrado en la tabla 2.1 para cada planeta.

Por otro lado, si consideramos una población original de Hildas mayores de 0,5km. de radio de $N_{i H}=10^{8}$ (Gil-Hutton y Brunini, 2000), y tenemos en cuenta que de nuestro ajuste para la población actual de Hildas (ecuación (1.10)) $N_{a}(>r=0,5) \sim 10^{5}$, entonces el número de partículas que han escapado de la resonancia $3: 2$ es $N_{e}=N_{i H}-N_{a} \sim$ $9,99 \times 10^{7}$.

En la tabla 2.1 mostramos en la última columna el porcentaje $P$ de las partículas que escapan que tienen encuentros con los planetas. Entonces, el número total de Hildas escapados que han tenido encuentros con los planetas terrestres está dado por: $n_{e t}=P N_{e}$.

Por lo tanto, el número total de Hildas que colisionaron con los planetas terrestres a lo largo de la vida del Sistema Solar es:

$$
n_{c t}=n_{e t}\left[\frac{R_{p}}{3 R_{H}}\right]^{2} \text {. }
$$

En la tabla B.1 mostramos el número de encuentros con los planetas terrestres $n_{e t} \mathrm{y}$ el número de colisiones $n_{c t}$. El número de colisiones podría ser levemente mayor si consideramos el enfocamiento gravitatorio del planeta. Es decir, en lugar del radio del planeta $R_{p}$ en la ecuación anterior, deberíamos poner $R_{p}\left(1+v_{e} / v_{r e l}\right)$ donde $v_{e}$ es la velocidad de escape del planeta y $v_{r e l}$ es la velocidad relativa partícula - planeta. Sin embargo, el número de colisiones con los planetas terrestres es tan bajo, que este factor no afecta significativamente los resultados. 


\begin{tabular}{|l|c|c|c|c|}
\hline Planeta & $R_{p}[k m]$ & $R_{H}[U A]$ & $n_{\text {et }}$ & $n_{c t}$ \\
\hline Venus & 6052 & 0.0068 & $5,4 \times 10^{6}$ & 21 \\
Tierra & 6378 & 0.01 & $8,4 \times 10^{6}$ & 17 \\
Marte & 3394 & 0.0072 & $1,1 \times 10^{7}$ & 107 \\
\hline
\end{tabular}

Tabla B.1: Para cada planeta, se muestra su radio $R_{p}$, el radio de Hill $R_{H}$, el número de encuentros $n_{\text {et }}$ y el número de colisiones $n_{c t}$ de los Hildas a lo largo de la historia del Sistema Solar.

Evidentemente, la cantidad de volátiles que pueden haber transportados los Hildas hacia la zona de los planetas terrestres es despreciable. Aunque, desde el punto de vista de la composición, podrían ser los cuerpos apropiados, los Hildas y probablemente los demás asteroides de la zona externa, no contribuyen al origen del agua en la Tierra.

Por otro lado, estudiamos el número de Hildas escapados que transitan por la zona de los NEOs. Como es de esperar, de los resultados anteriores, la contribución a la población de NEOs es también despreciable. 


\section{Bibliografía}

[1] Bell, J.F. 1986. Mineralogical evolution of meteorite parent bodies. Lunar and Planet. Sci.. XVII:985-986 (abstract).

[2] Bell, J.F., D.R. Davis, W.K. Hartmann and M.J. Gaffey. 1989 Asteroids: The Big Picture. In Asteroids II (R. P. Binzel, T. Gehrels, and M. S. Matthews, Eds.), pp 921-948, Univ. of arizona Press, Tuckson.

[3] Benner, L.A.M., Mc.Kinnon, W.B. 1995. On the orbital evolution and origin of Comet Shoemaker-Levy 9. Icarus. 118,155-168.

[4] Bierhaus, E. B., C. R. Chapman, W. J. Merline, S. M. Brooks and E. Asphaug. 2001 Pwyll Secondaries and Other Small Craters on Europa. Icarus. 153, 264-276.

[5] Bly, J. 1983. Galactic perturbations of nearly parabolic cometary orbits. Earth, Moon and Planets 29, 121-137.

[6] Barucci, M.A., Capria, M.T., Coradini, A. and Fulchignoni, M. 1987. Classification of asteroids using G-mode analysis. Icarus. 72, 304-324.

[7] Bottke, W. F., A Morbidelli, R. Jedicke, J. Petit, H. Levison, P. Michel, and T. S. Metcalfe 2002. Debiased orbital and absolute magnitud distribution of the near-Earth objects. Icarus. 156,399-433.

[8] Brunini, A., Di Sisto R.P., and Orellana R.B. 2003. Cratering rate on the jovian system: the contribution from Hilda asteroids. Icarus. 165,371-378.

[9] Burns, R.G. (1970) Mineralogical Applications of Crystal Field Theory. Cambridge Univ., New York. 224 pp. 
[10] Burns, R.G. (1981) Intervalence transitions in mixed - valence minerals of iron and titanium. Annu. Rev. Earth Planet Sci, 9, 245-383.

[11] Bus, S.J., Vilas, F., Barucci, M.A. 2002. Visible - wavelength Spectroscopy of Asteroids. In Asteroids III (W. Bottke, A. Cellino, P. Paolicchi and R. Binzel, Eds.), pp.. 169-182. Univ. of Arizona Press, Tucson.

[12] Carusi, A. and G. Valsechi 1987. Dynamical evolution of short period comets. In Interplanetary Matter (Z. Ceplecha and P. Pecina, Eds), pp. 21-28. Czechoslovak Academy of Sciences, Ondrejov.

[13] Chapman, C. R. \& W. B. Mc Kinnon 1986, Cratering on planetary satellites. IN Satellites (J. A. Burns and M. S. Matthews, Eds.) pp. 507-553. Univ. of Arizona Press, Tucson.

[14] Dahlgren, M. and C.-I. Lagerkvist. 1995. A study of Hildas asteroids. I. CCD spectroscopy of Hilda asteroids. Astronomy and Astrophysics. 302, 907-914.

[15] Dahlgren, M., C.-I. Lagerkvist, A. Fitzsimmons, I.P. Williams. and M. Gordon. 1997. A study of Hildas asteroids. II. Compositional implications from optical spectroscopy. Astronomy and Astrophysics. 323, 606-619.

[16] Davis, D. R., Chapman, C.R., Weidenschilling, S. J., and Greenberg, R. 1984. Asteroid collisional evolutions studies (abstract) Lunar and Planetary Science $X V$. pp 192-193,.Lunar and Planetary Institute, Houston.

[17] Davis, D. R., Weidenschilling, S. J., Farinella, P., Paolicchi, P. and Binzel, R. P. 1989. Asteroid collisional history: effects on sizes and spins. In Asteroids II (R. P. Binzel, T. Gehrels, and M. S. Matthews, Eds.), pp 805-826, Univ. of arizona Press, Tuckson.

[18] Davis, D. R., E. V. Ryan, and P. farinella 1994. Asteroid collisional evolution: results from current scaling algorithms. Planet. Space. Sci, 42, 599-610.

[19] Davis, D. R., Farinella, P. y Marzari F., The missing Psyche family: Collisional erode or never formed?. Icarus 137 pp.140-151. 
[20] Davis, D. R., Durda D. D., Marzari F., Campo Bagatin A., Gil-Hutton, R. Collisional Evolution of Small-Body populations. In Asteroids III. (W. Bottke, A. Cellino, P. Paolicchi and R. Binzel, Eds.), pp.. 169-182. Univ. of Arizona Press, Tucson.

[21] Delsemme, A. H. 1999. Planet. Space Sci. 47, 591.

[22] Duncan, M., T Quinn, and S. Tremaine 1988. The origin of short-period comets. Astrophys. J. Lett. 328, 69-73.

[23] Everhart, E. 1967. Intrinsic Distribution of Cometary Perihelia an Magnitudes. The Astronomical Journal 72, 1002-1011.

[24] Ferraz-Mello, S., Michtchenko, T. A. Nesvorný, D., Roig, F. and Simula, A. 1998(a). The depletion of the Hecuba gap vs. the long-lasting Hilda group. Planet. Space Sci.. 46, No 11/12 1425-1432.

[25] Ferraz-Mello, S., Nesvorný, D. and Michtchenko, T. A. 1998(b) Chaos, Diffusion, Escape and Permanence of Resonant Asteroids in Gaps and Groups. Solar System Formation and Evolution. Conference Series, 149, 65-82.

[26] Fernández, J. A. 1980. On the existence of a comet belt beyond Neptune. Mon. Not. R. Astron. Soc. 192,481-491.

[27] Fernández, J. A., G. Tancredi, H. Rickman, and J. Licandro. 1999. The population, magnitudes, and sizes of Jupiter family comets. Astron. Astrophys. 352, 327-340.

[28] Fernández, J. A., T. Gallardo, \& A. Brunini. 2002, Are there many inactive JupiterFamily Comets among the Near-Earth population? Icarus 159, 358-368.

[29] Fernández, J. A. y A. Brunini. 2000. The Buildup of a Tightly Bound Comet Cloud around an Early Sun Immersed in a Dense Galactic Environment: Numerical Experiments. Icarus 145, 580-590.

[30] Fitzsimmons, A., M. Dahlgren, C.-I. Lagerkvist, P Magnusson, and I.P. Williams. 1994. A spectroscopic survey of D-type asteroids. Astronomy and Astrophysics. 282, 634-642. 
[31] Gaffey, M.J., Bell, J.F., Cruikshank D.P. Reflectance spectroscopy and asteroid surface mineralogy. In In Asteroids II, Binzel, R. P., Gehrels, T. and Matthews, M. S. (eds), Univ . of Arizona Press, Tuscon. P. 921 (1989).

[32] Gault, D. E., Shoemaker, E. M. \& Moore H. J. 1963. Spray Ejected from the Lunar Surface by Meteoroid impact, NASA TN D-1767.

[33] Gil-Hutton, R. \& Brunini, A. 2000. Collisional Evolution of the Outer Asteroid Belt. Icarus $\mathbf{1 4 5}, 382-390$.

[34] Gladman, B. J., F. Migliorini, A. Morbidelli, V. Zappala, P. Michel, A. Cellino, C. Froeschle, H. Levison, M. Bailey, and M. Duncan. 1997. Dynamical lifetimes of objects injected into asteroid belt resonances. Science $\mathbf{2 7 7}$, 197-201.

[35] Goldreich, P. y Tremaine, S. 1982. The dynamics of planetary rings, Ann. Rev. Astron. Astrophys., 20, 249.

[36] Harris, A. W. \& Kaula, W. M. 1975, A Co-accretional model of satellite formation. Icarus 24, 516-524.

[37] Hartmann, W.K., D.J. Tholen and D.P. Cruikshank. 1987. The Relationship of Active Comets, "Extinct" Comets, and Dark Asteroids. Icarus 69 33-50.

[38] Howell, E.S., Merényi, E. and Lebofsky, L.A. 1994. Classification of asteroid spectra using a neural network. J. Geophys. Res.. 99, 10847-10865.

[39] Ip, W.-H., and Fernández, J. A. 1997. On dynamical scattering of Kuiper Belt objects in $2: 3$ resonance with Neptune into short-period comets. Astron. Astrophys., 324, 778-84.

[40] Jedicke, R., Larsen, J., and Spahr, T. 2002. Observational selection effects in asteroid surveys and estimates of asteroid population sizes. In Asteroids III. (W. Bottke, A. Cellino, P. Paolicchi and R. Binzel, Eds.), pp.. 169-182. Univ. of Arizona Press, Tucson.

[41] Jewitt, D. C. and Luu, J. X. 1990. CCD spectra of asteroids. II. The Troyans as spectral analogs of cometary nuclei. Astron. J., 100, 933-944 
[42] Jewitt, D. C. and Luu, J. X. 2000. Physical Nature of the Kuiper Belt. In Protostars and planets IV (V. Mannings, A.P. Boss and S.S. Russell Eds.) pp. 1201-1229. Univ. of Arizona Press. Tucson.

[43] Jewitt, D. C., Trujillo, C. A. and Luu, J. X. 2000 Population and size distribution of small jovian troyan asteroids. Astron. J., 120, 1140-1147.

[44] Kozai, Y. 1962. Secular perturbations of asteroids with high inclinations and eccentricities, Astron. J., 67, 591-598.

[45] Kresák, L. 1979. In Asteroids, ed. T.Gehrels, Univ. of Arizona Press. Tucson, Arizona. p.391.

[46] Levison, H. 1996. Comet taxonomy. In Completing the Inventory of the Solar System (T.W. Retting and J. M. Hahn, Eds.), Astron. Soc. of Pacific Conference Proceedings, 107, 233-244.

[47] Levison, H. and M. Duncan. 1997. From the Kuiper Belt to Jupiter-family comets: The spatial distribution of ecliptic comets. Icarus 127, 13-32.

[48] Levison, H. , E. M. Shoemaker, and C. S. Shoemaker. 1997. Dynamical evolution of Jupiter asteroids. Nature 385, 41-44.

[49] Levison, H., M. Duncan, K. Zahnle, M. Holman and L. Dones. 2000. Planetary Impact Rates from Ecliptic Comets. Note. Icarus 143, 415-420.

[50] Malhotra, R. 1998 Orbital Resonances and Chaos in the Solar System. Solar System Formation and Evolution. Conference Series, 149, 37-63.

[51] Malhotra, R. y Williams, J. G. 1997. Pluto's heliocentric orbit, in Pluto and Charon, (S.A. Stern y D. Tholen Eds.), Tucson: Univ. of Arizona Press.

[52] Mc Kinnon, W. B., C. R. Chapman \& K. R. Housen, 1991, Cratering of the Uranian satellites. In Uranus (J. T. Bergstrahl, E. D. Miner, and M. S. Matthews, Eds.), pp. 629-692. Univ. of Arizona Press, Tucson. 
[53] Marzari, F., Scholl, H., Murray, C., Lagerkvist, C. 2002. Origin and evolution of Trojan asteroids. In Asteroids III (W. Bottke, A. Cellino, P. Paolicchi and R. Binzel, Eds.), pp.. 169-182. Univ. of Arizona Press, Tucson.

[54] Morbidelli, A. 1997. Chaotic diffusion, and the origin of comets from the $3 / 2$ Resonance in the Kuiper Belt. Icarus, 127, 1-12.

[55] Morbidelli, A., Chambers, J.I., Lunine, J.M., Robert, F., Valsecchi, G.B. and Cyr, K.E. 2000 Source regions and time scales for the delivery of water to earth. Meteoritics and Planetary Sciences, 35 No 6, 1309-1320

[56] Moore, J. M., and 25 collegues 2001. Impact features on Europa: Results of the Galileo Europa Mission. Icarus 151, 93-111.

[57] Murray, C. D. and S. F. Dermot. 1999. Solar System Dynamics. Cambridge University Press.

[58] Nervorný, D. and Ferraz Mello, S. 1997. On the Asteroidal Population of the FirstOrder Jovian Resonances. Icarus 130, 247-258.

[59] Nelson, R.M. y Domingue D.L., 1999. The Solar System at uktraviolet wavelengths, en: Encyclopedia of the Solar System (Weissman, P.R., McFadden, L y Johnson, T.V. Eds.). Academic Press

[60] Roig, F. Nesvorný, D., Ferraz-Mello, S. 2002. Asteroids in the 2:1 resonance with Jupiter: dynamics and size distribution. Mon. Not. R. Astron. Soc. 335, 417-431.

[61] Safronov, V.S., 1969. Evolution of the Protoplanetary Cloud and Formation of the Earth and Planets. Nauka, Moscow. English transl.: NASA TTF-677, 1972.

[62] Schmidt, R.M., Housen, K.R. 1987. Some recent advances in the scaling of impact and explosion cratering. Int. J. Impact Eng. 5, 543-560.

[63] Scholl, H., Ch. Froeschlé, H. Kinoshita, M. Yoshikawa and J.G. Williams. 1989. Secular Resonances. In Asteroids II (R. P. Binzel, T. Gehrels, and M. S. Matthews, Eds.), pp 845-861, Univ. of arizona Press, Tuckson. 
[64] Sulivan, R.J., Thomas P.C., Murchie, S. L. y robinson, M.S. 2002. Asteroid geology from Galileo and NEAR Shoemaker data. In Asteroids III .(W. Bottke, A. Cellino, P. Paolicchi and R. Binzel, Eds.), pp.. 169-182. Univ. of Arizona Press, Tucson.

[65] Tancredi, G., Lindgren, M., y H. Rickman. 1990. Temporary satellite capture and orbital evolution of comet $\mathrm{P} /$ Helin-Roman-Crockett. Astronomy and Astrophysics. 239, 375-380.

[66] Tholen, D.J. 1984. Asteroid taxonomy from cluster analisys of photometry. Ph. D. tesis, Univesity of Arizona, Tucson.

[67] Tholen, D.J. and M. A. Barucci, 1989. Asteroid Taxonomy. In Asteroids II (R. P. Binzel, T. Gehrels, and M. S. Matthews, Eds.), pp 298-315, Univ. of arizona Press, Tuckson.

[68] Tedesco E.F., Williams, J.G. Matson, D.J. Veeder, G.J. Gradie, J.C. and Lebofsky L.A. 1989. Athree parameter asteroid taxonomy. Astronomical J.. 97, 580-606.

[69] Vilas F., Jarvis K.S., Gaffey M.J. 1994. Iron alteration minerals in the visible and near-infrared spectra of low - albedo asteroids.Icarus 109, 274-283.

[70] Weissman, P.R. 1982. in Comets. Dynamical History of the Oort Cloud ed. L. L. Wilkening, Univ. Arizona Press, Tucson. pp. 637-658.

[71] Weissman, P.R. 1983. The mass of the oort cloud. Astronom. Astrophs. 118, 90-94

[72] Weissman, P.R. 1986. Are cometary nuclei primordial rubble piles? Nature, 320, $242-244$.

[73] Weissman, P.R., W.F. Bottke Jr. y H.F. Levison. 2002. Evolution of Comets Into Asteroids. In Asteroids III .(W. Bottke, A. Cellino, P. Paolicchi and R. Binzel, Eds.), pp.. 669-686. Univ. of Arizona Press, Tucson.

[74] Wisdom, J. 1983. Chaotic behaviour and the origin of the 3/1 Kirkwood gap. Icarus, 56 р 71 - 74. 
[75] Wisdom, J. 1985. Meteorites may follow a chaotic route to earth. Nature, 315 p 731 - 733.

[76] Xu, S., Binzel, R.P., Burbine, T.H., Bus, S.J., 1995. Small main - belt asteroids spectroscopic survey: Initial results. Icarus 115, 1-35.

[77] Zahnle, K., Dones, L. and H.F. Levison. 1998. Cratering Rates on the Galilean Satellites. Icarus. 136, 202-222. 